\title{
Computational Architecture of the Parieto-Frontal Network Underlying Cognitive-Motor Control in Monkeys
}

\author{
Roberto Caminiti, ${ }^{1,2}$ Elena Borra, ${ }^{3}$ Federica Visco-Comandini, ${ }^{1}{ }^{10}$ Alexandra Battaglia-Mayer, ${ }^{1}$ Bruno B. \\ Averbeck, ${ }^{4}$ and ${ }^{\circledR}$ Giuseppe Luppino ${ }^{3}$
}

DOI:http://dx.doi.org/10.1523/ENEURO.0306-16.2017

${ }^{1}$ Department of Physiology and Pharmacology, University of Rome SAPIENZA, Rome, 00185, Italy, ${ }^{2}$ Department of Anatomy, Histology, Forensic Medicine, and Orthopedics, University of Rome SAPIENZA, Rome, 00185, Italy, ${ }^{3}$ Department of Medicine and Surgery, Section of Neuroscience, University of Parma, Parma, 43125, Italy, and ${ }^{4}$ Laboratory of Neuropsychology, National Institute of Mental Health, National Institutes of Health, Bethesda, MD 20892

\section{Visual Abstract}
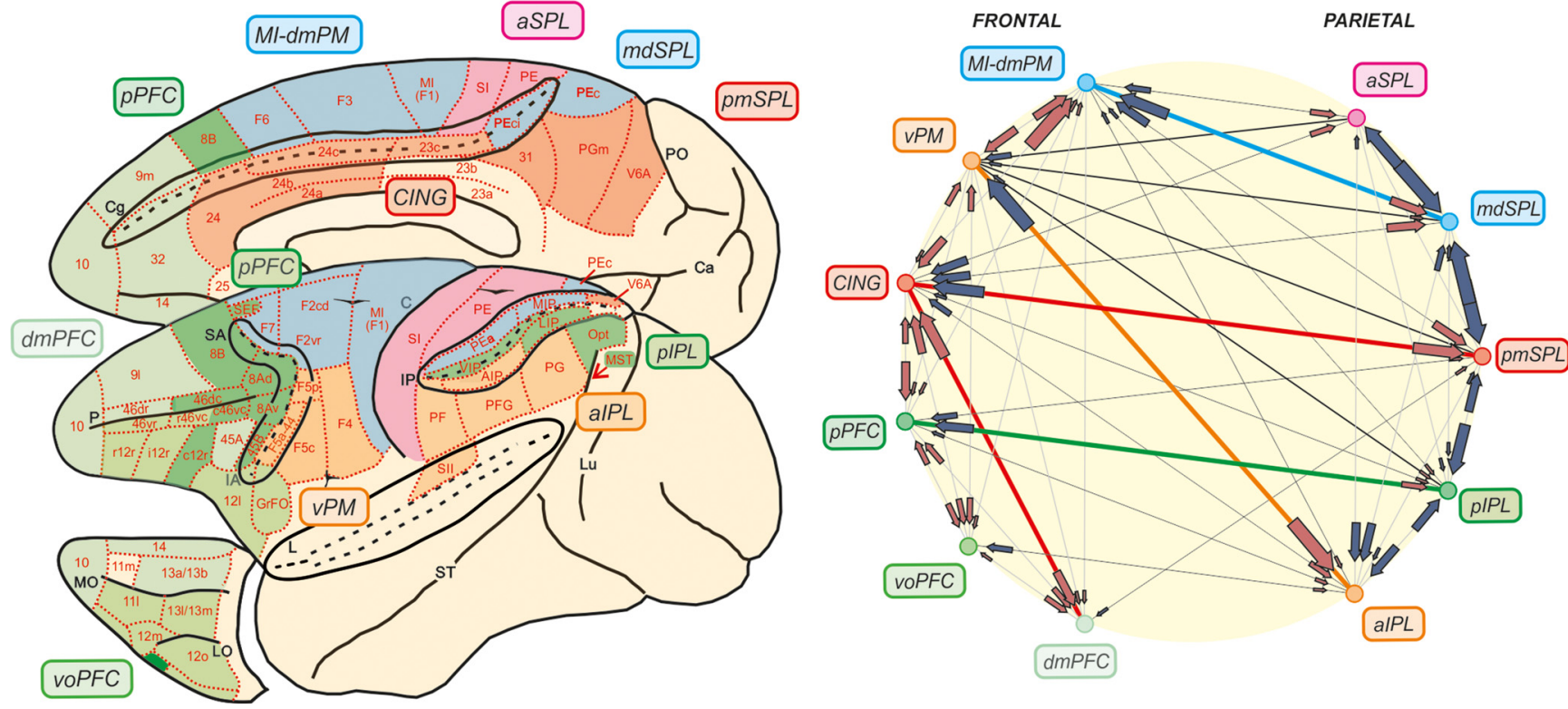

\section{Significance Statement}

The statistics of corticocortical connectivity between the parietal and frontal lobes, as well as that of intrinsic parietal connectivity of macaque monkeys, have been studied through a hierarchical cluster analysis. In both parietal and frontal cortex, we identified different clusters of interconnected areas. The analysis of their functional properties led to identification of five functional domains spanning posterior parietal, anterior parietal, cingulate, frontal, and prefrontal cortex. The scrutiny of interdomain connectivity revealed the existence of different information processing streams, related to the representation of action space, reaching, grasping, oculomotor intention and visual attention, action recognition, and selection of behavioral goals and strategies. They were all embedded within a distributed eye-hand matrix from which they can be selected by task demands. 
The statistical structure of intrinsic parietal and parieto-frontal connectivity in monkeys was studied through hierarchical cluster analysis. Based on their inputs, parietal and frontal areas were grouped into different clusters, including a variable number of areas that in most instances occupied contiguous architectonic fields. Connectivity tended to be stronger locally: that is, within areas of the same cluster. Distant frontal and parietal areas were targeted through connections that in most instances were reciprocal and often of different strength. These connections linked parietal and frontal clusters formed by areas sharing basic functional properties. This led to five different medio-laterally oriented pillar domains spanning the entire extent of the parieto-frontal system, in the posterior parietal, anterior parietal, cingulate, frontal, and prefrontal cortex. Different information processing streams could be identified thanks to inter-domain connectivity. These streams encode fast hand reaching and its control, complex visuomotor action spaces, hand grasping, action/intention recognition, oculomotor intention and visual attention, behavioral goals and strategies, and reward and decision value outcome. Most of these streams converge on the cingulate domain, the main hub of the system. All of them are embedded within a larger eye-hand coordination network, from which they can be selectively set in motion by task demands.

Key words: cluster analysis; cognitive-motor behavior; cortico-cortical connectivity; frontal lobe; macaque monkey; parietal lobe

\section{Introduction}

Elucidating the logic of cortical connectivity is relevant for understanding brain function and disease. This task has been boosted by the wealth of anatomic studies generated by the introduction of the axoplasmic transport of tracers (Kristensson and Olsson, 1971) that in monkeys have provided a description of brain connectivity at a meso- and micro-scale level. At macro-scale resolution, functional connectivity (Friston, 2011) and diffusion tractography have extended this study to humans, creating a large database that forms the core of the connectome project (Sporns et al., 2005; Van Essen 2013; Sporns, 2013).

From a theoretical perspective, cortical networks have been modeled through graph analysis (Bullmore and Sporns, 2009), which defines cortical areas as nodes and their interconnections as edges. Essential features of brain topology include highly clustered areas that are linked by dense local connections, as in small-world networks (Watts and Strogatz, 1998), long oligosynaptic pathways between distant areas, and central hubs linking local modules. This architecture would minimize communication distances, delays and costs. Novel studies have reconsidered this organization (Markov et al., 2011, 2014) by questioning the existence of small-world connectivity and modeling cortical architecture in terms of bow-tie representations (Markov et al., 2013).

Received October 10, 2016; accepted February 1, 2017; First published February 14, 2017.

Authors report no conflict of interest.

Author contributions: R.C. and A.B.M. designed study; B.A., A.B.M., E.B., G.L., F.V.C., and R.C. analyzed data; R.C. and G.L. wrote the paper.

This study was supported by grants from the University of Rome SAPIENZA (to ABM), from MIUR of Italy (protocol 2015AWSW2Y_002, to RC), and from the Intramural Research Program of the National Insitute of Mental Health (to BA).

Correspondence should be addressed to Roberto Caminiti, Department of Physiology and Pharmacology, University of Rome SAPIENZA, Piazzale Aldo Moro 5, 00185 Rome, Italy. E-mail: roberto.caminiti@uniroma1.it.

DOI:http://dx.doi.org/10.1523/ENEURO.0306-16.2017

Copyright () 2017 Caminiti et al.

This is an open-access article distributed under the terms of the Creative Commons Attribution 4.0 International, which permits unrestricted use, distribution and reproduction in any medium provided that the original work is properly attributed.
In recent years, the structural organization of the prefrontal (Averbeck and Seo, 2008) and parieto-frontal networks (Averbeck et al., 2009) have been analyzed in macaque monkeys. In both studies, the combined evaluation of structure and function has revealed the existence of different information processing streams that have been helpful in characterizing intrinsic frontal and distributed parieto-frontal functions beyond those commonly assumed. Since then, a significant number of new anatomic studies have extended the analysis of parietal connectivity, such that the data now includes additional prefrontal areas. Therefore, updating available knowledge on the statistical structure of parieto-frontal connectivity is essential and timely.

The outflow of intraparietal operations is conveyed to frontal cortex through parieto-frontal connections. Parietal mechanisms are influenced by the intrinsic connectivity between the areas of the superior (SPL; Brodmann area 5) and inferior (IPL; Brodmann area 7) parietal lobules. This connectivity has never been reported in detail. The original Brodmann parcellation of parietal cortex in macaque (1909) has been long abandoned in favor of more refined subdivisions combining cortical connectivity and functional properties of neurons. Therefore, the connectivity between SPL and IPL requires a full redefinition in terms of constituent areas, a theoretical reassessment, and a discussion in terms of functional relevance, also taking into consideration that this part of the cerebral cortex has expanded significantly during evolution (Caminiti et al., 2015).

To address these issues, we undertook a quantitative study of both long-range parieto-frontal and local intraparietal connections between SPL and IPL in macaque monkeys. For this, a hierarchical cluster analysis was used. The database consisted of virtually all published studies available from retrograde axoplasmic transport of tracers. Furthermore, the results have been evaluated in light of current knowledge on the functional organization of these areas, so as to provide a comprehensive picture of these networks at a mesoscale resolution. The underlying assumption is that there is a correspondence between structural and functional organization and that this and similar analyses can offer new tools for the study of 
Table 1. Connectional studies used for the generation of the connectivity matrix and areal attribution of the selected retrograde tracer injections

\begin{tabular}{|c|c|}
\hline Study & Area \\
\hline \multicolumn{2}{|l|}{ Frontal areas } \\
\hline Barbas, 1988 & 11I, 32 \\
\hline Barbas, 1993 & $13 \mathrm{l} / 13 \mathrm{~m}$ \\
\hline Barbas and Mesulam, 1985 & $46 v c, 46 v r$ \\
\hline Barbas and Pandya, 1987 & F2cd \\
\hline Barbas and Pandya, 1989 & 10 \\
\hline Barbas et al., 1999 & $9 m, 9 l$ \\
\hline Borra et al., 2011 & $12 r$ \\
\hline Caminiti et al., 1999 & F2cd, F2vr, F7 \\
\hline Carmichael and Price, 1995a & $11 \mathrm{l}, 12 \mathrm{o} / 12 \mathrm{~m}, 13 \mathrm{l} / 13 \mathrm{~m}, 14$ \\
\hline Carmichael and Price, 1995b & $11 \mathrm{I}, 12 \mathrm{o} / 12 \mathrm{~m}, 13 \mathrm{l} / 13 \mathrm{~m}, 14$ \\
\hline Carmichael and Price, 1996 & $11 \mathrm{l}, 12 \mathrm{o} / 12 \mathrm{~m}, 13 \mathrm{l} / 13 \mathrm{~m}, 14$ \\
\hline Eradath et al., 2015 & $8 \mathrm{~B}, 9 \mathrm{~m}$ \\
\hline Gerbella et al., 2010 & $8 \mathrm{Ad}, 8 \mathrm{Av}, 12 \mathrm{r}, 45 \mathrm{~A}, 45 \mathrm{~B}$ \\
\hline Gerbella et al., 2011 & $\mathrm{~F} 5 \mathrm{a}, \mathrm{F} 5 \mathrm{c}, \mathrm{F} 5 \mathrm{p}$ \\
\hline Gerbella et al., 2013 & $46 \mathrm{vc}, 46 \mathrm{vr}$ \\
\hline Gerbella et al., 2016 & GrFO \\
\hline Gharbawie et al., 2011 & $\mathrm{Ml}(\mathrm{F} 1)$ \\
\hline Ghosh and Gattera, 1995 & $\mathrm{~F} 2 \mathrm{~cd}, \mathrm{~F} 5 \mathrm{p}$ \\
\hline Gregoriou et al., 2006 & F2vr, F5p, F7 \\
\hline Hatanaka et al., 2001 & F1 \\
\hline Huerta and Kaas, 1990 & SEF \\
\hline Huerta et al., 1987 & $8 A d, 8 A v$ \\
\hline Johnson et al., 1996 & F2cd, F2vr, F7 \\
\hline Kurata, 1991 & F2cd, F5p \\
\hline $\begin{array}{l}\text { Luppino et al., } \\
1993\end{array}$ & F3, F6 \\
\hline Luppino et al., 1999 & $\mathrm{~F} 4, \mathrm{~F} 5 \mathrm{p}$ \\
\hline Luppino et al., 2001 & F2vr, F6, SEF \\
\hline Luppino et al., 2003 & F2cd, F2vr, F7, SEF \\
\hline Marconi et al., 2001 & F2cd, F2vr, F7 \\
\hline Matelli et al., 1986 & F1, F5p \\
\hline Matelli et al., 1998 & F2cd, F2vr, F7, SEF \\
\hline Morecraft and Van Hoesen, 1993 & F3, F6 \\
\hline Morecraft et al., 2012 & F2cd, F3, F6, F7 \\
\hline Petrides and Pandya, 1999 & $46 \mathrm{dc}, 8 \mathrm{~B}, 9 \mathrm{l}$ \\
\hline Petrides and Pandya, 2002 & $45 \mathrm{~A}, 46 \mathrm{vc}, 46 \mathrm{vr}$ \\
\hline Petrides and Pandya, 2007 & 10,32 \\
\hline Saleem et al., 2008 & $12 \mathrm{o} / 12 \mathrm{~m}, 13 \mathrm{l} / 13 \mathrm{~m}, 11 \mathrm{I}$ \\
\hline Saleem et al., 2014 & $\begin{array}{l}8 \mathrm{~B}, 9 \mathrm{~m}, 9 \mathrm{l}, 10,45 \mathrm{~A}, 46 \mathrm{dc}, \\
46 \mathrm{dr}\end{array}$ \\
\hline Schall et al., 1993 & SEF \\
\hline Schall et al., 1995 & $8 \mathrm{Ad}, 8 \mathrm{Av}$ \\
\hline Stanton et al., 1993 & $8 \mathrm{Ad}, 8 \mathrm{Av}$ \\
\hline Stanton et al., 1995 & $8 \mathrm{Ad}, 8 \mathrm{Av}$ \\
\hline Takada et al., 2004 & F6 \\
\hline Tanne-Gariépy et al., 2002 & $\mathrm{~F} 2 \mathrm{~cd}, \mathrm{~F} 2 \mathrm{vr}$ \\
\hline Vogt and Pandya, 1987 & 32 \\
\hline Wang et al., 2005 & F6, SEF \\
\hline \multicolumn{2}{|l|}{ Parietal areas } \\
\hline Bakola et al., 2010 & PEc \\
\hline Bakola et al., 2013 & $\mathrm{PE}$ \\
\hline Blatt et al., 1990 & LIP,MIP \\
\hline Borra et al., 2008 & AIP \\
\hline Boussaoud et al., 1990 & MST \\
\hline Caminiti et al., 1985 & PEc \\
\hline Caminiti et al., 1999 & PEc,V6A \\
\hline $\begin{array}{l}\text { Cavada and Goldman-Rakic, } \\
\text { 1989a }\end{array}$ & LIP, Opt,PGm \\
\hline \multicolumn{2}{|l|}{ (Continued) } \\
\hline
\end{tabular}

Table 1. Connectional studies used for the generation of the connectivity matrix and areal attribution of the selected retrograde tracer injections

\begin{tabular}{ll}
\hline $\begin{array}{l}\text { Study } \\
\text { Cavada and Goldman-Rakic, }\end{array}$ & \multicolumn{1}{c}{ Area } \\
1989b & SIP, Opt,PGm \\
Cerkevich et al., 2014 & SI \\
Cipolloni and Pandya, 1999 & SI, SII \\
Gamberini et al., 2009 & V6A \\
Gharbawie et al., 2011 & SI \\
Hihara et al., 2006 & PEa \\
Leichnetz, 2001 & PGm \\
Lewis and Van Essen, 2000 & VIP \\
Maioli et al., 1998; & MST \\
Marconi et al., 2001 & F2cd, F2vr, F7 \\
Morecraft et al., 2004 & PEci, SI, 31 \\
Passarelli et al., 2011 & V6A \\
Pons and Kaas, 1986 & SI, PEa \\
Rozzi et al., 2006 & PF, PFG, PG, Opt \\
Shipp et al., 1998 & V6A \\
Cingulate areas & \\
Arikuni et al., 1994 & 24a, 24b \\
Hatanaka et al., 2003 & 24c \\
Morecraft and Van Hoesen, 1993 & 23c, 24c \\
Morecraft and Van Hoesen, 1998 & 24c, 23c \\
Morecraft et al., 2004 & 23c \\
Morecraft et al., 2012 & 24a, 24b, 24c \\
&
\end{tabular}

brain disorders, most of which have been considered disconnection syndromes (Geschwind, 1965; Catani and Fftiche, 2005; Catani and Mesulam, 2008; Silasi and Murphy, 2014) and could potentially be reinterpreted from the perspective offered by brain network analysis (Carrera and Tononi, 2014).

\section{Methods}

\section{Classification of cortical areas}

The cluster analysis of parieto-frontal connectivity is based on a matrix of the cortical connectivity of all parietal and frontal areas so far characterized using architectonic or connectional and functional data. For the analysis of the intrinsic connectivity between the SPL and IPL, a subset of the larger matrix was used that contained only connections between the SPL and IPL. Connectional studies based on injections of retrograde neural tracers in parietal, frontal, or cingulate areas (listed in Table 1) have been examined throughout. Data from tracer injections that could be attributed unequivocally to any parietal, frontal, or cingulate area of the subdivision adopted in the present study were then considered for the generation of the matrix. Based on this analysis, inputs to each area from any other cortical area were indicated as strong (100), medium (67), moderate (33), weak (16), or absent. In most cases, this assessment has been based on quantitative data reported in the considered studies and, in a few cases, on evaluation of the description of the data. It must be stressed, however, that rigorous quantification of anatomic data remains problematic, because of methodological considerations concerning across-study differences in the type and amount of tracer used, its spread at the injection site, the status of the brain during survival 


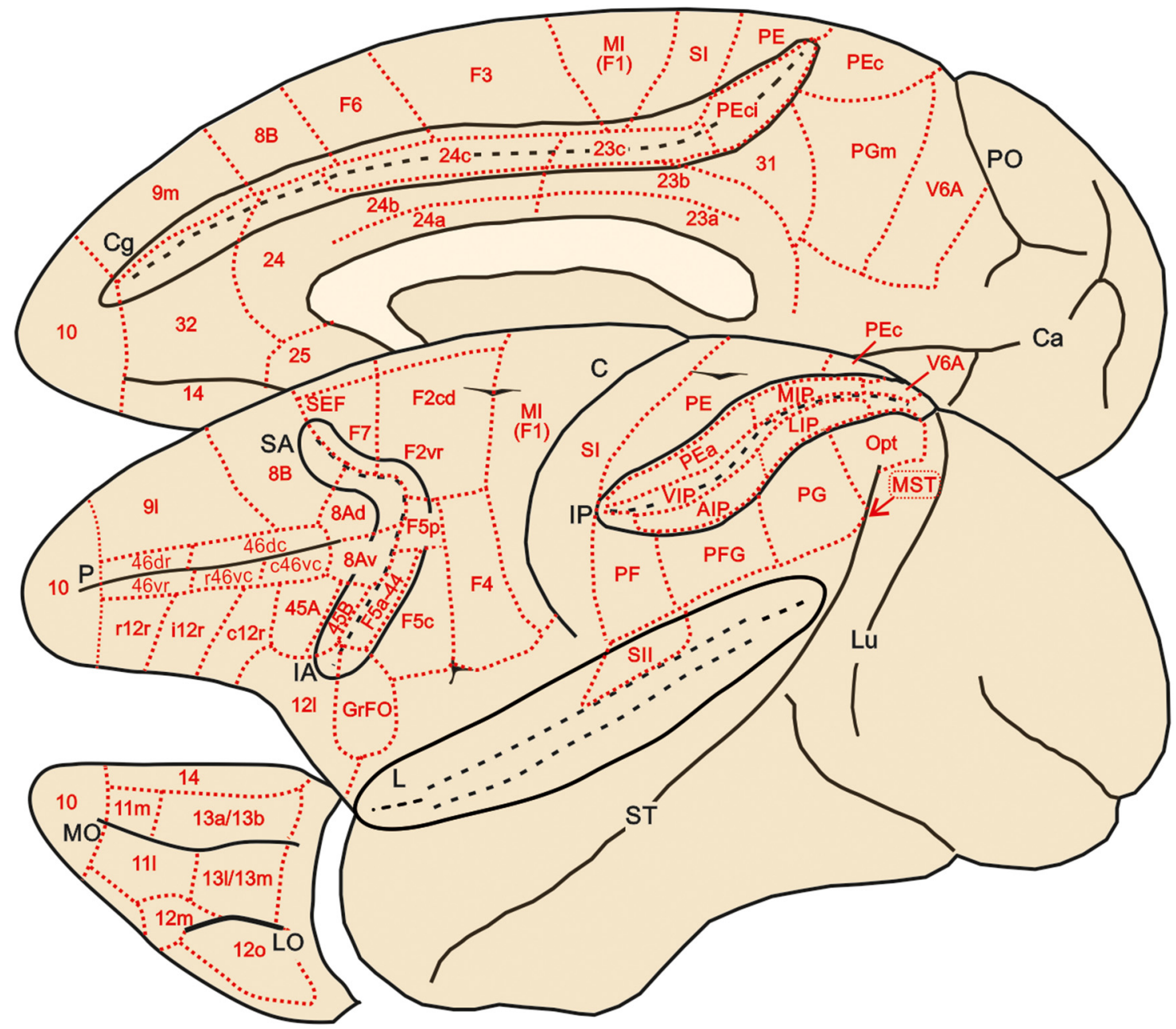

Fig. 1. Brain figurine showing the location of the cortical areas on the mesial, lateral, and orbitofrontal aspects of the macaque cerebral cortex. The cingulate $(\mathrm{Cg})$, superior arcuate $(\mathrm{SA})$, inferior arcuate $(\mathrm{IA})$, intra-parietal and lateral $(\mathrm{L})$ sulci are opened to better display the location of cortical areas buried in their banks. PO and $\mathrm{Ca}$ on the mesial aspect of the hemisphere indicate parieto-occipital sulcus and calcarine fissure, respectively. Lu, P and ST in the lateral view of the hemisphere indicate lunate, principal and superior temporal sulcus. LO and MO in the orbitofrontal cortex indicate lateral and medial orbital sulci, respectively. Cortical areas are defined on the basis of both architectonic and connectional criteria (see text).

periods (hence the efficacy of axonal transport), quality of tissue perfusion and histologic processing, etc. Despite this, we believe that a semiquantitative analysis of data using a gradation of strength values, such as those adopted in this study, is more informative that an all-or-none approach based on presence or absence of connections.

The subdivision of the parietal and frontal cortex adopted for the connectivity matrix is shown in Fig. 1. Specifically, for the parietal cortex, the subdivision and nomenclature proposed by Pandya and Seltzer (1982) has been primarily used. However, we also took into account data from later studies providing evidence for visual area 6 in the anterior bank of the parieto-occipital sulcus (V6A) medial intraparietal area (MIP; Colby and Duhamel, 1991; Galletti et al., 1996; Johnson et al., 1996; Luppino et al., 2005) in the caudal part of the SPL, ventral intraparietal area (VIP) along the fundus of the intraparietal sulcus (IPS; Colby and Duhamel, 1991; Lewis and Van Essen, 2000), lateral intraparietal (LIP) and anterior intraparietal (AIP; Blatt et al., 1990; Taira et al., 1990; Borra et al., 2008) areas in the lateral bank of the IPS. The connections of the various architectonic subdivisions $(3 a, 3 b, 1,2)$ of the anterior parietal cortex of the macaque are similar, although a detailed analysis of them will require further work (Darian-Smith et al. 1993; Burton and Fabri 1995; Huerta and Pons, 1990). Therefore, for the purposes of the present study, these cortical subdivisions have been considered as forming a single area, classically referred to as the primary somatosensory cortex (SI), although there is a general consensus that only area $3 \mathrm{~b}$ is homologous to $\mathrm{SI}$ of other mammals.

The second somatosensory area (SII), in the parietal operculum, has been considered as a single entity. Because of the difficulties in finding connectional data specific to one or several of its possible subdivisions, it has been mostly considered as a whole.

As for the caudal part of the frontal lobe, corresponding to the agranular frontal cortex, the subdivision and nomenclature proposed by Matelli et al. $(1985,1991)$ has been adopted. This subdivision has been modified as to 
incorporate data on a distinct oculomotor field-the supplementary eye field (SEF) - in the dorsorostral part of area F7 (Schlag and Schlag-Rey, 1987), a subdivision of area F2 into a ventrorostral and a dorsal "precentral dimple" sector (Matelli et al., 1998), and the subdivision of area F5 into three subareas (Belmalih et al., 2009). The dysgranular area 44 , originally shown by Petrides and Pandya $(1994,2002)$ and located along the fundus of the inferior arcuate sulcus, has been considered together with area F5a, as these two areas appear to share several connectional features, and their possible functional differences still remain to be fully assessed.

The subdivision adopted for the lateral prefrontal cortex is very similar to that used by Saleem et al. (2014), which was based on the descriptions by Walker (1940), Preuss and Goldman-Rakic (1991), and Petrides and Pandya (1999). Based on connectional evidence (Petrides and Pandya, 1999; Gerbella et al., 2013; Saleem et al., 2014), both the dorsal (46d) and the ventral (46v) parts of area 46 have been further subdivided into a rostral and a caudal sector, as also done for caudal area 46v (46vc). Furthermore, area $12 r$ was subdivided into caudal, intermediate, and rostral sectors based on differences in connectivity (Borra et al., 2011). As in Saleem et al. (2014), the prearcuate convexity cortex has been combined with the anterior bank of the arcuate sulcus, where the frontal eye fields (FEFs) are located (Stanton et al., 1989), into a single subdivision designated as area $8 \mathrm{~A}$. In most cases, tracer injections in this sector [which is in any case part of the frontal oculomotor system (e.g., Lynch and Tian, 2006)] have involved also the crown or the anterior bank of the arcuate sulcus. Area $8 \mathrm{~A}$ was then subdivided into a dorsal and a ventral part to distinguish between the dorsal and the ventral part of the FEF, where large-amplitude and small-amplitude saccades, respectively, are represented (Bruce et al., 1985). The subdivision adopted for the medial prefrontal and orbitofrontal cortex was based on the descriptions of Carmichael and Price (1994). However, because of the paucity or the incompleteness of information on the connectivity of some areas, and based on certain similarities in connectivity patterns, areas 120 and $12 \mathrm{~m}$ were considered together, as were areas $13 \mathrm{l}$ and $13 \mathrm{~m}$. Furthermore, areas $13 \mathrm{a}$ and $13 \mathrm{~b}$ were considered together with the subdivisions of area 14. Finally, areas 25 and $11 \mathrm{~m}$ have not been considered, as no complete descriptions of their connectivity appear to be available.

The cingulate cortex has been subdivided according to Brodmann (1909) into a caudal granular cingulate area 23 and a rostral agranular cingulate area 24. Both these areas were subdivided according to Vogt et al. (1987) into a gyral sector (23a and 23b; $24 a$ and 24b) and a sulcal sector (23c and 24c). Area 24c, as defined in the present study, includes 24d (Matelli et al., 1991; Vogt et al., 2005) and largely corresponds to the rostral cingulate motor area (CMAr; Dum and Strick, 1991), whereas area 23c largely corresponds to the dorsal (CMAd) and ventral (CMAv) cingulate motor areas (Dum and Strick, 1991), which are also collectively referred to as caudal cingulate motor area (CMAc). In the posterior cingulate cortex, area 31 was defined according to Morecraft et al. (2004).
Finally, the areal attribution of the temporal and insular connectivity of the parietal and frontal areas has been conducted according to Seltzer and Pandya (1978), Boussaoud et al. (1990), and Mesulam and Mufson (1982).

\section{Hierarchical cluster analysis}

We fitted hierarchical trees to the connectivity data. There is no algorithm available for finding the best tree for a dataset, because the tree-fitting algorithms get stuck in local minima and therefore are not guaranteed to find the global minimum, where the latter would correspond to the best fitting tree. Local minima occur because the function which fits the trees is iterative and reduces the lack of fit by a small amount on each iteration. However, it can end up in situations where any small changes to the tree would result in a tree that does not fit as well, i.e. a local minimum, without having settled into a global minimum. This happens because the fit of the tree has many local minima, but only one global minimum. Therefore, to improve our chances of finding very good trees, we fitted trees to bootstrap samples of the original dataset. The bootstrapping procedure in this case is not meant to destroy the structure in the dataset; rather, it is meant to generate datasets with areas similar to those of the original unsampled dataset, but that contain some variability around the original data. In this way, when trees are fitted to the bootstrap data, they are similar to (but variations on) the tree fitted to the original data. Often one of the trees found with this approach is superior to the tree found by the algorithm applied to the original data. Therefore, we generated 10,000 bootstrap datasets. The original data are a matrix, with columns indicating the inputs to each area, and the rows indicating areas that send inputs to each area. The clustering algorithm operates on a distance matrix found by taking the Euclidean distances between the vectors defined by each column. Therefore, each bootstrap dataset was formed by sampling with replacement from the rows of the connectivity table, where the rows define the inputs to each area from the other areas. This created datasets with random combinations of the inputs to each of the areas. For example the input from area PG to area 46 might be represented twice in a bootstrap table, whereas the input from area PE to area 46 might be absent. Entire rows were always kept from the table when a row was sampled.

We used an agglomerative tree-fitting algorithm from Matlab to generate a tree structure for each bootstrap dataset and the original, unsampled dataset. Thus, we fitted 10,001 candidate trees. The tree defined only the areas that were clustered together, not the distances of the clusters from each other, which are given by the length of each branch. Next, we used a maximumlikelihood (ML) tree-fitting algorithm to optimize the fit of each tree (i.e., the length of each branch, using the branch structure generated by the agglomerative tree-fitting algorithm) to the original, unsampled dataset (Felsenstein, 1973). In this way, we generated a fit statistic for each tree, based on the log-likelihood of the data, given the tree. The value of the ML algorithm is that it gives us an objective estimate of how well the tree fits the data and 
allows one to test hypotheses to confirm that we are describing significant structure in the data. We then sorted through the 10,001 trees and found the 100 trees that fit the original data best, in terms of the likelihood. It is important to point out that trees that were found by the agglomerative algorithm on bootstrapped tables were tested against the original, unsampled table. The bootstrap procedure was used only to identify candidate trees. In an additional analysis, we used an algorithm developed for phylogenetic trees (Margush and McMorris, 1981) to fit a consensus tree to the 100 best trees. The consensus tree contained the clusters that occurred most often in the 100 best (i.e., highest likelihood) trees. Thus, it defines the most frequent clusters in the best trees, as opposed to the ML tree, which defines just the "best" tree of the trees we searched.

To quantify the strength of the inputs that each cluster received by any other cluster, we considered the mean input value $(0-100)$ across the areas belonging to the receiving and the projecting cluster. Finally, to estimate whether clusters received an equal number of projections from all other clusters or received all their inputs from a few clusters, we computed the entropy (in nats; see Averbeck et al., 2009) of the distribution of the inputs, as reported in the spider plots of Figs. 4, 5, and 7. Maximum entropy will occur when the distribution of inputs is uniform, whereas minimum entropy will characterize a distribution in which all inputs stem from one other cluster. Entropy is given by

$$
H=-\sum_{\in\{\text { input areas\} }} p_{i} / n p_{i},
$$

where $p_{i}$ is the probability of the input or the fraction of inputs coming from each area.

\section{Results}

The connections of 37 frontal and 18 parietal areas have been used for the analysis of the parieto-frontal system; for the intrinsic parietal connectivity, we have studied the same 18 parietal areas, 9 in the SPL and 9 in the IPL.

\section{Parieto-frontal connections: clusters of parietal and frontal areas}

The basic assumption of cluster analysis is that areas sharing inputs cluster together to form hierarchical trees. Therefore, the second step of our analysis consisted of identifying the hierarchical clustering of the areas included in the connectivity matrix. The clustering algorithm adopted for this analysis used a log-likelihood metric of fit (see Materials and Methods), so that different trees could be statistically compared to determine how well the data were fitted by each tree. The best-fitting $M L$ tree obtained by clustering the parietal areas is shown in Fig. $2 A$, where all parietal clusters are shown. However, this analysis does not provide information on the degree to which each constituent cluster is supported by the data-in other words, how robust the ML clusters are. To determine how often individual clusters occurred, we analyzed the best $100 \mathrm{ML}$ trees and fitted a consensus tree (CT) that con- tained all the clusters most common in the ML tree and identified how frequently each cluster occurred. The CT for the parietal clusters is shown in Fig. 2B.The comparison of the $\mathrm{ML}$ and CT of parietal cortex shows a perfect correspondence between the two. Therefore, the ML tree is well supported by the data.

\section{Parietal clusters}

In the parietal cortex, we have identified five clusters (Fig. 2B). In the caudal and medial part of the SPL, areas V6A, PGm (or 7m), and 31 formed a postero-medial cluster (pmSPL). It extended from V6A to the mesial aspect of SPL (PGm) and adjacent posterior part of the cingulate gyrus, below the caudal sector of the cingulate sulcus (area 31).

A second cluster was located just more rostrally in the SPL and included areas PEci, in the caudalmost part of the cingulate sulcus, area PEc, extending from the crown of the parieto-occipital sulcus to the exposed part of SPL, area MIP, in the posterior part of the medial bank of the IPS, and area PEa, buried at a more rostral location within this same bank. Therefore, this SPL aggregate was labeled as mediodorsal superior parietal cluster (mdSPL).

Areas PE and SI formed a cluster spanning the anterior sector of SPL, as well as the entire extent of the postcentral gyrus (aSPL cluster).

In the best 100 trees, mdSPL and pmSPL occurred 48 and 37 times, respectively, and aSPL occurred 99 times, which suggests that the distinction between $\mathrm{SI}$ and $\mathrm{PE}$ could be a moot point, at least if drawn solely on the basis of cortical inputs. In the parietal cortex, the hierarchical level represented by SPL areas consisted of a higherorder cluster formed by pmSPL, mdSPL, and aSPL, which occurred 89 times in the best 100 trees.

In the IPL, we identified two main clusters. The first included area Opt at the parieto-occipital junction, area medial superior temporal (MST) in the medial bank of the superior temporal sulcus, LIP in the posterior part of the lateral bank of the IPS, and VIP, along the fundus of the IPS. This ensemble of areas in the posterior part of IPL was therefore labeled pIPL cluster, which occurred 81 times in the best 100 trees.

In a more anterior location, we identified a second cluster (alPL) formed by the areas occupying the cortex of IPL convexity, including PF, PFG, PG, the adjacent lateral bank of the anterior part of IPS, containing AIP, and SII in the upper bank of the Sylvian fissure. This cluster was also very robust, since it occurred 71 times in the best 100 trees. More impressive was the association between SII and PF, which occurred 100 times (therefore in all the best trees).

\section{Frontal clusters}

As for the parietal areas, there was also an excellent correspondence between ML and CT in the frontal cortex. Therefore, we only show the latter, which was characterized by a very complex hierarchical structure, formed by at least six distinct clusters (Fig. 3).

The first cluster extended from the medial wall of the hemisphere to the lateral frontal cortex and included the medial premotor areas F6 (pre-SMA), and F3 (SMA), 
A

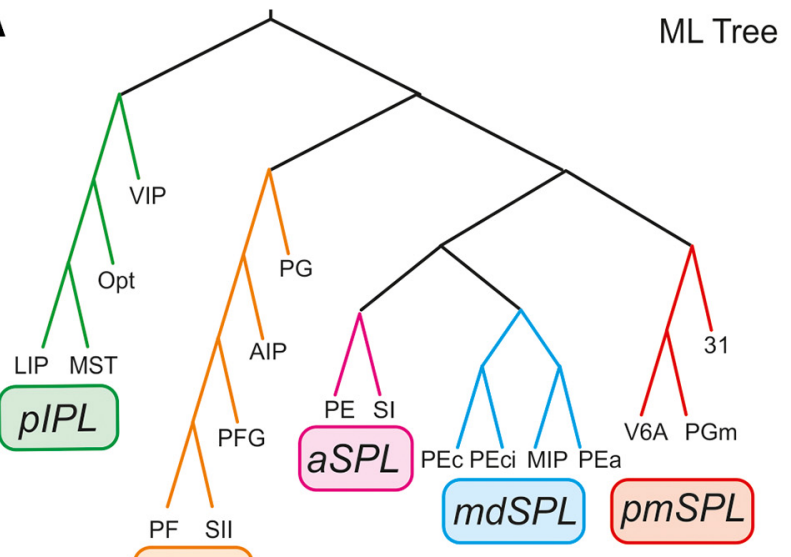

B

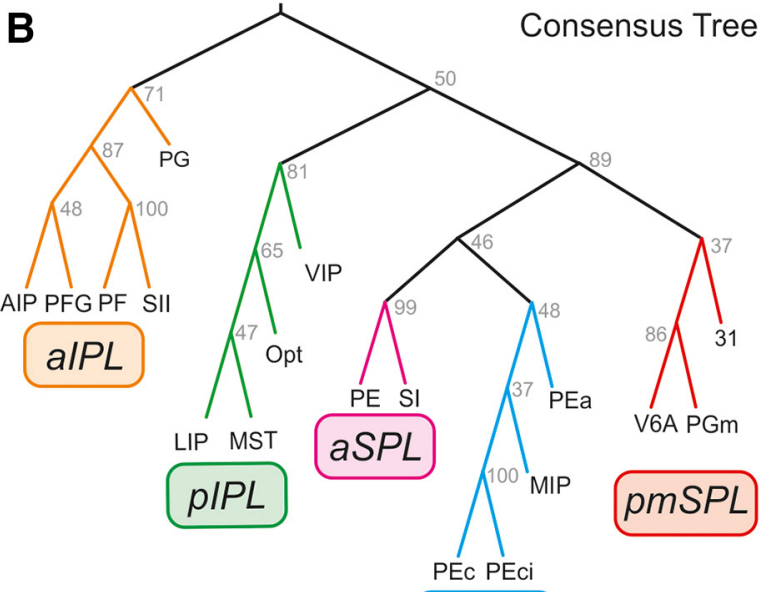

aIPL

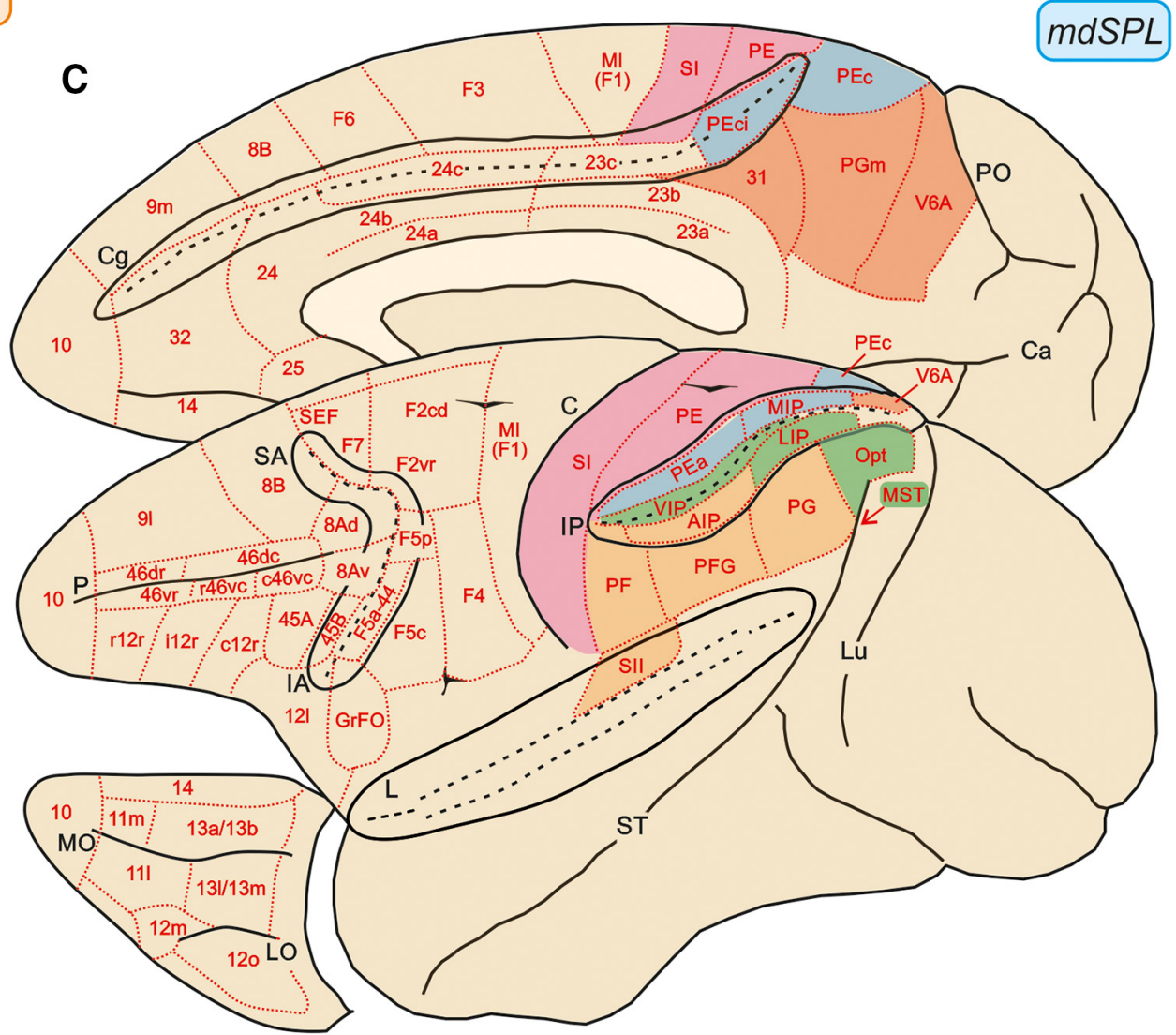

Figure 2. Trees fit of the data. $\boldsymbol{A}, \mathrm{ML}$ parietal tree generated from bootstrap analysis. Colors indicate the clusters we have identified for further analysis, labeled with different acronyms on the basis of their anatomic location. $\boldsymbol{B}$, Parietal tree generated from the 100 $\mathrm{ML}$ trees in frontal cortex. Numbers at each branch node indicate the number of times a cluster occurred in the $100 \mathrm{ML}$ trees. pIPL, aIPL, aSPL, mdSPL, and pmSPL indicate posterior IPL, anterior IPL, anterior SPL, mediodorsal SPL, and postero-medial SPL clusters. C, Location and topography of clusters in parietal cortex. Red, pmSPL; light blue, mdSPL; magenta, aSPL; green, pIPL; orange, alPL.

the dorsal premotor (PMd) areas F7 and F2, and the primary motor cortex (MI, F1). This family of areas was therefore labeled as Ml-dmPM cluster, representing the motor output of dorsal frontal cortex. Within this cluster, further structure can be seen at a lower hierarchical level, distinguishing the premotor areas projecting to $\mathrm{Ml}$ and spinal cord (F3, F2), from those lacking such projections (F7, F6), which instead connect with F3, F2, and prefrontal areas.
A second precentral cluster (VPM) was located in ventral premotor cortex and extended from the posterior bank of the inferior arcuate sulcus to the cortical convexity, so as to include areas F4 caudally, the F5 subdivisions, and area 44 rostrally.

Clusters MI-dmPM and vPM occurred 55 times and 80 times, respectively, in the best 100 trees. The higher-order cluster to which they both belong occurred 47 times. 
A Consensus Tree
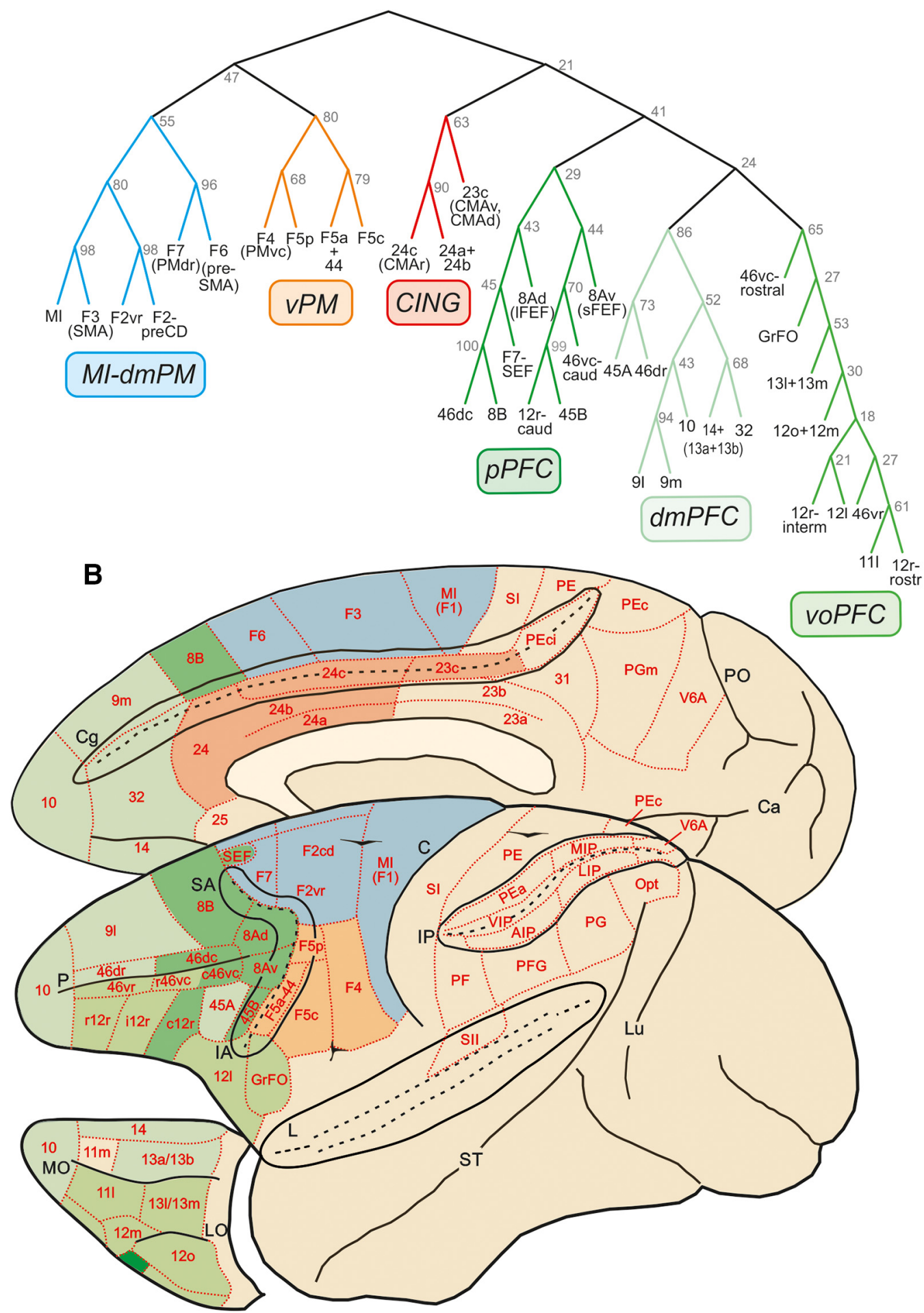

Figure 3. Trees fit of the data. $\boldsymbol{A}$, Consensus tree generated from the $100 \mathrm{ML}$ trees in frontal cortex. Clusters are labeled based on their anatomic location: MI-dmPM, primary motor/dorsal premotor; vPM, ventral premotor; CING, cingulate; pPFC, posterior prefrontal cortex; dmPFC, dorsomedial prefrontal cortex; voPFC, ventro-orbitofrontal cortex. $\boldsymbol{B}$, Location and topography of clusters in frontal cortex. The three prefrontal clusters (voPFC, dmPF, pPFC) are indicated with different green shades; red, CING; orange, vPM; light blue, MI-dmPM. Conventions as in Fig. 2.

On the medial aspect of the hemisphere, a third cluster included two cingulate areas: specifically, the more rostral area $24 \mathrm{c}$, corresponding to the rostral cingulate motor area (CMAr), and the more caudal area 23c, corresponding to the caudal cingulate motor area (CMAc), as well as areas $24 a$ and $24 b$ in the cingulate gyrus. This aggregate 
of areas was labeled as cingulate cluster (CING), which occurred 63 times in the best 100 trees.

Moving to the prefrontal cortex (PFC), a fourth cluster occupied the anterior bank of the arcuate sulcus, extending rostrally onto the caudal part of both ventrolateral (VLPF) and dorsolateral (DLPF) prefrontal cortex, excluding area 45A. This cluster also included the sector of F7 corresponding to the supplementary eye field (F7-SEF), up to the medial aspect of area 8B. For its location, we labeled this assembly as posterior prefrontal cluster (pPFC), which occurred 29 times in the best 100 trees. It was subdivided in two clusters of areas, one formed by 8B, F7-SEF, 8Ad (including the IFEF), and 46dc; the other by the caudal part of area $12 \mathrm{r}, 45 \mathrm{~B}, 46 \mathrm{vc}$-caudal, and $8 \mathrm{Av}$ (including the SFEF). These two clusters occurred 43 and 44 times, respectively, in the best 100 trees.

The fifth cluster was formed by areas mostly located in the dorsolateral and medial prefrontal cortex in front of the genu of the corpus callosum; therefore, it was labeled as dmPFC. It was formed by the polar frontal area 10, the medial areas $9 \mathrm{~m}, 32$, and 14, and the dorsolateral areas $46 \mathrm{dr}$ and 91 . This cluster also included the VLPF area 45A, which was commonly associated with area $46 \mathrm{dr}$. This cluster was detected 86 times in the best 100 trees.

The sixth cluster occupied most of the orbitofrontal cortex, extending on the cortex of the lateral convexity in the frontal operculum and in the VLPF, in front of the areas of the pPFC cluster. This ventral orbitofrontal cluster (voPFC) included areas 11 and 13, most of the subdivisions of area 12, 46vc-rostral and 46vr, and GrFO. It occurred 65 times in the best 100 trees.

\section{Inputs and functional properties of clusters}

Once the hierarchical relationships among families of areas were determined, we defined the dominant input to each cluster-that is, to hierarchically related sets of areas, from within and outside the parietal and frontal network (Figs. 4 and 5). Because the data set consisted of connections obtained through retrograde transport of tracers, these inputs originated not only from areas that were leaves of the trees used to fit the data, but also from external architectonic areas that were not leaves in the cluster analysis.

\section{Inputs and functional properties of parietal clusters: identification of parietal domains}

As a general rule, each parietal cluster (Fig. 4) received the main input from areas belonging to the same cluster, and to a lesser extent from other areas as well, confirming that connectivity tends to be strong locally. In the following sections, we describe and focus on the relative contribution of the different external inputs from the various parietal and frontal clusters to the overall connectivity of each cluster. Because the interpretation of anatomy both informs and benefits from functional studies, in this same section we also provide a brief description of the physiologic properties of cortical areas, in an attempt to identify general domains that could emerge by confronting the statistics of the connectivity and the physiologic properties of the areas in each cluster.

\section{pmSPL cluster}

This parieto-occipital cluster receives a large set of inputs that we have ordered on the basis of their strength. These stem from the (i) visuomotor areas of mdSPL (50); (ii) premotor areas of the cingulate cortex (CING; 31.4); (iii) pIPL (24.8), consisting of a set of areas related to visual attention, motor intention, decision-making, eye-hand coordination, and heading perception; (iv) the motor and dorsal premotor areas of the frontal lobe (MI-dmPM; 23); (v) oculomotor and attention-related areas of the pPFC (8.3); (vi) alPL(6.6); and (vii) dmPFC (6.3).

Known functional properties of the areas of the pmSPL cluster concern the role of area V6A in early coding of reaching (Galletti et al., 1997; Battaglia-Mayer et al., 2000, 2001; Marconi et al., 2001) and eye-hand coordination (Battaglia-Mayer et al., 2000, 2001; Marconi et al., 2001), a function to which also PGm contributes (Ferraina et al., 1997a, b). This cluster provides to the frontal lobe part of the visual input necessary for eye-hand coordination during reaching (Johnson et al., 1996; Marconi et al., 2001), and its areas are influenced by hand position and intended movement direction (Battaglia-Mayer et al., 2000). In V6A, neurons combine depth and arm movement direction information (Hadjidimitakis et al., 2014). Graspingrelated activity has also been described in this area (Fattori et al., 2010), suggesting early integration of reach and grasp information. It has been suggested (Pitzalis et al., 2015) that area V6A, thanks to the visual input from V6, can compute object location even in dynamic conditions, such as those created by self-motion. In a medial parietal region including PGm, Sato et al. (2006) have described neurons that combine local and virtual egomotion and whose neural activity was related to navigation in a virtual environment.

Area 31 is part of the posterior cingulate cortex. It has been reported as involved in visuomotor processing, since its neurons respond to visual signals (Dean et al., 2004) and contraversive gaze shifts (Olson et al., 1996; Dean et al., 2004) and monitor eye position and movement (Olson et al., 1996), although some of these properties seem to also belong to area 23 , where many neurons were recorded in the above studies. Their properties suggest a relationships to salience of objects or locations, preferentially in allocentric coordinates (Dean and Platt, 2006). Therefore, area 31 might serve as an intermediate node in the transformation from visuo-spatial egocentric frames in the parietal cortex to allocentric frames in the hippocampus (Vogt et al., 1992), although this transformation seems to be incomplete at this node, because of the coexistence of neuronal populations encoding visual events in retinocentric and egocentric coordinates (Dean and Platt, 2006).

\section{mdSPL cluster}

The inputs to this cluster stem from the (i) aSPL (45.8); (ii) parieto-occipital pmSPL cluster (44.3); (iii) MI-dmPM cluster (29); (iv) CING cluster (22); (v) alPL cluster (15.8); and (vi) pIPL cluster (5.1). In functional terms, this cluster is at the core of coordinate transformation for reaching.

This cluster encodes motor plans for reaches (Johnson et al., 1996; Snyder et al., 1997; Andersen and Cui, 

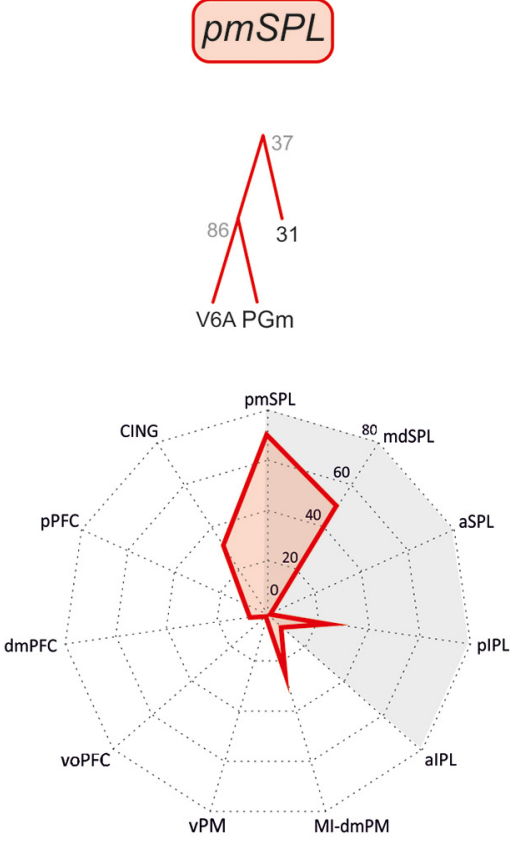

Entropy 1.92
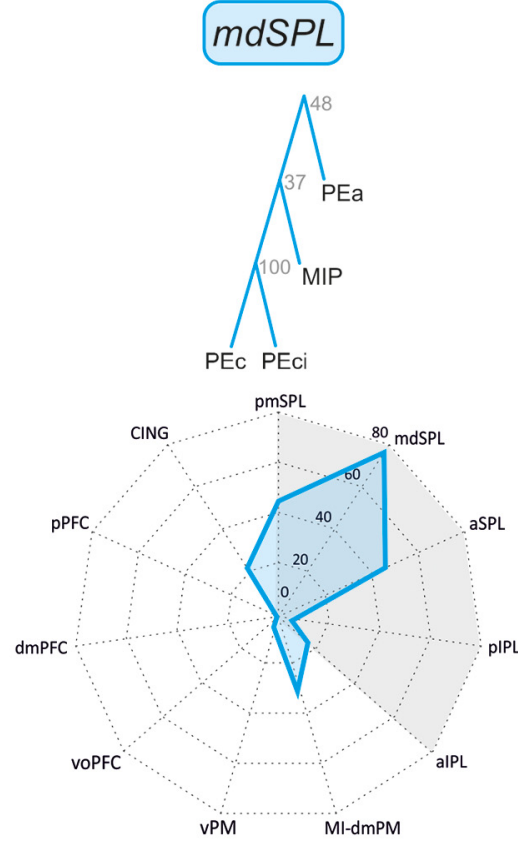

Entropy 1.77

\section{aSPL}
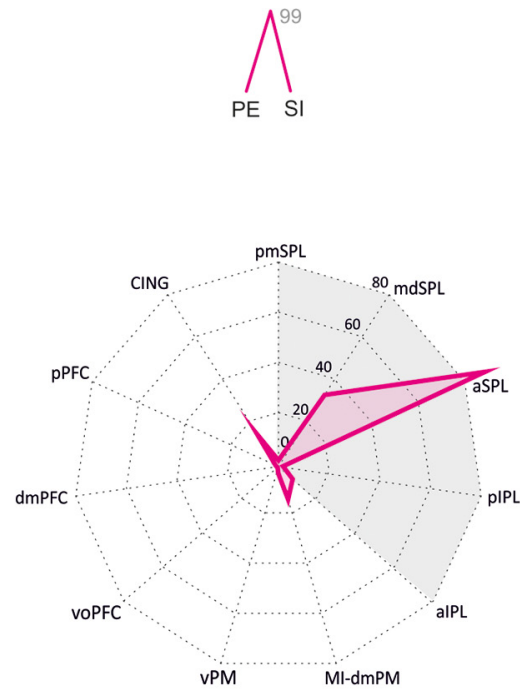

Entropy 1.44

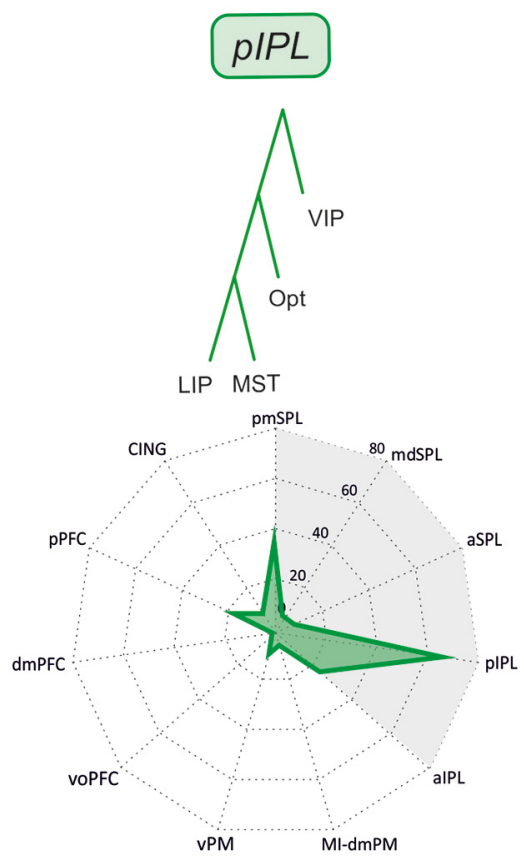

Entropy 1.81

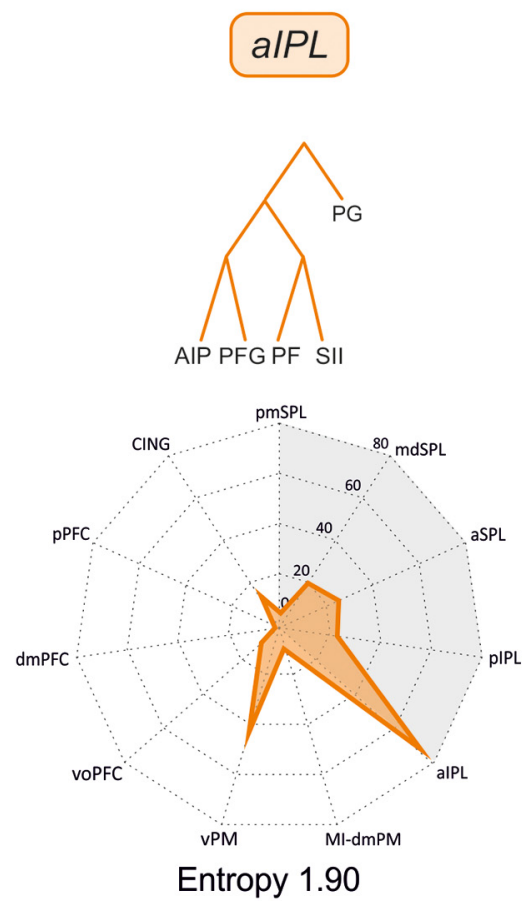

Figure 4. Inputs to the parietal clusters. Spider plots displaying the mean values (scale: 0-100) of frontal and parietal (gray shading) inputs to any given parietal cluster (top). The cluster entropy is also reported.

2009; Archambault et al., 2009; Caminiti et al., 2010) and their online correction (Archambault et al., 2009) and suppression (Mirabella et al., 2011) by combining visual and somatic information (Mountcastle et al., 1975; Kalaska et al., 1983; Georgopoulos et al., 1984; Kalaska et al., 1990; Caminiti et al., 1996; Johnson et al., 1996; Battaglia-Mayer et al., 2000, 2001; Pesaran et al., 2006; Bakola et al., 2010), as well by using nonvisual signals (Gregoriou and Savaki, 2003; Bosco et al., 2010; McGuire and Sabes, 2011).

In area MIP, neurons at different locations within the IPS display different activity types. Deep within the sulcus, cells are mostly visual; in the central part of the IPS, they are activated by hand reaching; and dorsally, they respond to passive somatosensory stimulation. Many cells respond to somatosensory and visual stimuli and are 
active during reaching (Colby and Duhamel, 1991). Quantitative analysis of activity types during reaching (Johnson et al., 1996) in behaving monkeys has shown an orderly progression of cells related to visual target presentation and hand reach planning and execution, as one moves from posterior to anterior in MIP, that is, from the fundus of IPL to its crown. Consistent with this organization, McGuire and Sabes (2011) have provided evidence for the existence of hybrid, rather than pure, reference frame representations for reaching (Battaglia-Mayer et al., 2003; McGuire and Sabes, 2009) in MIP, as well as in area PE. In a comparative study of the mechanisms leading to the formation of motor intentions of reaches versus saccades in MIP and LIP (de Lafuente et al., 2015) it has been shown that the gradual accumulation of information about decision variables in the activity of reaching-related neurons in MIP leads to the formation of a motor intention for a hand movement, but also significantly influences neural activity in LIP. When an eye movement was the outcome of the decision processes, activity was attenuated in MIP and remained well modulated in LIP. Therefore, during decision-making for reaches, there seems to exist a parallel flow of information to both MIP and LIP, whose outflow is directed, among others, to the hand and eye output domain, respectively, of the frontal cortex.

Area PEc is a visuomotor area where neural activity is tuned to hand position and reach direction (BattagliaMayer et al., 2001), and individual neurons display visual (Battaglia-Mayer et al., 2001; Raffi et al., 2002; Breveglieri et al., 2008) and somatosensory properties, often combining them (Battaglia-Mayer et al., 2001; Breveglieri et al., 2008). In this area, neurons are sensitive to optic flow (Battaglia-Mayer et al., 2001; Raffi et al., 2002), with specificity for the focus of expansion. Area PEc is considered an important node for visually guided reaching (Battaglia-Mayer et al., 2003); moreover, the visual properties of neurons suggest a role in navigation (Raffi et al., 2002; Breveglieri et al., 2008). Area PEci, in the medial wall of posterior parietal cortex, contains a somatosensory map of the periphery (Murray and Coulter, 1981). It has never been studied in alert monkeys, and its anatomic connections suggest a role in the somatosensory control of movement.

Together with the dorsal premotor and motor areas of the frontal lobe, this cluster participates in the distributed encoding of movement parameters, although at a higher hierarchical level. In fact, the integration of multijoint sensory and motor signals by individual neurons in area PEa, together with area PE in the aSPL cluster (see below), is at the core of an emerging abstract representation of hand position and movement direction occurring within a coordinate system that specifies the azimuth, elevation, and distance of the hand in space (Lacquaniti et al., 1995). In these areas, reach distance is encoded by combining inputs about retinal disparity and vergence (Bhattacharyya et al., 2009), and the latter with hand position information (Ferraina et al., 2009a, 2009b), a mechanism crucial for the computation of motor error. Beyond reaching, in PEa neural activity encodes information relevant to the subjective body image and its extension through tool use (Iriki et al., 1996; Obayashi et al., 2000; Iriki and Taoka, 2012).

\section{aSPL cluster}

This somatosensory cluster receives its main input from the (i) visuomotor mdSPL cluster (33.4); (ii) CING cluster (16.5); (iii) motor Ml-dmPMd areas (12.4); and (iii) areas of the parietal grasping and mirror system (alPL cluster; 6.7).

Beyond the classic studies on somatosensory discrimination (Mountcastle, 2005), area PE in this cluster participates in the control of reaches by encoding kinematic signals about hand position and movement direction (Mountcastle and Powell, 1959; Kalaska et al., 1983; Georgopoulos et al., 1984; Prud'homme and Kalaska, 1994; Ashe and Georgopoulos, 1994; Lacquaniti et al., 1995), probably as corollary discharge of motor commands from motor cortex. PE is a source of somatic information for motor cortex. Therefore, it can contribute to the somatosensory control of arm movements.

Area $3 \mathrm{a}$, at the transition between $\mathrm{SI}$ and $\mathrm{MI}$, encodes information from muscle spindles, related not only to the limb (Oscarsson and Rosen, 1963), but also to the eye, since eye position influences its neural activity (Wang et al., 2007).

\section{alPL cluster}

This cluster is connected to the (i) ventral premotor grasping and mirror areas of vPM (44.2); (ii) aSPL (24.8); (iii) pIPL(22.5); (iv) mdSPL (20.6); (v) CING (14.2); (vi) voPFC (9.6); (vii) Ml-dmPMd (7.1); and (viii) pmSPL(5.5).

This cluster includes areas involved in large-scale cortical networks for selecting and controlling purposeful reaching, hand and mouth actions, and action understanding.

The anterior intraparietal area (AIP) is a hand-related area playing a crucial role in visuomotor transformations for grasping. This area hosts motor, visuomotor, and visual neurons modulated by grip type and tuned to the geometrical properties and orientation of objects (Sakata et al., 1995; Murata et al., 2000). Early preparatory activity in AIP predicts both object and grip type. This differs from motor cortex that displays better encoding of object features during movement execution (Schaffelhofer et al., 2015). In the IPL convexity, Hyvärinen (1981) observed a rostro-caudal gradient from regions related to mouth and hand movement to reaching representations. This gradient was recently confirmed and correlated with architectonic subdivisions by Rozzi et al. (2008).

Areas PF and PFG are mostly involved in sensorimotor transformations for controlling hand and mouth movements. PFG is composed of neurons active during the execution of object-oriented hand actions (Gardner et al., 2007; Rozzi et al., 2008), often showing selectivity for grip type (Bonini et al., 2012). Concerning hand dynamics, neural activity in PFG encodes instantaneous force variation and retains memory of force signals for guiding hand action (Ferrari-Toniolo et al., 2015). These data suggest an involvement of this area in the cortical network for fine control of object grasping and manipulation. Many PFG grasping neurons are differentially active depending on the goal of the action (e.g., grasp-to-eat or grasp-to- 
place) in which the coded act is embedded (Fogassi et al., 2005; Bonini et al., 2010, 2011, 2012), likely reflecting sequential action organization according to goal or motor intention (Fogassi et al., 2005; Bonini et al., 2010, 2011, 2012). Finally, as many PFG neurons also display mirror properties (Rozzi et al., 2008; Bonini et al., 2010), this area has been considered the main parietal node of the mirror system (Rizzolatti and Craighero, 2004; Rizzolatti et al., 2014).

Area PG participates in the visuomotor control of reaching (Mountcastle et al., 1975; Hyvärinen, 1981; Battaglia-Mayer et al., 2005, 2007) and in the organization and control of reaching with the arm and the eye at the limit between peri- and extrapersonal space, probably by using several sources of visual information about the position, motion, and behavioral values of targets (Rozzi et al., 2008). Furthermore, neural activity in PG reflects the higher-order visuo-spatial analysis underlying the identification of maze path exit (Crowe et al., 2004, 2005), as well as that concerning object structure in construction tasks (Chafee et al., 2005, 2007).

The alPL cluster also includes the SIl region involved in higher-order aspects of somatosensory processing (e.g., Robinson and Burton, 1980; Murray and Mishkin, 1984; Hsiao et al., 1993; Romo et al., 2002; Hsiao, 2008; Pei et al., 2008). This region hosts somatosensory neurons preferentially active during the execution of objectoriented hand or mouth actions (Fitzgerald et al., 2004; Ishida et al., 2013; Taoka et al., 2013; Hihara et al., 2015). These properties suggest a role in haptic processing of object shape and somatomotor transformations for object-oriented hand actions. SII might provide somatosensory feedback information used for the timing of manipulation sequences and for monitoring and updating hand motor programs.

\section{pIPL cluster}

The main projections to this cluster originate from (i) pmSPL (36.2); (ii) alPL (23.3); (iii) pPFC (17.6); (iv) CING (8.3); (v) aSPL (8.3); (vi) vPM (8.3); and (vii) mdSPL (7.3).

This cluster is involved in visual attention (area 7a/PG; Lynch et al., 1977; Bushnell et al., 1981) and reorienting (LIP; Steinmetz and Constantidinis, 1995), including mirror reorienting (Shepherd et al., 2009), saliency (LIP; Gottlieb et al., 1998; Colby and Goldberg, 1999; Bisley and Goldberg, 2010; Suzuki and Gottlieb, 2013; Qi et al., 2015), and novelty (LIP; Foley et al., 2014). The locus of attention in area $7 \mathrm{a} / \mathrm{PG}$ is represented by patches of activation $\sim 800 \mu \mathrm{m}$ wide (Raffi and Siegel, 2005), embedded within pre- and postsaccadic signals (LIP/7a; Barash et al., 1991). The role of LIP in motor intention for eye movement control (Gnadt and Andersen, 1988; Snyder et al., 1997, 1998; Andersen and Cui, 2009) is another important function of LIP. Dorsal LIP (LIPd) is mostly involved in oculomotor planning; ventral LIP (LIPv) contributes to both attention and oculomotor mechanisms (Liu et al., 2010). Some studies (Dean et al., 2012) have proposed a role for LIP in eye-hand coordination, whereas others (Yttri et al., 2013) have denied such a possibility. Concerning the analysis of visual space, LIP participates in encoding the structure of visual objects (Gnadt and Mays, 1995;
Shikata et al., 1996; Sereno et al., 2002; Vanduffel et al., 2002; Orban, 2011). Finally, LIP activity relates to decision-making (Gold and Shadlen, 2007; Gottlieb et al., 2014; Kable and Glimcher, 2009) by varying firing frequency as a function of evidence in favor of or against each of the possible choices (Shadlen and Newsome, 2001; Roitman and Shadlen, 2002; Churchland et al., 2008), and of reward probability as well (Platt and Glimcher, 1999; Kiani and Shadlen, 2009). It has also been proposed that LIP decision-related activity is the result of integrative mechanisms encoding action value (Louie and Glimcher, 2010) in relation to alternative options (Louie et al., 2011, 2014). Interestingly, during accumulation of decision variables, neural activity in LIP is modulated when the decision outcome is not only a saccade, but also a reaching movement (de Lafuente et al., 2015). In the same vein, LIP neurons accumulate context-dependent sensory information to decide in a flexible way where to make a saccade in a task-switching condition (Kumano et al., 2016).

Areas VIP and MST are important parietal nodes of the distributed system for heading perception (Britten, 2008). In VIP (Colby et al., 1993), neurons are influenced by approaching visual stimuli and display visual and somatosensory receptive fields closely aligned (Duhamel et al., 1998). They also respond to vestibular and auditory signals (Schlack et al., 2002, 2005), smooth pursuit eye movement (Schlack et al., 2003), and 3D shape (Durand et al., 2009) of visual objects. Therefore, VIP has a crucial role in encoding heading signals derived from optic flow and vestibular information from ego-motion (Bremmer et al., 2002a, b; Bremmer 2005; Schlack et al., 2002, 2005; Chen et al., 2011, 2013). The general properties of MST are similar to those of VIP, although they suggest an involvement in large-scale image motion analysis. Concerning optic flow, the overrepresentation of expansion in this area suggests a role in locomotion, and its physiologic properties indicate a causal relation with heading perception. In MST, visual motion processing undergoes early attentional modulation (Treue and Maunsell, 1996). VIP is also part of the distributed system for numerosity (Nieder and Miller, 2004a, b; Nieder, 2016), which also includes LIP (Roitman et al., 2007) and prefrontal cortex (Diester and Nieder, 2007).

In Opt/PG, neurons overrepresent the contralateral directional continuum (Battaglia-Mayer et al., 2005) for intended eye-hand movement. This representation might provide a positive image of the directional motor disorder of neglect typical of parietal patients with directional hypokinesia (Mattingley et al., 1992; Heilman et al., 2000; Caminiti et al., 2010), supporting a role of parietal cortex in encoding motor intention. Neural activity in these areas is also related to manual interception of moving targets (Merchant et al., 2001, 2004).

\section{Inputs and functional properties of frontal clusters: identification of frontal domains}

The inputs to the frontal clusters (Fig. 5) were organized in a way that resembled those of parietal ones. 


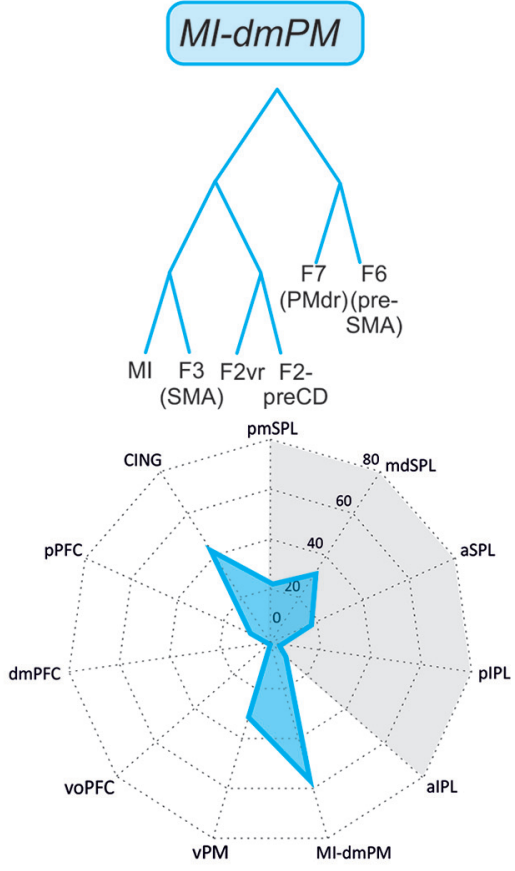

Entropy 1.94
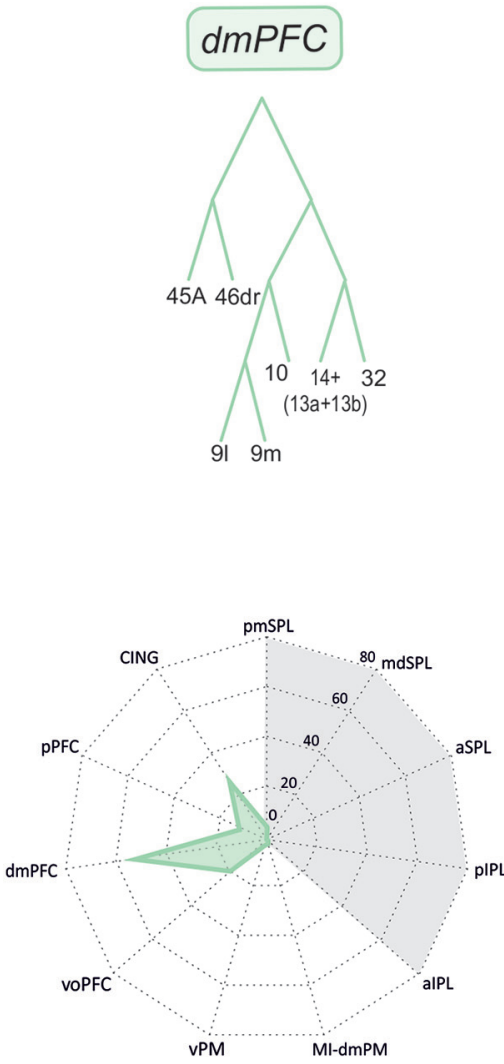

Entropy 1.37

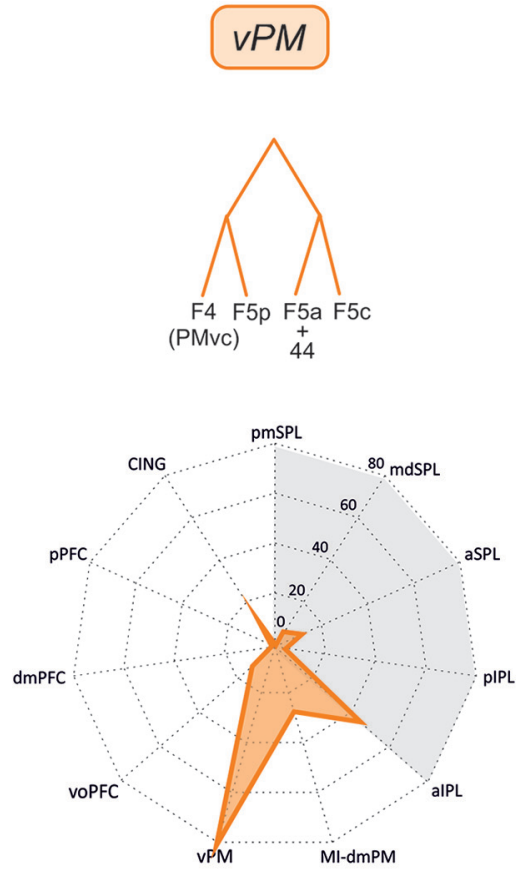

Entropy 1.68
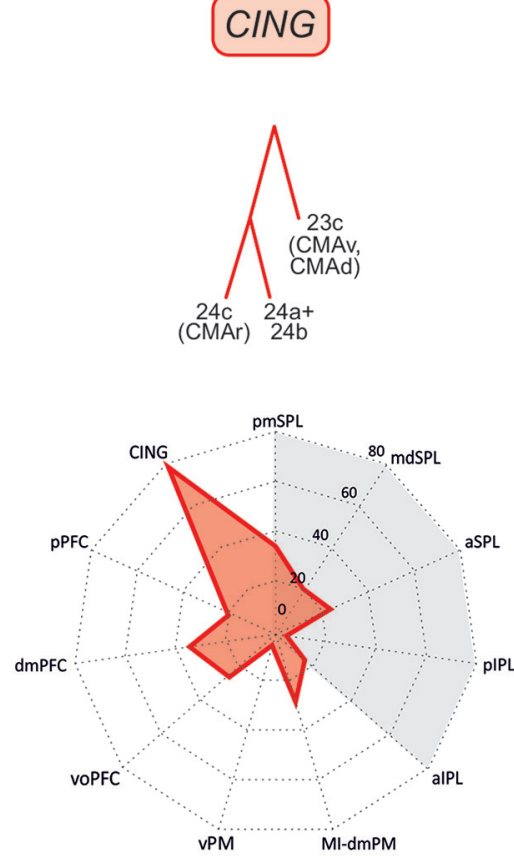

Entropy 2.16
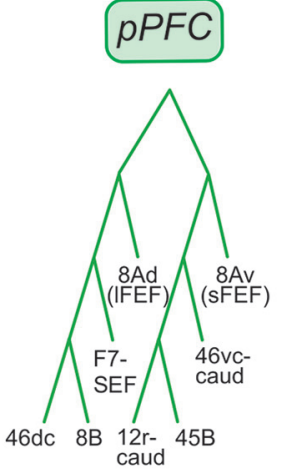

$46 \mathrm{dc} 8 \mathrm{~B} \underset{\substack{12 r-\\ \text { caud }}}{45 \mathrm{~B}}$

\section{VOPFC}
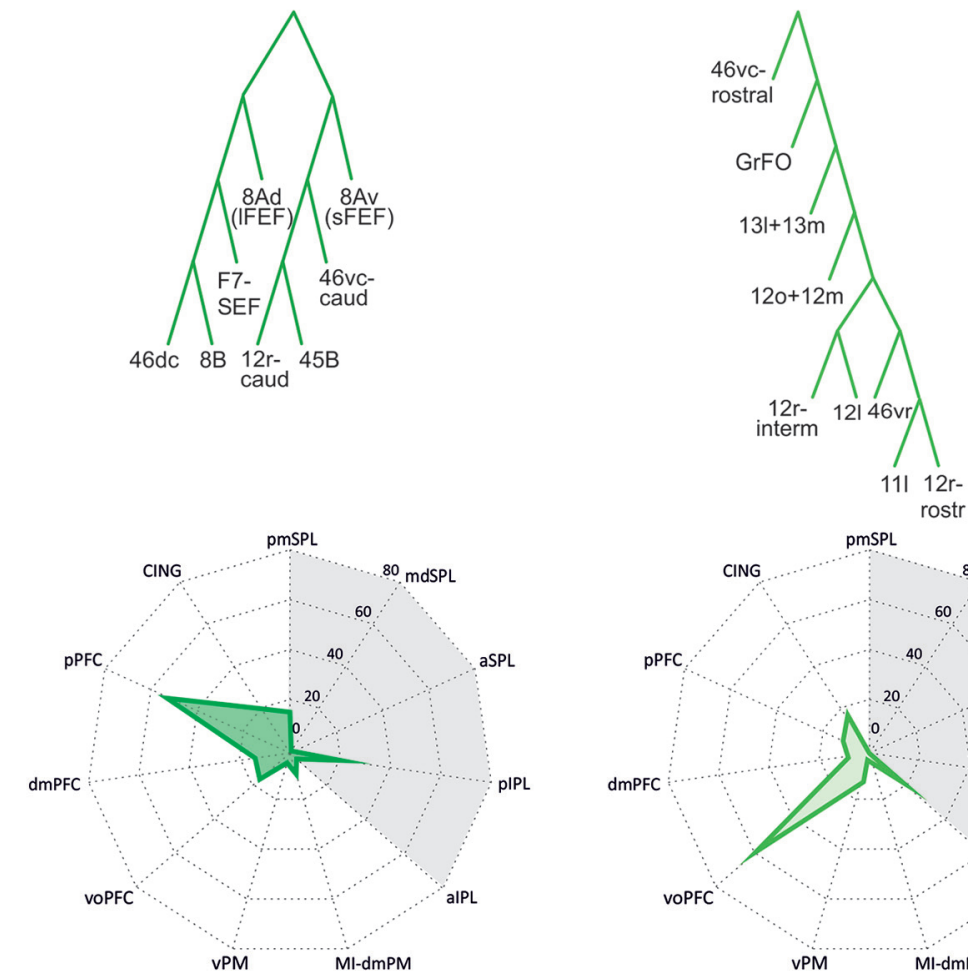

Entropy 1.71

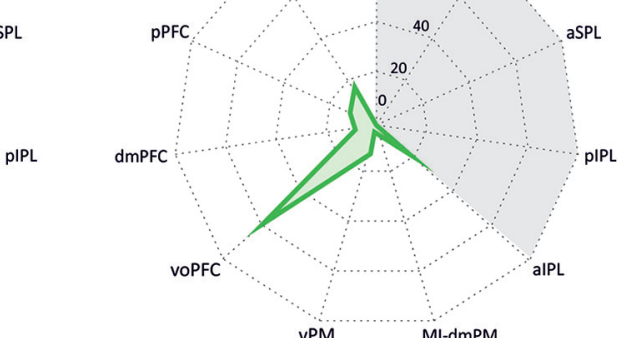

Entropy 1.32

Figure 5. Inputs to the frontal clusters. Spider plots displaying the mean values (scale: 0-100) of frontal (gray shading) and parietal inputs to any given parietal cluster (top). The cluster entropy is also reported. 


\section{MI-dmPM cluster}

The strongest input to this cluster originates from the (i) cingulate premotor areas (CING; 43.4); (ii) visuomotor areas of the mdSPL cluster (32.6); (iii) ventral premotor areas (vPM; 30.5); (iv) reaching-related areas of the parieto-occipital junction (pmSPL; 23.1); (v) somatosensory and reaching-related areas of aSPL (18); (vi) oculomotor and attention-related areas of prefrontal cortex (pPFC; 8.7); and (vii) somato- and visuo-motor areas of alPL (7.1).

This cluster can be considered as the main premotormotor module of the frontal lobe, since it includes areas serving as the interface between prefrontal and premotor cortex (F7 and F6), all the dorsomedial premotor areas, with motor cortex as the main output stage. Within this cluster, the two rostral premotor areas F7 and F6 (preSMA) tend to cluster separately from the dorso-caudal premotor areas and are commonly regarded as an interface between prefrontal cortex and this motor module of the frontal lobe.

Area F7 contains a dorsomedial oculomotor field commonly referred to as the supplementary eye field, which, however, belongs to another cluster (see below). Apart from this, there exists only scant information on the functional properties of this region. It is known that neural activity relates to both eye and limb movement (Johnson et al., 1996; Fujii et al., 2000). A subpopulation of F7 neurons is modulated by visual stimuli when these are also the target of a reaching movement (Vaadia et al., 1986). In this area, visual and eye-related signals predominate over coexisting hand information within a trend that is reversed as one moves caudally toward PMd and motor cortex.

Area F6 is a visually responsive, mostly arm-related area (Rizzolatti et al., 1990; Luppino et al., 1991, Matsuzaka et al., 1992) involved in several higher-order aspects of motor control. F6 neurons activate during preparation for movement (Matsuzaka et al., 1992) and can code the reprogramming of an arm movement to a direction opposite to the one previously rewarded (shift-related activity, Matsuzaka and Tanji, 1996). F6 is also involved in target localization and effector selection for movement (Hoshi and Tanji, 2000, 2004). Furthermore, this area participates in the acquisition of procedural learning (Hikosaka et al., 1999). It has been proposed that F6 could play a key role in the neural mechanisms underlying action selection and motor inhibition and in performance monitoring (Nachev et al., 2008; Ridderinkhof and Wijnen, 2011).

Area F2 hosts a representation of leg and arm movements located dorsal and ventral to the precentral dimple, respectively. Within the arm representation, hand and wrist movements tend to be mostly represented in the ventro-rostral part close to the arcuate sulcus (F2vr). Neural activity in this part of dorsal premotor cortex encodes non-standard, or arbitrary, sensorimotor associations (Wise et al., 1997) and combines reach signals about hand position and movement direction within a shouldercentered coordinate system (Caminiti et al., 1991; Burnod et al., 1992). PMd activity integrates hand, eye, and target information during reach plans (Pesaran et al., 2006), as in many areas of the parieto-frontal system. PMd plays a pivotal role in the formation (Caminiti et al., 1991; Mattia et al., 2013), suppression (Mirabella et al., 2011), and modification (Archambault et al., 2011; Battaglia-Mayer et al., 2014) of reach plans and in disconnecting the natural coupling in eye-hand coordination (Gail et al., 2009). This area can encode two potential targets for hand movement (Cisek and Kalaska, 2002, 2010), reaching decisions (Cisek and Kalaska, 2005), and switch of motor plans (Pastor-Bernier et al., 2012). These results provide an explanation from a neurophysiological perspective of the consequence of dorsal premotor cortex lesions in monkeys (Petrides, 1985; Passingham, 1988; Kurata and Hoffman, 1994; Wise et al., 1997). A recent study combining neural recording and reversible silencing (Ohbayashi et al., 2016) in behaving monkeys emphasizes the role of the PMd in sequential movements guided by internal instructions, but not by visual signals, thus enriching the functional repertoire of this area.

Area F3 (SMA) is electrically excitable with low-intensity currents and contains a complete body movement representation (Mitz and Wise, 1987; Luppino et al., 1991). Evoked movements mainly involve proximal and axial muscles and, typically, a combination of different joints. Distal movements, when evoked, are often observed in combination with the proximal ones. F3 neurons exhibit somatosensory responses time-locked to the movement onset (movement-related activity). This area hosts neurons coding specific sequences of movements (Tanji and Shima, 1996) and appears to contribute to initial stages of learning of motor sequences, by improving their performance (Hikosaka et al., 1999). Furthermore, in SMA/preSMA (Tanji and Shima, 1994; Shima and Tanji, 2000) and MI (Carpenter et al., 1999), neural activity is modulated by the ordinal position of hand or eye movements and, together with prefrontal, anterior cingulate cortex (ACC), and FEF, participates in the ordinal categorization of eye and hand movement (Nieder and Dehaene, 2009) and to the specification of movement sequences (Shima and Tanji, 2000).

Motor cortex (MI) encodes information related to both the abstract representation of movement parameters and higher-order motor processing. Among the first are arm/ limb movement, position (Mountcastle and Powel, 1959; Georgopoulos et al., 1984; Caminiti et al., 1990; Prud'homme and Kalaska, 1994; Lacquaniti et al., 1995), direction (Georgopoulos et al., 1981; Caminiti et al., 1990; Lacquaniti et al., 1995), amplitude (Fu et al., 1993), velocity (Ashe and Georgopoulos, 1994; Moran and Schwartz, 1999; Averbeck et al., 2005; Archambault et al., 2009, 2011), acceleration (Ashe and Georgopoulos, 1994), force (Hepp-Reymond et al., 1978; Cheney and Fetz, 1980; Georgopoulos et al., 1992; Maier et al., 1993; Kakei et al., 1999; Sergio et al., 2005), and hand grip type (Muir and Lemon, 1983; Schaffelhofer et al., 2015). In MI, the activity of individual cells encodes many movement parameters at the same time (Ashe and Georgopoulos, 1994), and their graded utilization is used in different functions, such as direct reaches and changes of hand trajectory (Archambault et al., 2011). Concerning higher-order processing, 
$\mathrm{Ml}$ activity is influenced by context-recall tasks (Pellizzer et al., 1995), mental rotation of intended movement directions (Georgopoulos et al., 1989), ordinal position of reaches (Carpenter et al., 1999), hand drawing (Schwartz, 1994), and update of motor intention (Georgopoulos et al., 1983b; Archambault et al., 2011). Most important, encoding of reaching parameters depends on population codes and dynamics (Georgopoulos et al., 1983a; Caminiti et al., 1991; Churchland et al., 2012). Finally, mirror activity has been reported in PMd (Tkach et al., 2007) and Ml (Tkach et al., 2007; Dushanova and Donoghue, 2010; Vigneswaran et al., 2013), suggesting a role in action recognition and movement suppression during action observation.

\section{vPM cluster}

This ventral premotor cluster receives selected inputs from (i) alPL (45.1); (ii) the motor complex (MI-dmPM; 27); (iii) ventro-orbital areas (voPFC; 11.1); (iv) mdSPL (7.3); (v) aSPL (12.5); and (vi) CING areas (10.9).

The areas of this cluster play an important role in sensorimotor transformations for guiding face/mouth and arm movements within peripersonal space and for selecting and controlling purposeful hand actions.

The caudal PMv area F4 contains a representation of arm, neck, face, and mouth movements (Godschalk et al., 1981; Gentilucci et al., 1988; Fogassi et al., 1996). Electrical stimulation with long train durations elicits complex protective movements similar to those observed when monkeys are presented with actual threat (Graziano, 2006). Most F4 neurons activate during the execution of purposeful arm movements, such as reaching or bringing food to the mouth (Gentilucci et al., 1988). Most of these neurons have tactile or tactile plus visual receptive fields organized in register. The visual receptive fields are independent of eye position, likely reflecting coding of peripersonal space based on a body part-centered frame of reference (Graziano et al., 1994; Fogassi et al., 1996). These responses could represent the activation of motor programs related to potential motor acts within the peripersonal space.

The rostral PMv area F5 hosts a motor representation of the hand, more dorsally, and the mouth, more ventrally, which overlap to a considerable extent. Neurons in this area typically encode specific goal-directed motor acts, such as grasping, many of them selectively coding specific grip types (Rizzolatti et al., 1988). A significant proportion of F5 neurons also display visual responses of two different types. The first type of visuomotor neurons activate also when graspable objects are simply observed (Murata et al., 1997; Raos et al., 2006; Umiltà et al., 2007; Fluet et al., 2010; Vargas-Irwin et al., 2015), likely reflecting extraction of object affordances. A second type of visuomotor neurons, designated as mirror neurons, fire during the execution of hand motor acts, as well as during the observation of similar acts done by others (Gallese et al., 1996; Rizzolatti et al., 1996). This neural activity likely reflects the involvement of this area in an observation-execution matching system (mirror system), which is at the basis of the ability to understand others' goal-directed motor acts (Rizzolatti and Craighero, 2004; Rizzolatti et al., 2014).

\section{CING cluster}

The cingulate areas of this cluster receive inputs from many other parietal and frontal clusters, such as (i) dmPFC (34); (ii) voPFC (24.5); (iii) Ml-dmPM (28.4); (iv) pPFC (19.3); (v) pmSPL (33.1); (vi) mdSPL (20.7); (vii) alPL (14.3); and (viii) aSPL (24.8).

Neural activity in both rostral (CMAr; 24c) and caudal (CMAc; 23c) cingulate motor areas is modulated by armhand movement (Shima et al., 1991; Cadoret and Smith, 1997; Russo et al., 2002), although Picard and Strick (2003) have reported weak 2-deoxyglucose (2-DG) activation in these areas during reaching. These areas differ in their stimulation threshold (Luppino et al., 1991) and motor-related activity (Shima et al., 1991). Self-paced and sensory-triggered reaches modulate the activity of $\sim 40 \%$ of neurons similarly in both areas. Long-lead activity related to self-paced movement dominates in CMAr, whereas signal-triggered movement activity prevails at more caudal locations. In the dorsal part of CMAc (CMAd of Dum and Strick, 1991), activation studies have shown strong 2-DG uptake associated with remembered sequences of reaches (Picard and Strick, 1996, 1997). In CMAr, neural activity is related to serial order of motor sequences (Procyk et al., 2000). Furthermore, in this area, neural activity encodes multiple decision variables, such as payoff, success probability, and cost (Kennerley et al., 2009), which assigns to it a role in addressing information about decision value to the motor complex of the frontal lobe. Cai and Padoa-Schioppa (2012) have reported significant differences in cell properties in the dorsal and ventral bank of the anterior cingulate sulcus. In the dorsal bank, cells were directionally selective and active during a delay period before eye movement onset, whereas in the ventral bank, cells were not spatially selective and fired after juice delivery. More relevant, in both areas, neurons encoded subjective value as distinguished from reward properties. The authors concluded that dorsal anterior cingulate cortex is a substrate through which signals from choice outcome and subjective value, in other words from the choice system, are addressed to the motor system. In this same area, Michelet et al. (2016) have reported neural activity compatible with a general monitoring function of movement outcome and with focal attentional control. CMAr has also been involved in the process of social error detection (Yoshida et al., 2012).

\section{pPFC cluster}

The main inputs to this cluster stem from (i) voPFC (14.8); (ii) dmPFC (13.4); (iii) pIPL(20.7); (iv) CING (20.6); (v) MI-dmPM (7.6); and (vi) pmSPL (15.3).

The areas of this cluster occupy the caudal part of the prefrontal cortex, including the FEF and a set of neighboring areas affiliated with the frontal oculomotor system. FEF (8Ad, 8Av) corresponds to an architectonically distinct area (Stanton et al., 1989; Gerbella et al., 2007) from which intracortical microstimulation with low current intensities evokes saccades (Bruce et al., 1985). Largerand smaller-amplitude saccades are represented more dorsally and more ventrally, respectively (Bruce et al., 1985). Neurons in this area fire before the initiation of saccadic eye movements and display motor, visual, or 
visuomotor properties (Moschovakis and Highstein, 1994; Schall and Thompson, 1999; Lynch and Tian, 2006). Furthermore, the FEFs are involved in visual attention (Moore et al., 2003; Moore and Fallah, 2004), including covert attention (Thompson et al., 2005) and salience (Kastner and Ungerleider, 2000; Thompson and Bichot, 2005; Corbetta and Shulman, 2011; Petersen and Posner, 2012). Neurons in FEF also encode the amount of reward (Roesch and Olson, 2003).

The SEF (Schlag and Schlag-Rey, 1987) is a sector of F7 where intracortical microstimulation evokes saccades and neurons are modulated by both visual stimuli, saccades and pursuit eye movements. The SEF contains a congruent representation of contralateral saccades and visual space, thought to participate in the visuomotor transformation for saccade generation. Neural activity in this area also predicts antisaccades (Schlag-Rey et al., 1997) and relates more to conditional oculomotor learning than to standard visuomotor control (Chen and Wise, 1995a, 1995b). SEF neurons also fire differentially as a function of the location on an object to which an eye movement is directed, suggesting an object-centered representation of visual space (Olson and Gettner, 1996). Conflict monitoring is another function proposed for this region (Stuphorn et al., 2000; Emeric et al., 2010; see, however, Nakamura et al., 2005), together with error and reward signaling (Emeric et al., 2010).

In area 8B, intracortical stimulation evokes eye and ear movements (Mitz and Godschalk, 1989; Bon and Lucchetti, 1994; Schall et al., 1995a). Neurons in this area are modulated by eye movement, regardless of the presence of a visual target (Mitz and Godschalk, 1989; Schlag et al., 1992), and respond to visual or acoustic stimuli (Ito, 1982; Azuma and Suzuki, 1984; Vaadia et al., 1986), suggesting their involvement in visual and acoustic processing for the control of orienting movements in space. A sector of this area also hosts neurons encoding different auditory environmental stimuli (Lucchetti et al., 2008; Lanzilotto et al., 2013). When an auditory stimulus is presented while the animal fixates on a visual one, the activity of some auditory and auditory-motor neurons is suppressed (Lucchetti et al., 2008).

The cortical sector rostral to the FEF and including the caudalmost part of both dorsal and ventral area 46 is involved in the generation and control of visually-guided and memory-guided saccades (Funahashi et al., 1993; Takeda and Funahashi, 2002; Watanabe et al., 2006; Kuwajima and Sawaguchi, 2007), as well as in controlling eye vergence and accommodation (Gamlin and Yoon, 2000). Indeed, this cortical sector has already been included in the oculomotor cortical network and is considered part of the so-called prefrontal eye field (Lynch and Tian, 2006). The caudal part of area 46 should correspond to a posterior region of PFC where neural activity in monkeys relates to hierarchical representation of task events (Sigala et al., 2008). This region, together with area 13, participates in the transformation of the outcome of economic decisions into motor plans (Cai and PadoaSchioppa, 2014).
The functional properties of area 45B remain to be fully elucidated. Functional MRI (fMRI; Premereur et al., 2015) and 2-deoxyglucose (Moschovakis et al., 2004) data have shown activation during the execution of saccades, fitting well with the proposed affiliation of this area to the oculomotor frontal system, as indicated by its connectivity pattern. A significant proportion of neurons in this zone display visual shape selectivity, and fMRI data have revealed activation for the observation of objects and faces (Denys et al., 2004; Peng et al., 2008; Tsao et al., 2008). It has been proposed that area 45B is a "pre-oculomotor" area involved in guiding the exploration of visual scenes for the perception of objects, actions, and faces (Gerbella et al., 2010). Consistent with this view, a recent study (Bichot et al., 2015) shows that neurons in the ventral pre-arcuate region encode features-based attention and are the source of this information for the FEF. Finally, there is evidence that area 45 , together with areas 9,46 , and $47 / 12$ l, is part of a lateral prefrontal network related to representation of decision values, since its neurons encodes one, over multiple, decision variables (Kennerley et al., 2009).

\section{dmPFC cluster}

This cluster is primarily connected with the (i) CING (27); (ii) ventral orbitofrontal areas (voPFC, 19.0); and (iii) oculomotor and attention-related areas of the frontal lobe (pPFC,11.9) and has scant parietal connections.

This cluster mostly includes dorsomedial prefrontal areas putatively involved in self-referential functions, such as monitoring previous behavior to guide subsequent choices (Petrides et al., 2002; Petrides, 2005), and rostral prefrontal areas involved in higher-order aspects of executive control of behavior, such as episodic control (Koechlin and Summerfield, 2007).

Neurophysiological data have shown that area 9 is involved in the selection of abstract response strategies for cognitive problems (Genovesio et al., 2005), as well as in the representation and memory of previous and future goals (Genovesio et al., 2006), functions shared with area $46 \mathrm{~d}$. Area 9 is also involved in the selection of response tactics (Matsuzaka et al., 2012) and the transformation of tactics into action (Matsuzaka et al., 2016). Based on intracortical microstimulation data, it has been recently proposed that lateral area 9 and the adjacent part of dorsal area $46(46 \mathrm{dr})$ could be involved in goal-directed orienting behaviors and gaze shift control (Lanzilotto et al., 2015).

To our knowledge, there are no functional studies in which neural activity has been unequivocally recorded from area $46 \mathrm{dr}$. However, a recent electrophysiological study of area 46 , in which recording sites involved the rostral part of both dorsal and ventral 46 , reported neural activity related to the use of abstract response strategies for guiding motor behavior (Tsujimoto et al., 2011).

Area 10, also referred to as fronto-polar cortex, in humans has properties similar to those reported for area 9 in human social cognition (Amodio and Frith, 2006; Gilbert et al., 2006; Yoshida et al., 2012). A different view holds that this region is important when in uncertain conditions subjects select their action on the basis of a flexible use of 
exploratory and exploitative strategies (Daw et al., 2006). Several authors have discussed the possibility that this region is unique to humans (Sallet et al., 2013); therefore, a discussion of data from human lesion and fMRI studies in the frame of current knowledge on area 10 in monkeys would be problematic. The only available cell recording study of area 10 (Tsujimoto et al., 2010) in behaving monkeys shows that neural activity is modulated by the evaluation of decision outcomes. In fact, rather than representing task events or strategies, as in more posterior parts of prefrontal cortex, cell modulation appears at the time of reward delivery. Consistent with this interpretation are the consequences of lesions in monkeys (Mansouri et al., 2015) trained in an analog of the Wisconsin Card Sorting Test. The results of that study suggest a role of area 10 in redistributing executive control resources from present to alternative tasks, so as to exploit new reward opportunities. In the hypothesis of Mansouri et al. (2015), area 10's role would differ from that of more posterior prefrontal areas, which seem to be more related to the optimization of the current task performance.

Area 32 in monkeys has recently been redefined by Vogt et al. (2013). Neural activity in this area is modulated by both positive and negative subjective values, and its microstimulation biases this representation toward negative decision-making, a behavior that is modulated by anti-anxiety drugs (Amemori and Graybel, 2012). Lesions in area 32 and in the anterior part of area 24 (Rudebeck et al., 2006) result in a reduced interest in other individuals and in the social signals coming from other monkeys, suggesting that this region is also important for social valuation.

Area 14 is a ventromedial orbitofrontal area located in a region traditionally associated with object choices based on value comparisons. In its anterior part (a14), neural activity is modulated by reward magnitude and probability (Strait et al., 2014), which is in line with previous studies showing the relevance of value encoding (PadoaSchioppa, 2011). Interestingly, area 14 neurons display anticorrelated tuning between offer values, suggesting that these populations are involved in decision-making for choice. Furthermore, neural activity in area 14 (Bouret and Richmond, 2010) encodes the perceived value of task events related to internal factors, such as reward size. A lesion in area 14 in monkeys tested during different reward-based tasks (Rudebeck and Murray, 2011a) impairs learning to inhibit responses to a previously rewarded object, whereas a lesion in area 11 and 13 impairs rapid updating of object value related to selective satiation. Thus, different subregions of orbitofrontal cortex would encode different aspects of reward-based behavior (for perspective from lesion studies see Rudebeck and Murray, 2011b). Overall, these results are consistent with theoretical models (Hunt et al., 2012) of value-based decision-making and previous studies of brain activation in humans (Rushworth et al., 2011; Levy and Glimcher, 2012).

The dmPFC cluster also includes area 45A, located in the caudal VLPF cortex. Functional data show that this sector is involved in multisensory processing of commu- nication stimuli (Romanski and Averbeck, 2009) and activates during action and face observation (Nelissen et al., 2005; Tsao et al., 2008; Kuraoka et al., 2015), suggesting a role in communication behavior. Moreover, this region is activated during eye movement (Premereur et al., 2015). Based on these properties and on connectional data (Gerbella et al., 2010, Saleem et al., 2014), it is possible that this area represents the neural substrate for gaze direction in communication behavior, an important communicative signal for social interactions (e.g., Emery, 2000; Ghazanfar et al., 2006).

\section{voPFC cluster}

This orbitofrontal cluster receives its main inputs from the areas of (i) CING (17.8); (ii) pPFC (12.4); (iii) dmPFC (9.2); (iv) alPL (10.7); and (v) VPM (10.6).

This cluster occupies a large prefrontal territory including VLPF areas mostly involved in executive control of skeletomotor behavior, as well as orbitofrontal areas. These seem to encode the significance of stimuli within emotional contexts, identities of goods (in an economic sense), and subjective value (Barbas, 2007; Grabenhorst and Rolls, 2011; Padoa-Schioppa and Cai, 2011). Some of the areas included in this cluster, such as $46 \mathrm{vr}$, rostral $12 r, 12 \mathrm{l}$, and GrFO, so far defined based on architectonic and/or connectional data, still lack a characterization in terms of functional properties.

Functional studies have shown that in area $46 \mathrm{vc}$, cells are active during tasks requiring oculomotor responses (e.g., Boch and Goldberg, 1989; Averbeck et al., 2006; Ichihara-Takeda and Funahashi, 2007), whereas arm and hand movement activity (e.g., Requin et al., 1990; Hoshi et al., 1998, 2000) tended to be located more caudally and more rostrally, respectively. These two distinct fields of area 46vc take part in different clusters. Indeed, in rostral area $46 \mathrm{vc}$, executive functions appear to be finalized for the control of hand, arm and, possibly, mouth movements (Bruni et al., 2015; Simone et al., 2015). Area 46v appears to encode context-related information for learning and behavioral rules for action selection (e.g., Hoshi et al., 1998; White and Wise, 1999; Hoshi et al., 2000; Murray et al., 2000; Wallis et al., 2001). Specifically, 46vc-rostral and the intermediate part of area $12 r$ include neurons coding contextual information used for selecting and guiding object-oriented hand actions (Bruni et al., 2015). Area $46 \mathrm{v}$ also appears to play a role in the organization of sequential motor behavior (Saito et al., 2005) and in representing multiple phases of behavioral events, providing the basis for the temporal regulation of behavior (Saga et al., 2011).

Area $12 r$ contains visual neurons tuned to the identity or features of objects (Wilson et al., 1993; Asaad et al., 1998) and is critically involved in functions related to object identity (Passingham, 1975; Mishkin and Manning, 1978; Wang et al., 2000). Accordingly, this area has been considered to play a role in working memory for objects and shapes (Wilson et al., 1993), in conditional learning based on object identity (Passingham, 1993; Passingham et al., 2000), and in encoding category membership (Freedman et al., 2002; Miller et al., 2002). The intermediate area 12r hosts neurons with hand-related activity (Simone et al., 
2015; Bruni et al., 2015). These data, as well as connectivity studies (Borra et al., 2011), suggest a role in retrieval, retention, and manipulation of information on objects or hand-object interactions for controlling object-oriented hand actions.

Areas 11 and 13 are treated together, since they show similar, although complementary, functional properties. In these areas, as well as in area 14, neural activity encodes reward predicting signals, reward expectation, and receipt (Tremblay and Schultz, 1999). Therefore, these areas have been considered as crucial nodes in the distributed system involved in encoding the motivational value of rewarding consequences of actions. In an orbitofrontal region that probably includes this area, neural activity is related to reward value (Roesch and Olson, 2004), expected time of delivery (Roesch and Olson, 2005), and risk (O'Neill and Schultz, 2010; Schultz, 2015, 2016 and references therein). Neurons in this region also encode economic value, since their activity relates to the offered value and chosen goods (Padoa-Schioppa and Assad, 2006), rather than the chosen action. Cai and Padoa-Schioppa (2014) have studied neural activity in area 13 and dorsal and ventral prefrontal cortex, most probably in areas 46dc and 46vc. In both regions, before target presentation, neurons encoded the choice outcome in goods space; after target presentation, they progressively encoded target location and motor plan. This suggests that a transformation of information from choice outcome into plans for action occurs, thanks to which signals from areas $46 \mathrm{v}$ and $46 \mathrm{~d}$ are addressed to the frontal premotor cortex (for underlying connectivity, see Takada et al., 2004; Petrides and Pandya, 2006; Takahara et al., 2012; Gerbella et al., 2013; Saleem et al., 2014). Furthermore, neurons in area $13 \mathrm{~m}$ encode the same value-related computations across different economic decisions (Xie and Padoa-Schioppa, 2016). In area 13, information about rewarding and aversive stimuli are combined, suggesting that both types of stimuli are processed by the same neuronal population (Morrison and Salzman, 2009). Finally, neural activity in areas 11/13 (Bouret and Richmond, 2010) is modulated by the perceived value of task events provided by external stimuli.

The analysis of the cluster's functional composition and inputs described above indicates that in both parietal and frontal cortex, whereas some clusters receive projections from many sources, others are connected with only a few other clusters in a rather selective fashion. As an example, in frontal cortex, the cluster with more inputs (no. 11) is the CING one; those with the least inputs (no. 7) were dmPFC and voPFC. The parietal clusters with the most inputs (no. 11) was the alPL; the one with the least inputs (no. 5) was the aSPL. As an index of the probability of connections, for each cluster we computed the entropy, which estimates whether clusters received their inputs from a small set of other clusters or an equal number of inputs from all other clusters (Figs. 4 and 5). Therefore, a broad distribution of inputs will have maximum entropy, and a situation in which all the inputs stem from just another cluster will have minimum or zero entropy. Considering that there were 11 inputs, the frontal cluster with highest entropy is the CING (2.16 nats), and that with the smallest entropy, the voPFC (1.32 nats). In parietal cortex, the highest entropy was observed in the pmSPL (1.92 nats), and the lowest in aSPL (1.44 nats). The average entropy of parietal and frontal areas was 1.69 and 1.67 nats, respectively (therefore very similar), indicating that both sets of areas tend to have a similar architecture of cortical connectivity.

The analysis of the relative strength of the inputs to each cluster provides an example of the connections between parietal and frontal cortex and their degree of reciprocity (Markov et al., 2014) and aids comprehension of the overall design of the parieto-frontal system (Fig. 6), as highlighted in the Discussion.

\section{The intraparietal connections between SPL and IPL areas: clusters of parietal areas}

The clusters of parietal areas identified from parietofrontal connectivity were also identified on the basis of the intrinsic connectivity between SPL and IPL areas (Fig. 7). In the SPL (Fig. 7A), we identified the same pmSPL cluster as before, however, now also including MIP. The mediodorsal SPL cluster (mdSPL) was formed by areas PEc and PEci. A third cluster in the anterior part of SPL (aSPL) included areas PE, SI, and PEa, the latter to be considered as a new entry in this cluster, since it belonged to the mdSPL cluster, when the cluster affiliation of parietal areas was decided on the basis of their connections with frontal cortex. These clusters were very robust, since in the best 100 trees the first occurred 85 times, the second 68 times, and the third 68 times. Thus, the cluster affiliation of cortical areas within parietal cortex can change depending on which set of connections is considered, medium-range intraparietal or long-range parieto-frontal, which might have intriguing functional consequences.

In the IPL (Fig. 7B), we found the same alPL and pIPL clusters previously identified from fronto-parietal connectivity. They were robust, both occurring 100 times in the best 100 trees.

The dominant inputs to these clusters are shown in Fig. $7 C$. With the exception of the mdSPL cluster, all other clusters entertain reciprocal SPL-IPL connections. The parietal cluster with highest entropy was mdSPL (1.42), whereas that with smaller entropy was pIPL (1.17).

The average entropy of the connectivity of SPL and IPL areas was 1.33 and 1.18 nats, respectively, which suggests a slightly more complex organization of inputs of the former relative to the latter. The overall organization of these internal SPL-IPL connections is schematized in Fig. 8 and discussed below.

\section{Discussion}

This study shows that parietal and frontal areas sharing cortical connectivity can be grouped into discrete clusters, within which cortical areas are linked by local connections with short average path length, whereas distant areas are targeted through long-distance corticocortical pathways. Within each cluster, cortical areas share several functional properties, thus shaping specific neural domains where cell activity is tuned in a preferential fashion to a given function, while representing at the same time other related information, although with different 


\section{FRONTAL}

\section{PARIETAL}

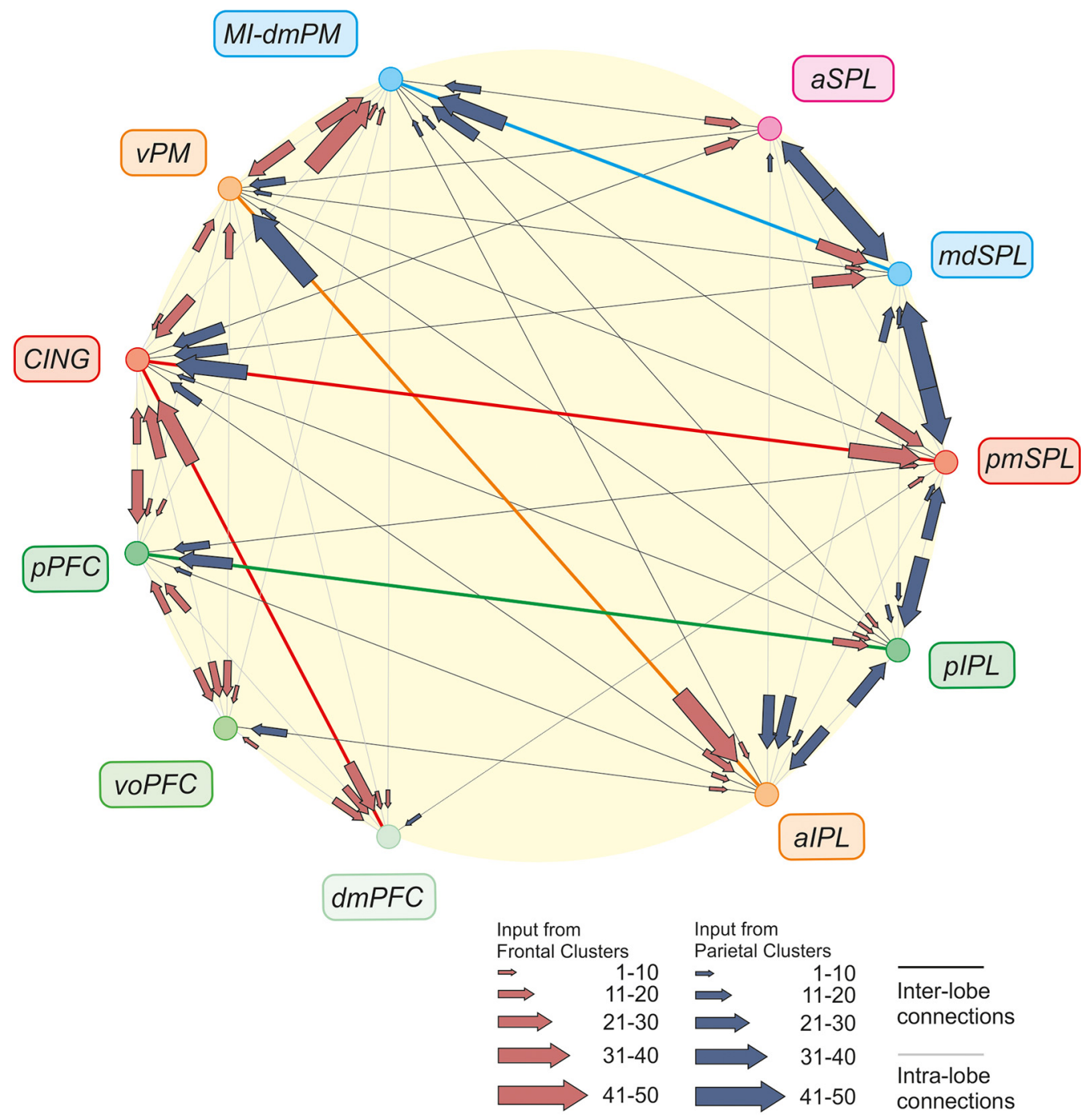

Figure 6. Parieto-frontal information systems. Organization of main cortical connections among parietal and frontal clusters. For each cluster, the arrow size indicates the strength (mean value across input areas; see Materials and Methods) of inputs (scale: 0-100). Note that the strongest detected mean input was equal to 50. Main systems are highlighted by colored thicker lines.

weight. Thus, the term domain refers to a cluster of areas, as identified by the statistics of their connectivity and their functional properties. Cortical connections between functionally equivalent domains sculpt information processing systems that operate on the basis of different inputs and distribute several outputs. Thus, the grand design of the network is redundant for the several entry or command nodes and outflow pathways, which can be selected on the basis of the congruence between properties of the node and task demands, as first hypothesized by Mountcastle (1978).

\section{Parieto-frontal domains and parieto-frontal systems}

The analysis of parieto-frontal connectivity (Figs. 6 and 9) reveals that the parieto-frontal system originates from the combinatorial (visual, eye, hand) visuomotor domains of postero-medial parietal areas (pmSPL; areas PGm, V6A, 31) and lateral (pIPL, area Opt) parieto-occipital cortex, which distribute visuomotor information to both SPL (mdSPL) and IPL (aIPL) domains.

Dorsal parieto-occipital areas encode the early visual, eye, and hand signals necessary for eye-hand coordination during reaching and other eye visuomotor functions related to navigation in extrapersonal space. As such, they can serves as an intermediate step in the coordinate transformation from retinal to allocentric coordinates, which is refined in the hippocampus. This information flow is also addressed to area F7 in the Ml-dmPM domain and can be regarded as forming an early eye-hand coordination and navigation system. In fact, reversible inactivation of $P G m$ impairs navigation in virtual environments (Sato et al., 2006). Lateral parieto-occipital areas, such as Opt, also distribute visual, eye- and hand-related information, which is however addressed to selected areas (LIP) within the same pIPL domain, as well as to areas (PG) that belong to a more rostral IPL domain (alPL). This is the 
A

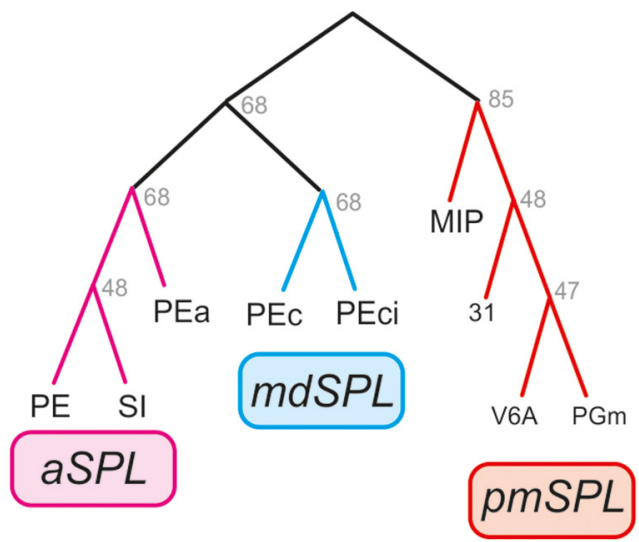

B

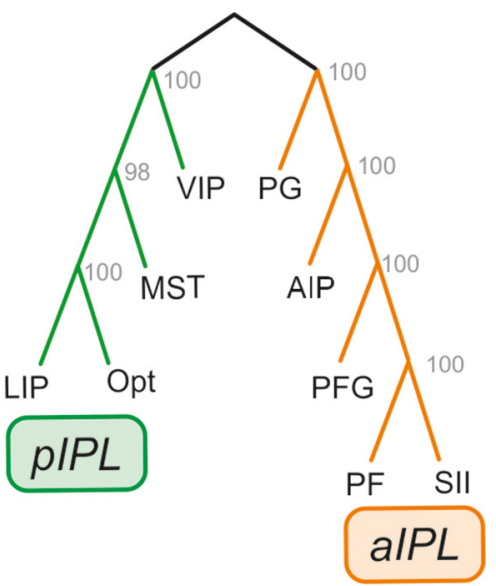

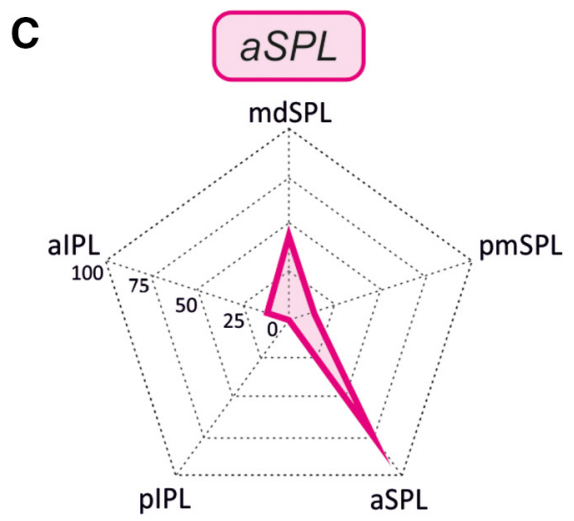

Entropy 1.20

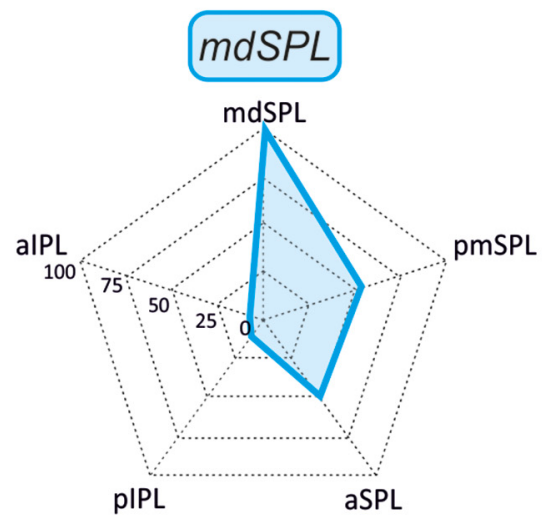

Entropy 1.42

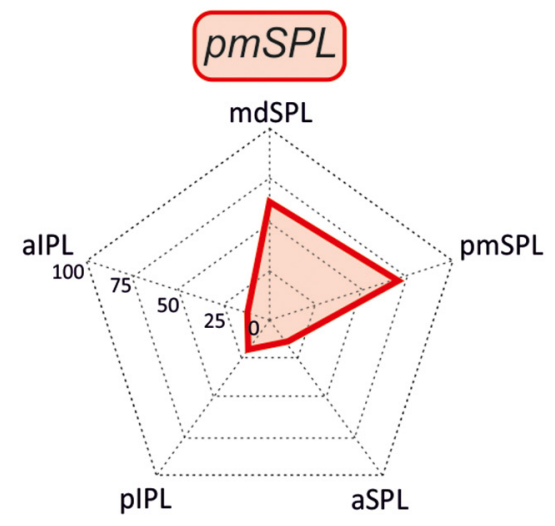

Entropy 1.37

\section{alPL}

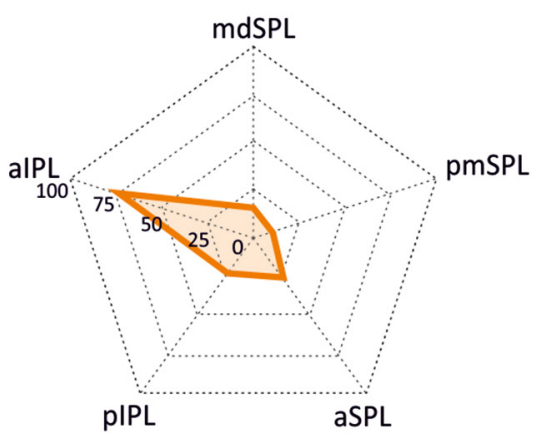

Entropy 1.18

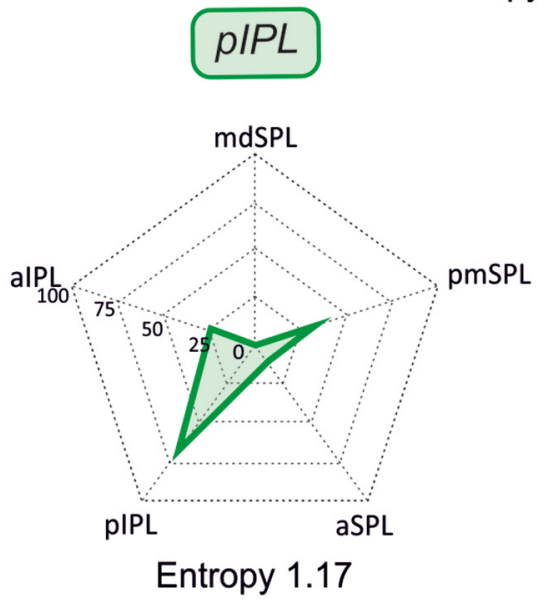

Figure 7. Trees fit of the data and intrinsic parietal inputs. Consensus trees of superior $(\boldsymbol{A})$ and inferior $(\boldsymbol{B})$ parietal clusters defined on the basis of the SPL-IPL connections. C, Spider plots displaying the mean values (scale: $0-100$ ) of parietal inputs to any given SPL and IPL cluster. The cluster entropy is also reported. Conventions and symbols as in Figs. 2 and 4.

origin of a system encoding reaching and complex manual action, as will be detailed below.

An important stream emerges from the projections of the parieto-occipital (V6A) and medial (PGm) parietal areas to the arm-dominant visuomotor domain of SPL (mdSPL; PEc, MIP, PEa), which in turns projects to the frontal arm motor output domain (MI-dmPM). This system encodes arm kinetics, kinematics, and the coordinate transformation underlying planning, execution, correction, and suppression of visual reaching (Fig. 9). This is the dorsal reaching system (Caminiti et al., 1996; Johnson et al., 1996; Battaglia-Mayer et al., 2000, 2001; Marconi et al., 


\section{PARIETAL}

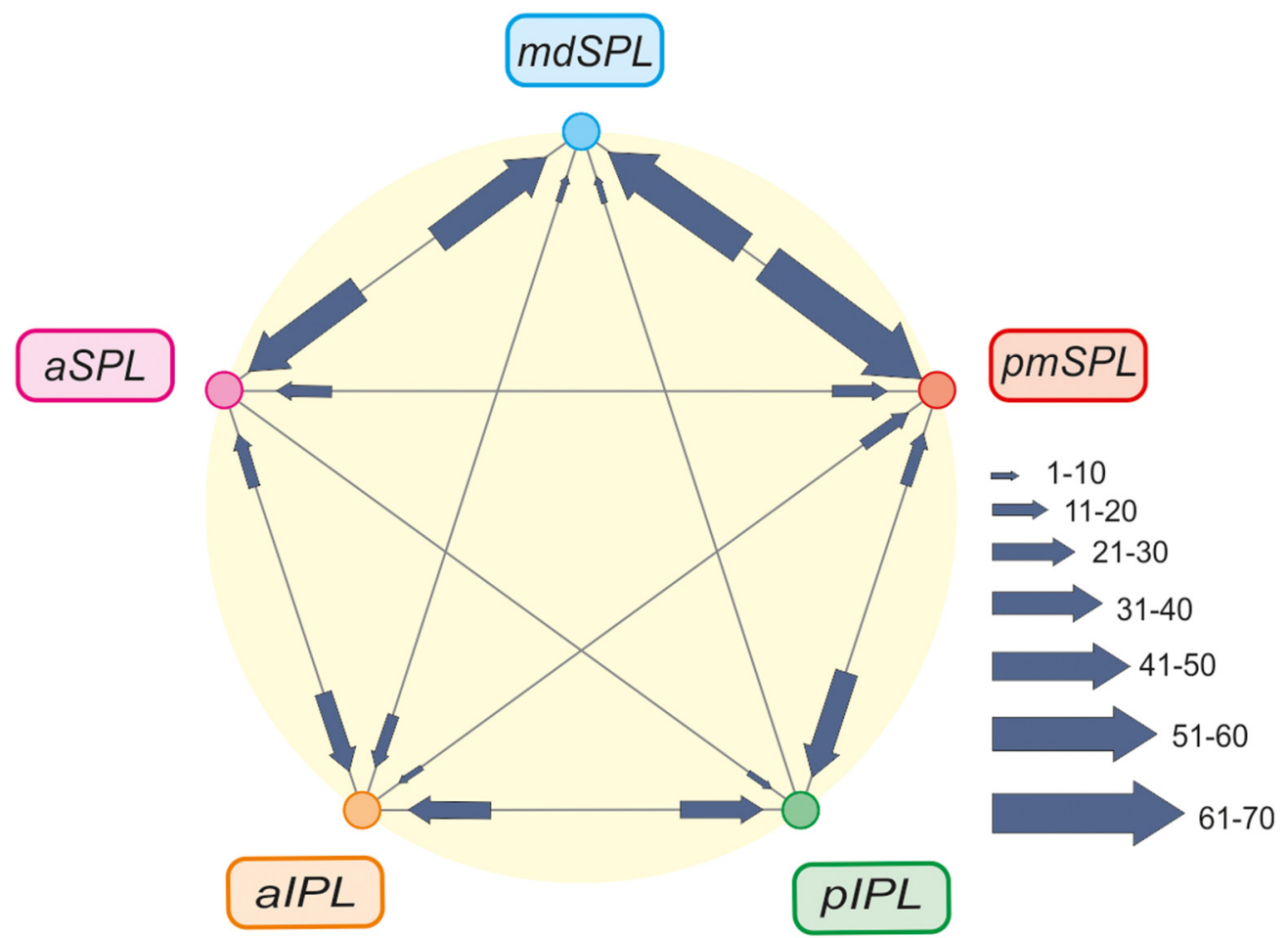

Figure 8. Overall view of SPL-IPL information flows. Organization of main cortical connections among SPL and IPL clusters. For each cluster, the arrow size indicates the strength (mean value across input areas; see Materials and Methods) of inputs (scale: $0-100)$. Note that the strongest detected mean input was equal to 70.

2001), which also participates in representation of the body scheme and its extension after tool use, thanks to its link with the anterior parietal somatosensory domain (aSPL). Reciprocal intraparietal connections link these two domains, as well as mdSPL with the dorsal parietooccipital areas (see also Fig. 8). This reentrant signaling within SPL can provide information about hand position and limb geometry essential for the visuomotor transformation underlying reach planning. The reciprocal connectivity between the aSPL domain (areas PE/SI) and dorsal premotor and motor cortex (Figs. 6 and 9) can subserve somatosensory control of arm and hand movement. This network's design and function are consistent with both the consequences of reversible inactivation of MdSPL in monkeys (Battaglia-Mayer et al., 2013), as well as with the observation that SPL and parieto-occipital lesions in humans result in optic ataxia.

Another crucial function concerns the representation of hand grasping and grip type (Fig. 9) and others' action and intention understanding. Grasping an object of interest requires visual information about the object's shape, physical properties, orientation, and expected weight, so as to specify the appropriate hand kinetics and kinematics. In this process, the necessary visual information can be supplied through internal IPL signaling between selected areas of the oculomotor intention and attention domain (pIPL, LIP) and those of the anterior IPL parietal domain (alPL, AIP), as well as from temporal areas (Borra et al., 2008) conveying information about object identity. The projection arising from AIP and PFG to F5a in the ventral premotor domain (VPM), and those from F5a to areas $46 \mathrm{vc}$-rostral and intermediate-12 $r$ in the lateral sector of the orbitofrontal domain (voPFC), shape the lateral grasping system (Fig. 9; Borra et al., 2014), which is therefore endowed with all the richness derived from the specification of action goal and strategy, and object affordance. Reversible inactivation of AIP results in a dramatic impairment of hand preshaping in monkeys trained to grasp objects of different features (Gallese et al., 1994).

This system shares areas PFG and part of F5 with the mirror system (not shown in Fig. 9), which provides an observation/execution matching mechanism for other's action and intention recognition (Rizzolatti et al., 2014).

The posterior visuomotor domain of IPL (pIPL) and the ventral premotor cortex (vPM) domain, thanks to the connections between VIP and F4, shape a parieto-frontal system (not shown in Fig. 9) dedicated to limb movements and probably to ethologically relevant actions. This system might implement a transformation of a multisensory peripersonal representation of space into a multimodal body-centered action space. Consistent with this interpretation are the consequences of lesions of the periarcuate areas of the ventral premotor domain (vPM), i.e., neglect of peripersonal space (Rizzolatti et al., 1983; Schieber, 2000). 


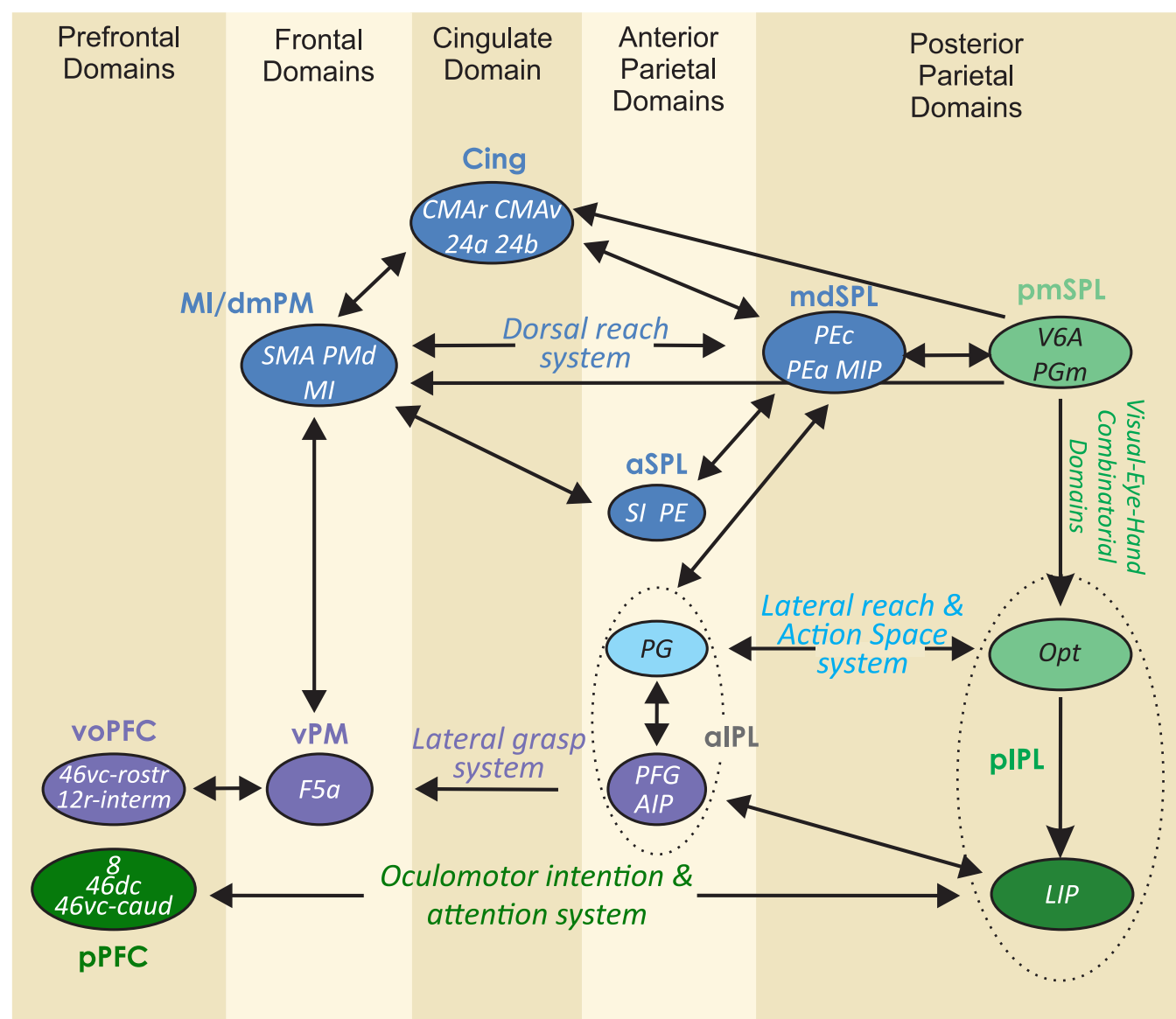

Figure 9. Parietal and frontal domains and parieto-frontal information systems. Parietal, frontal, and prefrontal domains underlying the dorsal reaching system, the lateral grasping system, the lateral reach and action space system, and the oculomotor intention and attention system. The domain acronyms (pmSPL, pIPL, etc.) correspond to those of the clusters. However, in each domain, only the areas (ovals) that participate in any given systems are indicated.

Beyond VIP, the posterior IPL domain (pIPL) includes areas Opt, LIP, and MST, which shape the IPL oculomotor intention and attention domain. This, together with the frontal eye field motor output domain of the posterior prefrontal cortex (cluster pPFC), forms a complex system devoted to oculomotor intention and control, selective visual attention, visuo-acoustic orienting and communication, and recognition of numerosity. The visual functions encoded by this system also include the analysis of 3D object properties, large-scale motion analysis for heading perception, and manual interception of moving targets. This system is also involved in the transformation of action choices into motor plans and participates in encoding decision value, thus providing a path from the reward and decision value domain of ventral orbitofrontal cortex (voPFC) to the motor output. Therefore, this system relates to oculomotor intention and decision-making, attention, visual analysis of objects structure and motion, numerosity, and heading perception. The function encoded in this system can explain, among others, why human IPL lesions result in hemispatial neglect (Vallar and Bolognini, 2014), and acalculia (Nieder and Dehaene, 2009; Nieder, 2016), depending on where they occur in the parieto-frontal gradient.
The CING cluster (Fig. 6) is the target of projections from all SPL domains and projects to them, mostly to the eye-hand coordination and navigation domain (pmSPL) and to the SPL hand-dominant domain. It also entertains reciprocal connections with the frontal motor output domain (MI-dmPM). The CING domain is a target of the dopaminergic and serotoninergic systems, as well as of the noradrenergic outflow of the locus coeruleus, all exerting a strong modulatory influence on neural activity, and probably also on information transfer through corticocortical connections. Therefore, this domain allows signals from the command mechanism of the parietal lobe to be combined with internal drive for action selection and monitoring, related to encoding visually driven, internally generated and remembered movements, as well as motor sequences. In this domain reward, decision value and choice outcome meet motivation and can be evaluated by the error monitoring system, thanks to the input (Fig. 9) from the reward and decision value domain of the ventroorbital prefrontal cortex (voPFC). Interestingly, the CING domain is reciprocally linked to the goal and strategy domain of dorsomedial prefrontal and polar frontal cortex (dmPFC; Fig. 9). This interplay can allow action goal, strategy, and tactics to be evaluated, and eventually ve- 
toed, by the monitoring system of the cingulate cortex. Lesions involving the mid-dorsolateral prefrontal cortex, including areas $46 \mathrm{~d}$ and 9 , impair performance on working memory tasks that require monitoring the selection of stimuli from a set or the occurrence of stimuli from an expected set (Petrides, 1991, 2000). The cingulate domain can be considered a hub for internal drive, cognition, motor intention, and performance monitoring. Therefore, the complex interplay of parietal, frontal, prefrontal, and cingulate domains can tentatively be regarded as forming a cognitive-motor intention and executive function monitoring system.

The ventral orbitofrontal domain (voPFC) includes orbitofrontal areas involved in encoding reward and subjective decision value and VLPF areas involved in controlling skeletomotor behavior. Orbitofrontal areas encode rewards in an explicit fashion independently from sensory signals, in the form of values related to objects, actions, and differences aimed at economic decision-making (Schultz, 2015, 2016). Beyond the above relations with the cingulate domain, the outflow of the orbitofrontal operations can be addressed to the motor output through the connections of VLPF areas of this domain with VPM and IPL areas or indirectly through the PPFC domain.

\section{SPL-IPL connections and functional interplay with the parieto-frontal network: the lateral reach and action space system}

The design of the medium-range connections between SPL and IPL areas (Figs. 8 and 9) details the participation of the dorsal parieto-occipital areas (pmSPL; V6A, PGm) and the visuomotor areas (PEc, MIP and PEa) of the SPL hand-dominant visuomotor domain (mdSPL) to the dorsal reaching system, as illustrated above.

However, closer scrutiny of this intraparietal network and its relationships with the parieto-frontal system reveals the existence of another relevant action system (Fig. 9), which however stems from area Opt. This parietooccipital area is characterized by a graded coexistence of visual, eye, and hand related-signals in neural activity (Battaglia-Mayer et al., 2005, 2007). Opt projects to area PG (Rozzi et al., 2006), which in turns projects to MIP and PEc in the SPL arm-dominant visuomotor domain (md$\mathrm{SPL}$ ), through which all SPL operations seem to reach the frontal motor output domain (Johnson et al., 1996; Battaglia-Mayer et al., 2001; Marconi et al., 2001). Therefore, the outflow of this IPL system uses the SPL segment of the dorsal reaching system to address its messages to the dorsal premotor and motor cortex. This shapes the lateral reach and action space system, in which area PG plays a pivotal role as a parietal broadcasting center allowing cross-talk between the SPL dorsal reaching and this IPL lateral action systems. The latter, beyond visual reaching to both stationary and moving targets, processes visuospatial information underlying complex actions, such as assembling parts to construct an object or analyzing maze architecture and finding its exit. At variance from fast reaching, these tasks unfold over long periods of time and require continuous access to sensory information and constant evaluation of intermediate ac- tion outcomes. Within this system, the representation of action space is uniform during memory or delay periods intervening between the visual analysis of the workspace and the onset of eye and hand action, whereas it becomes anisotropic and highly skewed toward contralateral space at the onset of actions relying on different forms of eye-hand coordination movement (BattagliaMayer et al., 2005), solution of visual mazes (Crowe et al., 2004, 2005), and construction tasks (Chafee et al., 2005, 2007; Crowe et al., 2008). This is in keeping with the difficulties of action initiation typical of directional hypokinesia in patients suffering neglect after inferior parietal lesion and with the consequence of IPL lesion in humans suffering from constructional apraxia (Kleist, 1934).

\section{The eye-hand coordination network}

All information processing systems described above imply eye-hand coordination, which seems to percolate from the design of the intraparietal and parieto-frontal networks, in which these systems are embedded. This edifice can be idealized as formed by five antero-posterior pillar domains, oriented medio-laterally in posterior parietal, anterior parietal, cingulate, frontal, and prefrontal cortex (Fig. 9). Early combination of retinal, eye and hand signals can occur in the dorsal (areas PGm and V6A) and lateral (area Opt) parieto-occipital nodes of the posterior parietal domains. V6A and PGm are the main source of visual input to the areas of the SPL arm-dominant visuomotor domain (mdSPL; MIP, PEc, PEa), which projects to dorsal premotor and motor cortex (Ml-dmPM domain). Area Opt projects to LIP, in the IPL oculomotor intention and attention domain (pIPL). In this context, it is important to stress that there are not direct connections between SPL areas MIP, PEc, PEa, and LIP (see Figs. 8 and 9). However, a parallel signal concerning the accumulation of decision variables is addressed to both MIP and LIP before a hand (MIP) or either an eye or a hand movement (LIP) is made (de Lafuente et al., 2015). When the decision outcome is an eye movement, neural activity in MIP is attenuated. Thus, an early temporal locking of hand and eye movement onset time can be achieved through lateral communication between dorsal and lateral parieto-occipital areas, and LIP (pIPL domain). The presaccadic outflow from LIP is addressed to the FEF and the caudal part of area 46 in the prefrontal eye motor output domain, thus shaping a parieto-frontal oculomotor intention and attention system that also provides the allocation of visual attention to salient eye and hand movement targets.

The subcortical parietal and frontal outflows to motor structures converge on the mesencephalic reticular formation (MRF) and the intermediate and deep layers of the superior colliculus (SC), which receive not only eye but also a substantial proportion of arm signals, which probably confer reach-related activity to the SC (Werner, 1993; Werner et al., 1997a, b; Reyes-Puerta et al., 2011). The final temporal locking between the eye and the hand might occur at this subcortical stage. The output of premotor and motor cortex is addressed to spinal interneurons and motor neurons controlling arm and hand 
movement, where it might also be integrated with that coming from the MRF, while the SC projects to the oculomotor centers of the brainstem.

The information transfer from caudal to rostral domains allows coordinate transformation and leads to the eye and hand motor output. Reentrant signaling between areas belonging to different rostro-caudal parietal and frontal domains can subserve diverse functions, such as coordinate transformation, formation of efferent copies or corollary discharges of eye and hand motor commands, sensory control of movement and evaluation of the sensory consequences of actions, central representation of body image, and control of intermediate steps of complex tasks (such as tool use, object construction, and maze analysis and solution), among many others. This information transfer is characterized by temporally dispersed conduction delays, resulting from the wide spectrum of axon diameters typical of interareal communication (Caminiti et al., 2009, 2013; Innocenti et al., 2014). This seems to expand the number of oscillatory regimes of the cerebral cortex, and therefore might result in an increase of the computational power of parieto-frontal networks.

\section{Conclusions}

In both parietal and frontal cortex, different areas can be grouped into discrete clusters or domains, based on their cortical connectivity and functional properties. Areas belonging to any given domain display partially common functional properties, thus allowing a flexible combination of retinal, eye, and hand signals necessary for different functions, therefore suitable for satisfying different task demands. These domains combine signals from different modalities and effectors, although with different degrees of dominance, which are determined by the domain location in the parieto-frontal functional gradient. In the more posterior parietal domains, retinal and eye signals dominate over hand information, whereas in the rostralmost parietal domains, the opposite is true. A similar gradient is oriented from rostral to caudal in frontal cortex. Thus, with exclusion of FEF and motor cortex, there are not effectorspecific domains in parietal and frontal cortex, but rather hand-dominant and eye-dominant domains. Therefore, models of eye-hand coordination based on the interplay between hand- and eye-specific modules are not consistent with available knowledge on cortical organization. Although at the output level the eye and hand motor control centers are largely segregated in the brain, eyehand coordination seems to occur first in the posterior parietal cortex, thanks to internal reentrant signaling between different hand- and eye-dominant domains located in the SPL and IPL, where the initial temporal locking between eye and hand coordinate transformation and movement seems to occur.

The parietal outflow pathways toward the premotor and motor output domains of the frontal lobe shapes different information processing systems, such as the dorsal reaching system, the lateral reach and action space system, the lateral grasping system, the mirror system, and the oculomotor intention and attention system. These different systems mostly rely on independent, parallel pathways, although at times they rely on common outflows, as to minimize connection costs and maximizing information transfer efficiency.

The cingulate domain links motor intention with motivation. Moreover, its interplay with the prefrontal cortex domains, where the selection of goals and strategies and the associated reward and economic decision value occur, might allow evaluation and monitoring of cognitive motor operations, for error detection and correction aimed at optimizing action outcome.

In conclusion, the logic of this edifice seems redundant, in the sense that there are many access nodes and parallel outflow paths that can be set in motion by different task demands. Thanks to this, different systems can use common domains, which complicates the interpretation of results of cortical lesions restricted to a single area. Studies of axon diameters and lengths also indicate that parietal and frontal areas communicate through temporally dispersed conduction delays that can produce an expansion of the oscillatory regimes of the cortex. This is consistent with the consequences of lesions that when involving a single area are milder and less disruptive than when affecting a distributed system, thus providing a basis for interpreting neuropsychological syndromes as the result of the collapse of interareal communication and temporal dynamics.

\section{References}

Amemori K, Graybiel AM (2012) Localized microstimulation of primate pregenual cingulate cortex induces negative decisionmaking. Nat Neurosci 15:776-785. CrossRef Medline

Amodio DM, Frith CD (2006) Meeting of minds: the medial frontal cortex and social cognition. Nat Rev Neurosci 7:268-277. CrossRef Medline

Andersen RA, Cui H (2009) Intention, action planning, and decision making in parietal-frontal circuits. Neuron 63:568-583. CrossRef Medline

Archambault PS, Caminiti R, Battaglia-Mayer A (2009) Cortical mechanisms for online control of hand movement trajectory: the role of the posterior parietal cortex. Cereb Cortex 19:2848-2864. CrossRef

Archambault PS, Ferrari-Toniolo S, Battaglia-Mayer A (2011) Online control of hand trajectory and evolution of motor intention in the parietofrontal system. J Neurosci 31:742-752. CrossRef Medline

Arikuni T, Sako H, Murata A (1994) Ipsilateral connections of the anterior cingulate cortex with the frontal and medial temporal cortices in the macaque monkey. Neurosci Res 21:19-39. CrossRef

Asaad WF, Rainer G, Miller EK (1998) Neural activity in the primate prefrontal cortex during associative learning. Neuron 21:13991407. Medline

Ashe J, Georgopoulos AP (1994) Movement parameters and neural activity in motor cortex and area 5. Cereb Cortex 4:590-600. Medline

Averbeck BB, Seo M (2008) The statistical neuroanatomy of frontal networks in the macaque. PLoS Comput Biol 4:e1000050. CrossRef Medline

Averbeck BB, Battaglia-Mayer A, Guglielmo C, Caminiti R (2009) Statistical analysis of parieto-frontal cognitive-motor networks. J Neurophysiol 102:1911-1920. CrossRef Medline

Averbeck BB, Chafee MV, Crowe DA, Georgopoulos AP (2005) Parietal representation of hand velocity in a copy task. J Neurophysiol 93:508-518. CrossRef Medline 
Averbeck BB, Sohn JW, Lee D (2006) Activity in prefrontal cortex during dynamic selection of action sequences. Nat Neurosci 9:276-282. CrossRef Medline

Azuma M, Suzuki H (1984) Properties and distribution of auditory neurons in the dorsolateral prefrontal cortex of the alert monkey. Brain Res 298:343-346. Medline

Bakola S, Gamberini M, Passarelli L, Fattori P, Galletti C (2010) Cortical connections of parietal field PEc in the macaque: linking vision and somatic sensation for the control of limb action. Cereb Cortex 20:2592-2604. CrossRef Medline

Bakola S, Passarelli L, Gamberini M, Fattori P, Galletti C (2013) Cortical connectivity suggests a role in limb coordination for macaque area pe of the superior parietal cortex. J Neurosci 33:66486658. CrossRef Medline

Barash S, Bracewell RM, Fogassi L, Gnadt JW, Andersen RA (1991) Saccade-related activity in the lateral intraparietal area. I. Temporal properties; comparison with area 7a. J Neurophysiol 66:10951108. Medline

Barbas H (1988) Anatomic organization of basoventral and mediodorsal visual recipient prefrontal regions in the rhesus monkey. $J$ Comp Neur 276:313-342. CrossRef Medline

Barbas H (1993) Organization of cortical afferent input to orbitofrontal areas in the rhesus monkey. Neuroscience 56:841-864. Medline

Barbas H (2007) Specialized elements of orbitofrontal cortex in primates. Ann N Y Acad Sci 1121:10-32. CrossRef Medline

Barbas H, Mesulam MM (1985) Cortical afferent input to the principalis region of the rhesus monkey. Neuroscience 15:619-637. Medline

Barbas H, Pandya DN (1987) Architecture and frontal cortical connections of the premotor cortex (area 6 ) in the rhesus monkey. $J$ Comp Neur 256:211-228. CrossRef Medline

Barbas H, Pandya DN (1989) Architecture and intrinsic connections of the prefrontal cortex in the rhesus monkey. J Comp Neur 286:353-375. CrossRef Medline

Barbas H, Ghashghaei H, Dombrowski SM, Rempel-Clower NL (1999) Medial prefrontal cortices are unified by common connections with superior temporal cortices and distinguished by input from memory-related areas in the rhesus monkey. J Comp Neur 410:343-367. Medline

Battaglia-Mayer A, Buiatti T, Caminiti R, Ferraina S, Lacquaniti F, Shallice T (2014) Correction and suppression of reaching movements in the cerebral cortex: physiological and neuropsychological aspects. Neurosci Biobehav Rev 42:232-251. CrossRef Medline

Battaglia-Mayer A, Caminiti R, Lacquaniti F, Zago M (2003) Multiple levels of representation of reaching in the parieto-frontal network. Cereb Cortex 13:1009-1022. Medline

Battaglia-Mayer A, Ferraina S, Genovesio A, Marconi B, Squatrito S, Molinari M, Lacquaniti F, Caminiti R (2001) Eye-hand coordination during reaching. II. An analysis of the relationships between visuomanual signals in parietal cortex and parieto-frontal association projections. Cereb Cortex 11:528-544. Medline

Battaglia-Mayer A, Ferraina S, Mitsuda T, Marconi B, Genovesio A, Onorati P, Lacquaniti F, Caminiti R (2000) Early coding of reaching in the parietooccipital cortex. J Neurophysiol 83:2374-2391. Medline

Battaglia-Mayer A, Ferrari-Toniolo S, Visco-Comandini F, Archambault PS, Saberi-Moghadam S, Caminiti R (2013) Impairment of online control of hand and eye movements in a monkey model of optic ataxia. Cereb Cortex. 23:2644-2656.

Battaglia-Mayer A, Mascaro M, Brunamonti E, Caminiti R (2005) The over-representation of contralateral space in parietal cortex: a positive image of directional motor components of neglect? Cereb Cortex 15:514-525. CrossRef Medline

Battaglia-Mayer A, Mascaro M, Caminiti R (2007) Temporal evolution and strength of neural activity in parietal cortex during eye and hand movements. Cereb Cortex 17:1350-1363. CrossRef Medline

Belmalih A, Borra E, Contini M, Gerbella M, Rozzi S, Luppino G (2009) Multimodal architectonic subdivision of the rostral part (area
F5) of the macaque ventral premotor cortex. J Comp Neur 512: 183-217. CrossRef Medline

Bhattacharyya R, Musallam S, Andersen RA (2009) Parietal reach region encodes reach depth using retinal disparity and vergence angle signals. J Neurophysiol 102:805-816. CrossRef Medline

Bichot NP, Heard MT, DeGennaro EM, Desimone R (2015) A source for feature-based attention in the prefrontal cortex. Neuron 88: 832-844. CrossRef Medline

Bisley JW, Goldberg ME (2010) Attention, intention, and priority in the parietal lobe. Annu Rev Neurosci 33:1-21. CrossRef Medline

Blatt GJ, Andersen RA, Stoner GR (1990) Visual receptive field organization and cortico-cortical connections of the lateral intraparietal area (area LIP) in the macaque. J Comp Neur 299:421445. CrossRef Medline

Boch RA, Goldberg ME (1989) Participation of prefrontal neurons in the preparation of visually guided eye movements in the rhesus monkey. J Neurophysiol 61:1064-1084. Medline

Bon L, Lucchetti C (1994) Ear and eye representation in the frontal cortex, area 8b, of the macaque monkey: an electrophysiological study. Exp Brain Res 102:259-271. Medline

Bonini L, Rozzi S, Serventi FU, Simone L, Ferrari PF, Fogassi L (2010) Ventral premotor and inferior parietal cortices make distinct contribution to action organization and intention understanding. Cereb Cortex 20:1372-1385.

Bonini L, Serventi FU, Simone L, Rozzi S, Ferrari PF, Fogassi L (2011) Grasping neurons of monkey parietal and premotor cortices encode action goals at distinct levels of abstraction during complex action sequences. J Neurosci 31:5876-5886. CrossRef Medline

Bonini L, Ugolotti Serventi F, Bruni S, Maranesi M, Bimbi M, Simone L, Rozzi S, Ferrari PF, Fogassi L (2012) Selectivity for grip type and action goal in macaque inferior parietal and ventral premotor grasping neurons. J Neurophysiol 108:1607-1619. CrossRef Medline

Borra E, Belmalih A, Calzavara R, Gerbella M, Murata A, Rozzi S, Luppino $G$ (2008) Cortical connections of the macaque anterior intraparietal (AIP) area. Cereb Cortex 18:1094-1111. CrossRef Medline

Borra E, Gerbella M, Rozzi S, Luppino G (2011) Anatomical evidence for the involvement of the macaque ventrolateral prefrontal area $12 r$ in controlling goal-directed actions. J Neurosci 31:1235112363. CrossRef Medline

Borra E, Gerbella M, Rozzi S, Tonelli S, Luppino G (2014) Projections to the superior colliculus from inferior parietal, ventral premotor, and ventrolateral prefrontal areas involved in controlling goaldirected hand actions in the macaque. Cereb Cortex 24:10541065. CrossRef Medline

Bosco A, Breveglieri R, Chinellato E, Galletti C, Fattori P (2010) Reaching activity in the medial posterior parietal cortex of monkeys is modulated by visual feedback. J Neurosci 30:1477314785. CrossRef Medline

Bouret S, Richmond BJ (2010) Ventromedial and orbital prefrontal neurons differentially encode internally and externally driven motivational values in monkeys. J Neurosci 30:8591-8601. CrossRef Medline

Boussaoud D, Ungerleider LG, Desimone R (1990) Pathways for motion analysis: cortical connections of the medial superior temporal and fundus of the superior temporal visual areas in the macaque. J Comp Neur 296:462-495. CrossRef Medline

Bremmer F (2005) Navigation in space-the role of the macaque ventral intraparietal area. J Physiol 566:29-35. CrossRef Medline

Bremmer F, Duhamel JR, Ben Hamed S, Graf W (2002a) Heading encoding in the macaque ventral intraparietal area (VIP). Eur $\mathrm{J}$ Neurosci 16:1554-1568. Medline

Bremmer F, Klam F, Duhamel JR, Ben Hamed S, Graf W (2002b) Visual-vestibular interactive responses in the macaque ventral intraparietal area (VIP). Eur J Neurosci 16:1569-1586. Medline

Breveglieri R, Galletti C, Monaco S, Fattori P (2008) Visual, somatosensory, and bimodal activities in the macaque parietal area PEc. Cereb Cortex 18:806-816. CrossRef Medline 
Britten KH (2008) Mechanisms of self-motion perception. Annu Rev Neurosci 31:389-410. CrossRef Medline

Brodmann K (1909) Vergleichende Lokalisationslehre der Groshirnrinde. Leipzig, Barth.

Bruce CJ, Goldberg ME, Bushnell MC, Stanton GB (1985) Primate frontal eye fields. II. Physiological and anatomical correlates of electrically evoked eye movements. J Neurophysiol 54:714-734. Medline

Bruni S, Giorgetti V, Bonini L, Fogassi L (2015) Processing and integration of contextual information in monkey ventrolateral prefrontal neurons during selection and execution of goal-directed manipulative actions. J Neurosci 35:11877-11890. CrossRef Medline

Bullmore E, Sporns O (2009) Complex brain networks: graph theoretical analysis of structural and functional systems. Nat Rev Neurosci 10:186-198. CrossRef Medline

Burnod Y, Grandguillaume P, Otto I, Ferraina S, Johnson PB, Caminiti R (1992) Visuomotor transformations underlying arm movements toward visual targets: a neural network model of cerebral cortical operations. J Neurosci 12:1435-1453. Medline

Burton H, Fabri M (1995) Ipsilateral intracortical connections of physiologically defined cutaneous representations in area $3 \mathrm{~b}$ and 1 of macaque monkeys: projections in the vicinity of the central sulcus. J Comp Neur 355:508-538. CrossRef Medline

Bushnell MC, Goldberg ME, Robinson DL (1981) Behavioral enhancement of visual responses in monkey cerebral cortex. I. Modulation in posterior parietal cortex related to selective visual attention. J Neurophysiol 46:755-772. Medline

Cadoret G, Smith AM (1997) Comparison of the neuronal activity in the SMA and the ventral cingulate cortex during prehension in the monkey. J Neurophysiol 77:153-166. Medline

Cai X, Padoa-Schioppa C (2012) Neuronal encoding of subjective value in dorsal and ventral anterior cingulate cortex. J Neurosci 32:3791-3808. CrossRef Medline

Cai X, Padoa-Schioppa C (2014) Contributions of orbitofrontal and lateral prefrontal cortices to economic choice and the good-toaction transformation. Neuron 81:1140-1151. CrossRef Medline

Caminiti R, Carducci F, Piervincenzi C, Battaglia-Mayer A, Confalone G, Visco-Comandini F, Pantano P, Innocenti GM (2013) Diameter, length, speed, and conduction delay of callosal axons in macaque monkeys and humans: comparing data from histology and magnetic resonance imaging diffusion tractography. J Neurosci 33: 14501-14511. CrossRef Medline

Caminiti R, Chafee MV, Battaglia-Mayer A, Averbeck BB, Crowe DA, Georgopoulos AP (2010) Understanding the parietal lobe syndrome from a neurophysiological and evolutionary perspective. Eur J Neurosci 31:2320-2340. CrossRef Medline

Caminiti R, Ferraina S, Johnson PB (1996) The sources of visual information to the primate frontal lobe: a novel role for the superior parietal lobule. Cereb Cortex 6:319-328. Medline

Caminiti R, Genovesio A, Marconi B, Mayer AB, Onorati P, Ferraina S, Mitsuda T, Giannetti S, Squatrito S, Maioli MG, Molinari M (1999) Early coding of reaching: frontal and parietal association connections of parieto-occipital cortex. Eur J Neurosci 11:33393345. Medline

Caminiti R, Ghaziri H, Galuske R, Hof PR, Innocenti GM (2009) Evolution amplified processing with temporally dispersed slow neuronal connectivity in primates. Proc Natl Acad Sci U S A 106:19551-19556. CrossRef Medline

Caminiti R, Innocenti GM, Battaglia-Mayer A (2015) Organization and evolution of parieto-frontal processing streams in macaque monkeys and humans. Neurosci Biobehav Rev 56:73-96. CrossRef Medline

Caminiti R, Johnson PB, Galli C, Ferraina S, Burnod Y (1991) Making arm movements within different parts of space: the premotor and motor cortical representation of a coordinate system for reaching to visual targets. J Neurosci 11:1182-1197. Medline

Caminiti R, Johnson PB, Urbano A (1990) Making arm movements within different parts of space: dynamic aspects in the primate motor cortex. J Neurosci 10:2039-2058. Medline
Caminiti R, Zeger S, Johnson PB, Urbano A, Georgopoulos AP (1985) Corticocortical efferent systems in the monkey: a quantitative spatial analysis of the tangential distribution of cells of origin. J Comp Neur 241:405-419. CrossRef Medline

Carmichael ST, Price JL (1994) Architectonic subdivision of the orbital and medial prefrontal cortex in the macaque monkey. $J$ Comp Neur 346:366-402. CrossRef Medline

Carmichael ST, Price JL (1995a) Sensory and premotor connections of the orbital and medial prefrontal cortex of macaque monkeys. $J$ Comp Neur 363:642-664.

Carmichael ST, Price JL (1995b) Limbic connections of the orbital and medial prefrontal cortex in macaque monkeys. J Comp Neur 363:615-641.

Carmichael ST, Price JL (1996) Connectional networks within the orbital and medial prefrontal cortex of macaque monkeys. J Comp Neur 371:179-207. CrossRef Medline

Carpenter AF, Georgopoulos AP, Pellizzer G (1999) Motor cortical encoding of serial order in a context-recall task. Science 283: 1752-1757. Medline

Carrera E, Tononi G (2014) Diaschisis: past, present, future. Brain 137:2408-2422. CrossRef Medline

Catani M, Ffytche DH (2005) The rises and falls of disconnection syndromes. Brain 128:2224-2239. CrossRef Medline

Catani M, Mesulam M (2008) What is a disconnection syndrome? Cortex 44:911-913. CrossRef Medline

Cavada C, Goldman-Rakic PS (1989a) Posterior parietal cortex in rhesus monkey: I. Parcellation of areas based on distinctive limbic and sensory corticocortical connections. J Comp Neur 287:393421.

Cavada C, Goldman-Rakic PS (1989b) Posterior parietal cortex in rhesus monkey: II. Evidence for segregated corticocortical networks linking sensory and limbic areas with the frontal lobe. $J$ Comp Neur 287:422-445.

Cerkevich CM, Qi HX, Kaas JH (2014) Corticocortical projections to representations of the teeth, tongue, and face in somatosensory area 3b of macaques. J Comp Neur 522:546-572. CrossRef Medline

Chafee MV, Averbeck BB, Crowe DA (2007) Representing spatial relationships in posterior parietal cortex: single neurons code object-referenced position. Cereb Cortex 17:2914-2932. CrossRef Medline

Chafee MV, Crowe DA, Averbeck BB, Georgopoulos AP (2005) Neural correlates of spatial judgement during object construction in parietal cortex. Cereb Cortex 15:1393-1413. CrossRef Medline Chen A, DeAngelis GC, Angelaki DE (2011) A comparison of vestibular spatiotemporal tuning in macaque parietoinsular vestibular cortex, ventral intraparietal area, and medial superior temporal area. J Neurosci 31:3082-3094. CrossRef Medline

Chen A, Deangelis GC, Angelaki DE (2013) Functional specializations of the ventral intraparietal area for multisensory heading discrimination. J Neurosci 33:3567-3581. CrossRef Medline

Chen LL, Wise SP (1995a) Supplementary eye field contrasted with the frontal eye field during acquisition of conditional oculomotor associations. J Neurophysiol 73:1122-1134.

Chen LL, Wise SP (1995b) Neuronal activity in the supplementary eye field during acquisition of conditional oculomotor associations. $J$ Neurophysiol 73:1101-1121.

Cheney PD, Fetz EE (1980) Functional classes of primate corticomotoneuronal cells and their relation to active force. J Neurophysiol 44:773-791. Medline

Churchland AK, Kiani R, Shadlen MN (2008) Decision-making with multiple alternatives. Nat Neurosci 11:693-702. CrossRef Medline

Churchland MM, Cunningham JP, Kaufman MT, Foster JD, Nuyujukian P, Ryu SI, Shenoy KV (2012) Neural population dynamics during reaching. Nature 487:51-56. CrossRef Medline

Cipolloni PB, Pandya DN (1999) Cortical connections of the frontoparietal opercular areas in the rhesus monkey. J Comp Neur 403:431-458. Medline 
Cisek P, Kalaska JF (2002) Simultaneous encoding of multiple potential reach directions in dorsal premotor cortex. J Neurophysiol 87:1149-1154. Medline

Cisek P, Kalaska JF (2005) Neural correlates of reaching decisions in dorsal premotor cortex: specification of multiple direction choices and final selection of action. Neuron 45:801-814. CrossRef Medline

Cisek P, Kalaska JF (2010) Neural mechanisms for interacting with a world full of action choices. Annu Rev Neurosci 33:269-298. CrossRef Medline

Colby CL, Duhamel JR (1991) Heterogeneity of extrastriate visual areas and multiple parietal areas in the macaque monkey. Neuropsychologia 29:517-537. Medline

Colby CL, Goldberg ME (1999) Space and attention in parietal cortex. Annu Rev Neurosci 22:319-349. CrossRef Medline

Colby CL, Duhamel JR, Goldberg ME (1993) Ventral intraparietal area of the macaque: anatomic location and visual response properties. J Neurophysiol 69:902-914. Medline

Corbetta M, Shulman GL (2011) Spatial neglect and attention networks. Annu Rev Neurosci 34:569-599. CrossRef Medline

Crowe DA, Averbeck BB, Chafee MV (2008) Neural ensemble decoding reveals a correlate of viewer- to object-centered spatial transformation in monkey parietal cortex. J Neurosci 28:52185228. CrossRef Medline

Crowe DA, Averbeck BB, Chafee MV, Georgopoulos AP (2005) Dynamics of parietal neural activity during spatial cognitive processing. Neuron 47:885-891. CrossRef Medline

Crowe DA, Chafee MV, Averbeck BB, Georgopoulos AP (2004) Neural activity in primate parietal area 7 a related to spatial analysis of visual mazes. Cereb Cortex 14:23-34. Medline

Darian-Smith C, Darian-Smith I, Burman K, Ratcliffe N (1993) Ipsilateral cortical projections to areas $3 a, 3 b$, and 4 in the macaque monkey. J Comp Neur 335:200-213. CrossRef Medline

Daw ND, O'Doherty JP, Dayan P, Seymour B, Dolan RJ (2006) Cortical substrates for exploratory decisions in humans. Nature 441:876-879. CrossRef Medline

de Lafuente V, Jazayeri M, Shadlen MN (2015) Representation of accumulating evidence for a decision in two parietal areas. $J$ Neurosci 35:4306-4318. CrossRef Medline

Dean HL, Platt ML (2006) Allocentric spatial referencing of neuronal activity in macaque posterior cingulate cortex. J Neurosci 26: 1117-1127. CrossRef Medline

Dean HL, Crowley JC, Platt ML (2004) Visual and saccade-related activity in macaque posterior cingulate cortex. J Neurophysiol 92:3056-3068. CrossRef Medline

Dean HL, Hagan MA, Pesaran B (2012) Only coherent spiking in posterior parietal cortex coordinates looking and reaching. Neuron 73:829-841. CrossRef Medline

Denys K, Vanduffel W, Fize D, Nelissen K, Peuskens H, Van Essen D, Orban GA (2004) The processing of visual shape in the cerebral cortex of human and nonhuman primates: a functional magnetic resonance imaging study. J Neurosci 24:2551-2565. CrossRef Medline

Diester I, Nieder A (2007) Semantic associations between signs and numerical categories in the prefrontal cortex. PLoS Biol 5:e294. CrossRef Medline

Duhamel JR, Colby CL, Goldberg ME (1998) Ventral intraparietal area of the macaque: congruent visual and somatic response properties. J Neurophysiol 79:126-136. Medline

Dum RP, Strick PL (1991) The origin of corticospinal projections from the premotor areas in the frontal lobe. J Neurosci 11:667-689. Medline

Durand JB, Peeters R, Norman JF, Todd JT, Orban GA (2009) Parietal regions processing visual $3 \mathrm{D}$ shape extracted from disparity. Neuroimage 46:1114-1126. CrossRef Medline

Dushanova J, Donoghue J (2010) Neurons in primary motor cortex engaged during action observation. Eur J Neurosci 31:386-398. CrossRef Medline

Emeric EE, Leslie M, Pouget P, Schall JD (2010) Performance monitoring local field potentials in the medial frontal cortex of primates: supplementary eye field. J Neurophysiol 104:1523-1537. CrossRef Medline

Emery NJ (2000) The eyes have it: the neuroethology, function and evolution of social gaze. Neurosci Biobehav Rev 24:581-604. Medline

Eradath MK, Abe H, Matsumoto M, Matsumoto K, Tanaka K, Ichinohe N (2015) Anatomical inputs to sulcal portions of areas $9 \mathrm{~m}$ and $8 \mathrm{Bm}$ in the macaque monkey. Front Neuroanat 9:30. CrossRef Medline

Fattori P, Raos V, Breveglieri R, Bosco A, Marzocchi N, Galletti C (2010) The dorsomedial pathway is not just for reaching: grasping neurons in the medial parieto-occipital cortex of the macaque monkey. J Neurosci 30:342-349. CrossRef

Felsenstein J (1973) Maximum-likelihood estimation of evolutionary trees from continuous characters. Am J Hum Genet 25:471-492

Ferraina S, Battaglia-Mayer A, Genovesio A, Archambault P, Caminiti R (2009a) Parietal encoding of action in depth. Neuropsychologia 47:1409-1420. CrossRef Medline

Ferraina S, Brunamonti E, Giusti MA, Costa S, Genovesio A, Caminiti $R$ (2009b) Reaching in depth: hand position dominates over binocular eye position in the rostral superior parietal lobule. J Neurosci 29:11461-11470. CrossRef Medline

Ferraina S, Garasto MR, Battaglia-Mayer A, Ferraresi P, Johnson PB, Lacquaniti F, Caminiti R (1997a) Visual control of hand-reaching movement: activity in parietal area $7 \mathrm{~m}$. Eur $\mathrm{J}$ Neurosci 9:10901095. Medline

Ferraina S, Johnson PB, Garasto MR, Battaglia-Mayer A, Ercolani L, Bianchi L, Lacquaniti F, Caminiti R (1997b) Combination of hand and gaze signals during reaching: activity in parietal area $7 \mathrm{~m}$ of the monkey. J Neurophysiol 77:1034-1038. Medline

Ferrari-Toniolo S, Visco-Comandini F, Papazachariadis O, Caminit R, Battaglia-Mayer A (2015) Posterior parietal cortex encoding of dynamic hand force underlying hand-object interaction. J Neurosci 35:10899-10910. CrossRef Medline

Fitzgerald PJ, Lane JW, Thakur PH, Hsiao SS (2004) Receptive field properties of the macaque second somatosensory cortex: evidence for multiple functional representations. J Neurosci 24: 11193-11204. CrossRef Medline

Fluet MC, Baumann MA, Scherberger H (2010) Context-specific grasp movement representation in macaque ventral premotor cortex. J Neurosci 30:15175-15184. CrossRef Medline

Fogassi L, Ferrari PF, Gesierich B, Rozzi S, Chersi F, Rizzolatti G (2005) Parietal lobe: from action organization to intention understanding. Science 308:662-667. CrossRef Medline

Fogassi L, Gallese V, Fadiga L, Luppino G, Matelli M, Rizzolatti G (1996) Coding of peripersonal space in inferior premotor cortex (area F4). J Neurophysiol 76:141-157. Medline

Foley NC, Jangraw DC, Peck C, Gottlieb J (2014) Novelty enhances visual salience independently of reward in the parietal lobe. J Neurosci 34:7947-7957. CrossRef Medline

Freedman DJ, Riesenhuber M, Poggio T, Miller EK (2002) Visual categorization and the primate prefrontal cortex: neurophysiology and behavior. J Neurophysiol 88:929-941. Medline

Friston KJ (2011) Functional and effective connectivity: a review. Brain Connect 1:13-36. CrossRef Medline

Fu QG, Suarez JI, Ebner TJ (1993) Neuronal specification of direction and distance during reaching movements in the superior precentral premotor area and primary motor cortex of monkeys. J Neurophysiol 70:2097-2116. Medline

Fujii N, Mushiake H, Tanji J (2000) Rostrocaudal distinction of the dorsal premotor area based on oculomotor involvement. J Neurophysiol 83:1764-1769. Medline

Funahashi S, Chafee MV, Goldman-Rakic PS (1993) Prefrontal neuronal activity in rhesus monkeys performing a delayed antisaccade task. Nature 365:753-756. CrossRef Medline

Gail A, Klaes C, Westendorff S (2009) Implementation of spatial transformation rules for goal-directed reaching via gain modulation in monkey parietal and premotor cortex. J Neurosci 29:94909499. CrossRef Medline 
Gallese V, Fadiga L, Fogassi L, Rizzolatti G (1996) Action recognition in the premotor cortex. Brain 119:593-609. CrossRef

Gallese V, Murata A, Kaseda M, Niki N, Sakata H (1994) Deficit of hand preshaping after muscimol injection in monkey parietal cortex. Neuroreport 5:1525-1529. Medline

Galletti C, Fattori P, Battaglini PP, Shipp S, Zeki S (1996) Functional demarcation of a border between areas V6 and V6A in the superior parietal gyrus of the macaque monkey. Eur J Neurosci 8:30-52. Medline

Galletti C, Fattori P, Kutz DF, Battaglini PP (1997) Arm movementrelated neurons in the visual area V6A of the macaque superior parietal lobule. Eur J Neurosci 9:410-413. Medline

Gamberini M, Passarelli L, Fattori P, Zucchelli M, Bakola S, Luppino G, Galletti C (2009) Cortical connections of the visuomotor parietooccipital area V6Ad of the macaque monkey. J Comp Neur 513:622-642. CrossRef Medline

Gamlin PD, Yoon K (2000) An area for vergence eye movement in primate frontal cortex. Nature 407:1003-1007. CrossRef Medline

Gardner EP, Babu KS, Reitzen SD, Ghosh S, Brown AS, Chen J, Hall AL, Herzlinger MD, Kohlenstein JB, Ro JY (2007) Neurophysiology of prehension. I. Posterior parietal cortex and object-oriented hand behaviors. J Neurophysiol 97:387-406. CrossRef Medline

Genovesio A, Brasted PJ, Mitz AR, Wise SP (2005) Prefrontal cortex activity related to abstract response strategies. Neuron 47:307320. CrossRef Medline

Genovesio A, Brasted PJ, Wise SP (2006) Representation of future and previous spatial goals by separate neural populations in prefrontal cortex. J Neurosci 26:7305-7316. CrossRef Medline

Gentilucci M, Fogassi L, Luppino G, Matelli M, Camarda R, Rizzolatti $G$ (1988) Functional organization of inferior area 6 in the macaque monkey. I. Somatotopy and the control of proximal movements. Exp Brain Res 71:475-490. Medline

Georgopoulos AP, Ashe J, Smyrnis N, Taira M (1992) The motor cortex and the coding of force. Science 256:1692-1695. Medline

Georgopoulos AP, Caminiti R, Kalaska JF (1984) Static spatial effects in motor cortex and area 5: quantitative relations in a twodimensional space. Exp Brain Res 54:446-454. Medline

Georgopoulos AP, DeLong MR, Crutcher MD (1983a) Relations between parameters of step-tracking movements and single cell discharge in the globus pallidus and subthalamic nucleus of the behaving monkey. J Neurosci 3:1586-1598.

Georgopoulos AP, Kalaska JF, Caminiti R, Massey JT (1983b) Interruption of motor cortical discharge subserving aimed arm movements. Exp Brain Res 49:327-340. Medline

Georgopoulos AP, Kalaska JF, Massey JT (1981) Spatial trajectories and reaction times of aimed movements: effects of practice, uncertainty, and change in target location. J Neurophysiol 46:725743. Medline

Georgopoulos AP, Lurito JT, Petrides M, Schwartz AB, Massey JT (1989) Mental rotation of the neuronal population vector. Science 243:234-236. Medline

Gerbella M, Belmalih A, Borra E, Rozzi S, Luppino G (2007) Multimodal architectonic subdivision of the caudal ventrolateral prefrontal cortex of the macaque monkey. Brain Struct Funct 212: 269-301. CrossRef Medline

Gerbella M, Belmalih A, Borra E, Rozzi S, Luppino G (2010) Cortical connections of the macaque caudal ventrolateral prefrontal areas 45A and 45B. Cereb Cortex 20:141-168. CrossRef Medline

Gerbella M, Belmalih A, Borra E, Rozzi S, Luppino G (2011) Cortical connections of the anterior ( $\mathrm{F} 5 \mathrm{a}$ ) subdivision of the macaque ventral premotor area F5. Brain Struct Funct 216:43-65. CrossRef Medline

Gerbella M, Borra E, Rozzi S, Luppino G (2016) Connections of the macaque Granular Frontal Opercular (GrFO) area: a possible neural substrate for the contribution of limbic inputs for controlling hand and face/mouth actions. Brain Struct Funct 221:59-78. CrossRef Medline

Gerbella M, Borra E, Tonelli S, Rozzi S, Luppino G (2013) Connectional heterogeneity of the ventral part of the macaque area 46. Cereb Cortex 23:967-987. CrossRef Medline
Geschwind N (1965) Disconnexion syndromes in animals and man. I. Brain 88:237-294. Medline

Gharbawie OA, Stepniewska I, Qi H, Kaas JH (2011) Multiple parietal-frontal pathways mediate grasping in macaque monkeys. J Neurosci 31:11660-11677. CrossRef Medline

Ghazanfar AA, Nielsen K, Logothetis NK (2006) Eye movements of monkey observers viewing vocalizing conspecifics. Cognition 101: 515-529. CrossRef Medline

Ghosh S, Gattera R (1995) A comparison of the ipsilateral cortical projections to the dorsal and ventral subdivisions of the macaque premotor cortex. Somat Mot Res 12:359-378. CrossRef

Gilbert SJ, Spengler S, Simons JS, Frith CD, Burgess PW (2006) Differential functions of lateral and medial rostral prefrontal cortex (area 10) revealed by brain-behavior associations. Cereb Cortex 16:1783-1789. CrossRef Medline

Gnadt JW, Andersen RA (1988) Memory related motor planning activity in posterior parietal cortex of macaque. Exp Brain Res 70:216-220. Medline

Gnadt JW, Mays LE (1995) Neurons in monkey parietal area LIP are tuned for eye-movement parameters in three-dimensional space. $J$ Neurophysiol 73:280-297. Medline

Godschalk M, Lemon RN, Nijs HG, Kuypers HG (1981) Behaviour of neurons in monkey peri-arcuate and precentral cortex before and during visually guided arm and hand movements. Exp Brain Res 44:113-116. Medline

Gold JI, Shadlen MN (2007) The neural basis of decision making. Annu Rev Neurosci 30:535-574. CrossRef Medline

Gottlieb J, Hayhoe M, Hikosaka O, Rangel A (2014) Attention, reward, and information seeking. J Neurosci 34:15497-15504. CrossRef Medline

Gottlieb JP, Kusunoki M, Goldberg ME (1998) The representation of visual salience in monkey parietal cortex. Nature 391:481-484. CrossRef Medline

Grabenhorst F, Rolls ET (2011) Value, pleasure and choice in the ventral prefrontal cortex. Trends Cogn Sci 15:56-67. CrossRef Medline

Graziano MS (2006) Progress in understanding spatial coordinate systems in the primate brain. Neuron 51:7-9. CrossRef Medline

Graziano MS, Yap GS, Gross CG (1994) Coding of visual space by premotor neurons. Science 266:1054-1057. Medline

Gregoriou GG, Savaki HE (2003) When vision guides movement: a functional imaging study of the monkey brain. Neuroimage 19: 959-967. Medline

Gregoriou GG, Borra E, Matelli M, Luppino G (2006) Architectonic organization of the inferior parietal convexity of the macaque monkey. J Comp Neur 496:422-451. CrossRef Medline

Hadjidimitrakis K, Bertozzi F, Breveglieri R, Bosco A, Galletti C, Fattori P (2014) Common neural substrate for processing depth and direction signals for reaching in the monkey medial posterior parietal cortex. Cereb Cortex 24:1645-1657. CrossRef Medline

Hatanaka N, Nambu A, Yamashita A, Takada M, Tokuno H (2001) Somatotopic arrangement and corticocortical inputs of the hindlimb region of the primary motor cortex in the macaque monkey. Neurosci Res 40:9-22. Medline

Hatanaka $N$, Tokuno $\mathrm{H}$, Hamada I, Inase $\mathrm{M}$, Ito $\mathrm{Y}$, Imanishi $\mathrm{M}$, Hasegawa N, Akazawa T, Nambu A, Takada M (2003) Thalamocortical and intracortical connections of monkey cingulate motor areas. J Comp Neur 462:121-138. CrossRef Medline

Heilman KM, Valenstein E, Watson RT (2000) Neglect and related disorders. Semin Neurol 20:463-470. CrossRef Medline

Hepp-Reymond MC, Wyss UR, Anner R (1978) Neuronal coding of static force in the primate motor cortex. J Physiol (Paris). 74:287291.

Hihara S, Notoya T, Tanaka M, Ichinose S, Ojima H, Obayashi S, Fujii $\mathrm{N}$, Iriki A (2006) Extension of corticocortical afferents into the anterior bank of the intraparietal sulcus by tool-use training in adult monkeys. Neuropsychologia 44:2636-2646. CrossRef Medline

Hihara S, Taoka M, Tanaka M, Iriki A (2015) Visual responsiveness of neurons in the secondary somatosensory area and its surrounding 
parietal operculum regions in awake macaque monkeys. Cereb Cortex 25:4535-4550. CrossRef Medline

Hikosaka O, Nakahara H, Rand MK, Sakai K, Lu X, Nakamura K, Miyachi S, Doya K (1999) Parallel neural networks for learning sequential procedures. Trends Neurosci 22:464-471. Medline

Hoshi E, Tanji J (2000) Integration of target and body-part information in the premotor cortex when planning action. Nature 408:466470. CrossRef Medline

Hoshi E, Tanji J (2004) Functional specialization in dorsal and ventral premotor areas. Prog Brain Res 143:507-511. CrossRef Medline

Hoshi E, Shima K, Tanji J (1998) Task-dependent selectivity of movement-related neuronal activity in the primate prefrontal cortex. J Neurophysiol 80:3392-3397. Medline

Hoshi E, Shima K, Tanji J (2000) Neuronal activity in the primate prefrontal cortex in the process of motor selection based on two behavioral rules. J Neurophysiol 83:2355-2373. Medline

Hsiao S (2008) Central mechanisms of tactile shape perception. Curr Opin Neurobiol 18:418-424. CrossRef Medline

Hsiao SS, O'Shaughnessy DM, Johnson KO (1993) Effects of selective attention on spatial form processing in monkey primary and secondary somatosensory cortex. J Neurophysiol 70:444-447. Medline

Huerta MF, Kaas JH (1990) Supplementary eye field as defined by intracortical microstimulation: connections in macaques. J Comp Neur 293:299-330. Medline

Huerta MF, Pons TP (1990) Primary motor cortex receives input from area $3 a$ in macaques. Brain Res 537:367-371. Medline

Huerta MF, Krubitzer LA, Kaas JH (1987) Frontal eye field as defined by intracortical microstimulation in squirrel monkeys, owl monkeys, and macaque monkeys. II. Cortical connections. J Comp Neur 265:332-361. CrossRef Medline

Hunt LT, Kolling N, Soltani A, Woolrich MW, Rushworth MF, Behrens TE (2012) Mechanisms underlying cortical activity during valueguided choice. Nat Neurosci 15:470-476. S471-473. CrossRef

Hyvärinen J (1981) Regional distribution of functions in parietal association area 7 of the monkey. Brain Res 206:287-303. CrossRef

Ichihara-Takeda S, Funahashi S (2007) Activity of primate orbitofrontal and dorsolateral prefrontal neurons: task-related activity during an oculomotor delayed-response task. Exp Brain Res 181:409425. CrossRef Medline

Innocenti GM, Vercelli A, Caminiti R (2014) The diameter of cortical axons depends both on the area of origin and target. Cereb Cortex 24:2178-2188. CrossRef Medline

Iriki A, Taoka M (2012) Triadic (ecological, neural, cognitive) niche construction: a scenario of human brain evolution extrapolating tool use and language from the control of reaching actions. Philos Trans R Soc Lond B Biol Sci 367:10-23. CrossRef Medline

Iriki A, Tanaka M, Iwamura Y (1996) Coding of modified body schema during tool use by macaque postcentral neurones. Neuroreport 7:2325-2330. Medline

Ishida H, Fornia L, Grandi LC, Umiltà MA, Gallese V (2013) Somatomotor haptic processing in posterior inner perisylvian region (SII/ $\mathrm{pIC}$ ) of the macaque monkey. PLoS One 8:e69931. CrossRef Medline

Ito SI (1982) Prefrontal unit activity of macaque monkeys during auditory and visual reaction time tasks. Brain Res 247:39-47. Medline

Johnson PB, Ferraina S, Bianchi L, Caminiti R (1996) Cortical networks for visual reaching: physiological and anatomical organization of frontal and parietal lobe arm regions. Cereb Cortex 6:102119. Medline

Kable JW, Glimcher PW (2009) The neurobiology of decision: consensus and controversy. Neuron 63:733-745. CrossRef Medline

Kakei S, Hoffman DS, Strick PL (1999) Muscle and movement representations in the primary motor cortex. Science 285:2136-2139. Medline

Kalaska JF (1994) Central neural mechanisms of touch and proprioception. Can J Physiol Pharmacol 72:542-545. Medline

Kalaska JF, Caminiti R, Georgopoulos AP (1983) Cortical mechanisms related to the direction of two-dimensional arm movements: relations in parietal area 5 and comparison with motor cortex. Exp Brain Res 51:247-260. Medline

Kalaska JF, Cohen DA, Prud'homme M, Hyde ML (1990) Parietal area 5 neuronal activity encodes movement kinematics, not movement dynamics. Exp Brain Res 80:351-364. CrossRef

Kastner S, Ungerleider LG (2000) Mechanisms of visual attention in the human cortex. Annu Rev Neurosci 23:315-341. CrossRef Medline

Kennerley SW, Dahmubed AF, Lara AH, Wallis JD (2009) Neurons in the frontal lobe encode the value of multiple decision variables. J Cogn Neurosci 21:1162-1178. CrossRef Medline

Kiani R, Shadlen MN (2009) Representation of confidence associated with a decision by neurons in the parietal cortex. Science 324 : 759-764. CrossRef Medline

Kleist K (1934) Konstruktive (optische) Apraxie. Leipzig: Barth.

Koechlin E, Summerfield C (2007) An information theoretical approach to prefrontal executive function. Trends Cogn Sci 11:229235. CrossRef Medline

Kristensson K, Olsson Y (1971) Retrograde axonal transport of protein. Brain Res 29:363-365. Medline

Kumano H, Suda Y, Uka T (2016) Context-dependent accumulation of sensory evidence in the parietal cortex underlies flexible task switching. J Neurosci 36:12192-12202. CrossRef Medline

Kuraoka K, Konoike N, Nakamura K (2015) Functional differences in face processing between the amygdala and ventrolateral prefrontal cortex in monkeys. Neuroscience 304:71-80. CrossRef Medline

Kurata K (1991) Corticocortical inputs to the dorsal and ventral aspects of the premotor cortex of macaque monkeys. Neurosci Res 12:263-280. Medline

Kurata K, Hoffman DS (1994) Differential effects of muscimol microinjection into dorsal and ventral aspects of the premotor cortex of monkeys. J Neurophysiol71:1151-1164.

Kuwajima M, Sawaguchi T (2007) Involvement of the lateral prefrontal cortex in conditional suppression of gaze shift. Neurosci Res. 59:431-445.

Lacquaniti F, Guigon E, Bianchi L, Ferraina S, Caminiti R (1995) Representing spatial information for limb movement: role of area 5 in the monkey. Cereb Cortex 5:391-409. Medline

Lanzilotto M, Perciavalle V, Lucchetti C (2013) Auditory and visual systems organization in Brodmann Area 8 for gaze-shift control: where we do not see, we can hear. Front Behav Neurosci 7:198. CrossRef

Lanzilotto M, Perciavalle V, Lucchetti C (2015) Orienting movements in area 9 identified by long-train ICMS. Brain Struct Funct 220: 763-779. CrossRef Medline

Leichnetz GR (2001) Connections of the medial posterior parietal cortex (area 7m) in the monkey. The Anat Rec 263:215-236. Medline

Levy DJ, Glimcher PW (2012) The root of all value: a neural common currency for choice. Curr Opin Neurobiol 22:1027-1038. CrossRef Medline

Lewis JW, Van Essen DC (2000) Corticocortical connections of visual, sensorimotor, and multimodal processing areas in the parietal lobe of the macaque monkey. J Comp Neur 428:112-137. Medline

Liu Y, Yttri EA, Snyder LH (2010) Intention and attention: different functional roles for LIPd and LIPV. Nat Neurosci 13:495-500. CrossRef Medline

Louie K, Glimcher PW (2010) Separating value from choice: delay discounting activity in the lateral intraparietal area. J Neurosci 30:5498-5507. CrossRef Medline

Louie K, Grattan LE, Glimcher PW (2011) Reward value-based gain control: divisive normalization in parietal cortex. J Neurosci 31: 10627-10639. CrossRef Medline

Louie K, LoFaro T, Webb R, Glimcher PW (2014) Dynamic divisive normalization predicts time-varying value coding in decisionrelated circuits. J Neurosci 34:16046-16057. CrossRef Medline

Lucchetti C, Lanzilotto M, Bon L (2008) Auditory-motor and cognitive aspects in area 8B of macaque monkey's frontal cortex: a premo- 
tor ear-eye field (PEEF). Exp Brain Res 186:131-141. CrossRef Medline

Luppino G, Ben Hamed S, Gamberini M, Matelli M, Galletti C (2005) Occipital (V6) and parietal (V6A) areas in the anterior wall of the parieto-occipital sulcus of the macaque: a cytoarchitectonic study. Eur J Neurosci 21:3056-3076. CrossRef Medline

Luppino G, Calzavara R, Rozzi S, Matelli M (2001) Projections from the superior temporal sulcus to the agranular frontal cortex in the macaque. Eur J Neurosci 14:1035-1040. Medline

Luppino G, Matelli M, Camarda RM, Gallese V, Rizzolatti G (1991) Multiple representations of body movements in mesial area 6 and the adjacent cingulate cortex: an intracortical microstimulation study in the macaque monkey. J Comp Neur 311:463-482. CrossRef Medline

Luppino G, Matelli M, Camarda R, Rizzolatti G (1993) Corticocortical connections of area F3 (SMA-proper) and area F6 (pre-SMA) in the macaque monkey. J Comp Neur 338:114-140. CrossRef Medline

Luppino G, Murata A, Govoni P, Matelli M (1999) Largely segregated parietofrontal connections linking rostral intraparietal cortex (areas AIP and VIP) and the ventral premotor cortex (areas F5 and F4). Exp Brain Res 128:181-187. Medline

Luppino G, Rozzi S, Calzavara R, Matelli M (2003) Prefrontal and agranular cingulate projections to the dorsal premotor areas F2 and F7 in the macaque monkey. Eur J Neurosci 17:559-578. Medline

Lynch JC, Tian JR (2006) Cortico-cortical networks and corticosubcortical loops for the higher control of eye movements. Prog Brain Res 151:461-501. CrossRef Medline

Lynch JC, Mountcastle VB, Talbot WH, Yin TC (1977) Parietal lobe mechanisms for directed visual attention. J Neurophysiol 40:362389. Medline

Maier MA, Bennett KM, Hepp-Reymond MC, Lemon RN (1993) Contribution of the monkey corticomotoneuronal system to the control of force in precision grip. J Neurophysiol 69:772-785. Medline

Maioli MG, Squatrito S, Samolsky-Dekel BG, Sanseverino ER (1998) Corticocortical connections between frontal periarcuate regions and visual areas of the superior temporal sulcus and the adjoining inferior parietal lobule in the macaque monkey. Brain Res 789: 118-125. Medline

Mansouri FA, Buckley MJ, Mahboubi M, Tanaka K (2015) Behavioral consequences of selective damage to frontal pole and posterior cingulate cortices. Proc Natl Acad Sci U S A 112:E3940-E3949. CrossRef Medline

Marconi B, Genovesio A, Battaglia-Mayer A, Ferraina S, Squatrito S, Molinari M, Lacquaniti F, Caminiti R (2001) Eye-hand coordination during reaching. I. Anatomical relationships between parietal and frontal cortex. Cereb Cortex 11:513-527. Medline

Margush T, McMorris FR (1981) Consensus n-trees. Bltn Mathcal Biology 43:239-244.

Markov NT, Ercsey-Ravasz MM, Ribeiro Gomes AR, Lamy C, Magrou L, Vezoli J, Misery P, Falchier A, Quilodran R, Gariel MA, et al. (2014) A weighted and directed interareal connectivity matrix for macaque cerebral cortex. Cereb Cortex 24:17-36. CrossRef Medline

Markov NT, Ercsey-Ravasz M, Van Essen DC, Knoblauch K, Toroczkai Z, Kennedy H (2013) Cortical high-density counterstream architectures. Science 342:1238406. CrossRef Medline

Markov NT, Misery P, Falchier A, Lamy C, Vezoli J, Quilodran R, Gariel MA, Giroud P, Ercsey-Ravasz M, Pilaz LJ, Huissoud C, Barone P, Dehay C, Toroczkai Z, Van Essen DC, Kennedy H, Knoblauch K (2011) Weight consistency specifies regularities of macaque cortical networks. Cereb Cortex 21:1254-1272. CrossRef Medline

Matelli M, Camarda R, Glickstein M, Rizzolatti G (1986) Afferent and efferent projections of the inferior area 6 in the macaque monkey. J Comp Neur 251:281-298. CrossRef Medline

Matelli M, Govoni P, Galletti C, Kutz DF, Luppino G (1998) Superior area 6 afferents from the superior parietal lobule in the macaque monkey. J Comp Neur 402:327-352. Medline
Matelli M, Luppino G, Rizzolatti G (1985) Patterns of cytochrome oxidase activity in the frontal agranular cortex of the macaque monkey. Behav Brain Res 18:125-136. Medline

Matelli M, Luppino G, Rizzolatti G (1991) Architecture of superior and mesial area 6 and the adjacent cingulate cortex in the macaque monkey. J Comp Neur 311:445-462. CrossRef Medline

Matsuzaka Y, Tanji J (1996) Changing directions of forthcoming arm movements: neuronal activity in the presupplementary and supplementary motor area of monkey cerebral cortex. J Neurophysiol 76:2327-2342. Medline

Matsuzaka Y, Aizawa H, Tanji J (1992) A motor area rostral to the supplementary motor area (presupplementary motor area) in the monkey: neuronal activity during a learned motor task. J Neurophysiol 68:653-662. Medline

Matsuzaka Y, Akiyama T, Tanji J, Mushiake H (2012) Neuronal activity in the primate dorsomedial prefrontal cortex contributes to strategic selection of response tactics. Proc Natl Acad Sci U S A 109:4633-4638. CrossRef Medline

Matsuzaka Y, Tanji J, Mushiake H (2016) Representation of behavioral tactics and tactics-action transformation in the primate medial prefrontal cortex. J Neurosci 36:5974-5987. CrossRef Medline

Mattia M, Pani P, Mirabella G, Costa S, Del Giudice P, Ferraina S (2013) Heterogeneous attractor cell assemblies for motor planning in premotor cortex. J Neurosci 33:11155-11168. CrossRef Medline

Mattingley JB, Bradshaw JL, Phillips JG (1992) Impairments of movement initiation and execution in unilateral neglect. Directional hypokinesia and bradykinesia. Brain 115:1849-1874. CrossRef

McGuire LM, Sabes PN (2009) Sensory transformations and the use of multiple reference frames for reach planning. Nat Neurosci 12:1056-1061. CrossRef Medline

McGuire LM, Sabes PN (2011) Heterogeneous representations in the superior parietal lobule are common across reaches to visual and proprioceptive targets. J Neurosci 31:6661-6673. CrossRef Medline

Merchant H, Battaglia-Mayer A, Georgopoulos AP (2001) Effects of optic flow in motor cortex and area 7a. J Neurophysiol 86:19371954. Medline

Merchant H, Battaglia-Mayer A, Georgopoulos AP (2004) Neural responses during interception of real and apparent circularly moving stimuli in motor cortex and area 7a. Cereb Cortex 14:314-331. Medline

Mesulam MM, Mufson EJ (1982) Insula of the old world monkey. I. Architectonics in the insulo-orbito-temporal component of the paralimbic brain. J Comp Neur 212:1-22. CrossRef Medline

Michelet T, Bioulac B, Langbour N, Goillandeau M, Guehl D, Burbaud P (2016) Electrophysiological correlates of a versatile executive control system in the monkey anterior cingulate cortex. Cereb Cortex 26:1684-1697. CrossRef Medline

Miller EK, Freedman DJ, Wallis JD (2002) The prefrontal cortex: categories, concepts and cognition. Philos Trans R Soc Lond B Biol Sci 357:1123-1136. CrossRef Medline

Mirabella G, Pani P, Ferraina S (2011) Neural correlates of cognitive control of reaching movements in the dorsal premotor cortex of rhesus monkeys. J Neurophysiol 106:1454-1466. CrossRef Medline

Mishkin M, Manning FJ (1978) Non-spatial memory after selective prefrontal lesions in monkeys. Brain Res 143:313-323. Medline

Mitz AR, Godschalk M (1989) Eye-movement representation in the frontal lobe of rhesus monkeys. Neurosci Lett 106:157-162. Medline

Mitz AR, Wise SP (1987) The somatotopic organization of the supplementary motor area: intracortical microstimulation mapping. $J$ Neurosci 7:1010-1021. Medline

Moore T, Fallah M (2004) Microstimulation of the frontal eye field and its effects on covert spatial attention. J Neurophysiol 91:152-162. CrossRef Medline

Moore T, Armstrong KM, Fallah M (2003) Visuomotor origins of covert spatial attention. Neuron 40:671-683. Medline 
Moran DW, Schwartz AB (1999) Motor cortical representation of speed and direction during reaching. J Neurophysiol 82:26762692. Medline

Morecraft RJ, Van Hoesen GW (1993) Frontal granular cortex input to the cingulate (M3), supplementary (M2) and primary (M1) motor cortices in the rhesus monkey. J Comp Neur 337:669-689. CrossRef Medline

Morecraft RJ, Van Hoesen GW (1998) Convergence of limbic input to the cingulate motor cortex in the rhesus monkey. Brain Res Bull 45:209-232. Medline

Morecraft RJ, Cipolloni PB, Stilwell-Morecraft KS, Gedney MT, Pandya DN (2004) Cytoarchitecture and cortical connections of the posterior cingulate and adjacent somatosensory fields in the rhesus monkey. J Comp Neur 469:37-69. CrossRef Medline

Morecraft RJ, Stilwell-Morecraft KS, Cipolloni PB, Ge J, McNeal DW, Pandya DN (2012) Cytoarchitecture and cortical connections of the anterior cingulate and adjacent somatomotor fields in the rhesus monkey. Brain Res Bull 87:457-497. CrossRef Medline

Morrison SE, Salzman CD (2009) The convergence of information about rewarding and aversive stimuli in single neurons. J Neurosci 29:11471-11483. CrossRef Medline

Moschovakis AK, Highstein SM (1994) The anatomy and physiology of primate neurons that control rapid eye movements. Annu Rev Neurosci 17:465-488. CrossRef Medline

Moschovakis AK, Gregoriou GG, Ugolini G, Doldan M, Graf W, Guldin W, Hadjidimitrakis K, Savaki HE (2004) Oculomotor areas of the primate frontal lobes: a transneuronal transfer of rabies virus and [14C]-2-deoxyglucose functional imaging study. J Neurosci 24:5726-5740. CrossRef Medline

Mountcastle VB (1978) Brain mechanisms for directed attention. J R Soc Med 71:14-28. Medline

Mountcastle VB (2005) The sensory hand: neural mechanisms of somatic sensation. Cambridge, MA: Harvard University Press.

Mountcastle VB, Powell TP (1959) Central nervous mechanisms subserving position sense and kinesthesis. Bull Johns Hopkins Hosp 105:173-200. Medline

Mountcastle VB, Lynch JC, Georgopoulos A, Sakata H, Acuna C (1975) Posterior parietal association cortex of the monkey: command functions for operations within extrapersonal space. J Neurophysiol 38:871-908.

Muir RB, Lemon RN (1983) Corticospinal neurons with a special role in precision grip. Brain Res 261:312-316. Medline

Murata A, Fadiga L, Fogassi L, Gallese V, Raos V, Rizzolatti G (1997) Object representation in the ventral premotor cortex (area F5) of the monkey. J Neurophysiol 78:2226-2230. Medline

Murata A, Gallese V, Luppino G, Kaseda M, Sakata H (2000) Selectivity for the shape, size, and orientation of objects for grasping in neurons of monkey parietal area AIP. J Neurophysiol 83:25802601. Medline

Murray EA, Coulter JD (1981) Organization of corticospinal neurons in the monkey. J Comp Neur 195:339-365. CrossRef Medline

Murray EA, Mishkin M (1984) Relative contributions of SII and area 5 to tactile discrimination in monkeys. Behav Brain Res 11:67-83. Medline

Murray EA, Bussey TJ, Wise SP (2000) Role of prefrontal cortex in a network for arbitrary visuomotor mapping. Exp Brain Res 133: 114-129. CrossRef Medline

Nachev P, Kennard C, Husain M (2008) Functional role of the supplementary and pre-supplementary motor areas. Nat Rev Neurosci 9:856-869. CrossRef Medline

Nakamura K, Roesch MR, Olson CR (2005) Neuronal activity in macaque SEF and ACC during performance of tasks involving conflict. J Neurophysiol 93:884-908. CrossRef Medline

Nelissen K, Luppino G, Vanduffel W, Rizzolatti G, Orban GA (2005) Observing others: multiple action representation in the frontal lobe. Science 310:332-336. CrossRef Medline

Nieder A (2016) The neuronal code for number. Nat Rev Neurosci 17:366-382. CrossRef Medline

Nieder A, Dehaene S (2009) Representation of number in the brain. Annu Rev Neurosci 32:185-208. CrossRef Medline
Nieder A, Miller EK (2004a) Analog numerical representations in rhesus monkeys: evidence for parallel processing. J Cogn Neurosci 16:889-901.

Nieder A, Miller EK (2004b) A parieto-frontal network for visual numerical information in the monkey. Proc Natl Acad Sci U S A 101:7457-7462. CrossRef Medline

Obayashi S, Tanaka M, Iriki A (2000) Subjective image of invisible hand coded by monkey intraparietal neurons. Neuroreport 11: 3499-3505.

O'Neill M, Schultz W (2010) Coding of reward risk by orbitofrontal neurons is mostly distinct from coding of reward value. Neuron 68:789-800.

Ohbayashi M, Picard N, Strick PL (2016) Inactivation of the dorsal premotor area disrupts internally generated, but not visually guided, sequential movements. J. Neurosci 36:1971-1976. CrossRef

Olson CR, Gettner SN (1996) Representation of object-centered space in the primate frontal lobe. Brain Res Cogn Brain Res 5:147-156. Medline

Olson CR, Musil SY, Goldberg ME (1996) Single neurons in posterior cingulate cortex of behaving macaque: eye movement signals. $J$ Neurophysiol 76:3285-3300. Medline

Orban GA (2011) The extraction of 3D shape in the visual system of human and nonhuman primates. Annu Rev Neurosci 34:361-388. CrossRef Medline

Oscarsson O, Rosen I (1963) Projection to cerebral cortex of large muscle-spindle afferents in forelimb nerves of the cat. J Physiol 169:924-945. Medline

Padoa-Schioppa C (2011) Neurobiology of economic choice: a good-based model. Annu Rev Neurosci 34:333-359. CrossRef Medline

Padoa-Schioppa C, Assad JA (2006) Neurons in the orbitofrontal cortex encode economic value. Nature 441:223-226. CrossRef Medline

Padoa-Schioppa C, Cai X (2011) The orbitofrontal cortex and the computation of subjective value: consolidated concepts and new perspectives. Ann N Y Acad Sci 1239:130-137. CrossRef Medline

Pandya DN, Seltzer B (1982) Intrinsic connections and architectonics of posterior parietal cortex in the rhesus monkey. J Comp Neur 204:196-210. CrossRef Medline

Passarelli L, Rosa MG, Gamberini M, Bakola S, Burman KJ, Fattori P, Galletti C (2011) Cortical connections of area V6Av in the macaque: a visual-input node to the eye/hand coordination system. J Neurosci 31:1790-1801. CrossRef Medline

Passingham R (1975) Delayed matching after selective prefrontal lesions in monkeys (Macaca mulatta). Brain Res 92:89-102. Medline

Passingham RE (1988) Premotor cortex and preparation for movement. Exp Brain Res 70:590-596. Medline

Passingham R (1993) The frontal lobes and voluntary action. Oxford, UK: Oxford University Press.

Passingham RE, Toni I, Rushworth MF (2000) Specialisation within the prefrontal cortex: the ventral prefrontal cortex and associative learning. Exp Brain Res 133:103-113. CrossRef Medline

Pastor-Bernier A, Tremblay E, Cisek P (2012) Dorsal premotor cortex is involved in switching motor plans. Front Neuroeng 5:5. CrossRef Medline

Pei YC, Hsiao SS, Bensmaia SJ (2008) The tactile integration of local motion cues is analogous to its visual counterpart. Proc Natl Acad Sci U S A 105:8130-8135. CrossRef Medline

Pellizzer G, Sargent P, Georgopoulos AP (1995) Motor cortical activity in a context-recall task. Science 269:702-705. Medline

Peng X, Sereno ME, Silva AK, Lehky SR, Sereno AB (2008) Shape selectivity in primate frontal eye field. J Neurophysiol 100:796814. CrossRef Medline

Pesaran B, Nelson MJ, Andersen RA (2006) Dorsal premotor neurons encode the relative position of the hand, eye, and goal during reach planning. Neuron 51:125-134. CrossRef Medline 
Petersen SE, Posner MI (2012) The attention system of the human brain: 20 years after. Annu Rev Neurosci 35:73-89. CrossRef Medline

Petrides M (1985) Deficits in non-spatial conditional associative learning after periarcuate lesions in the monkey. Behav Brain Res 16:95-101. Medline

Petrides M (1991) Monitoring of selections of visual stimuli and the primate frontal cortex. Proc Biol Sci 246:293-298. CrossRef Medline

Petrides M (2000) The role of the mid-dorsolateral prefrontal cortex in working memory. Exp Brain Res 133:44-54. CrossRef Medline

Petrides M (2005) Lateral prefrontal cortex: architectonic and functional organization. Philos Trans R Soc Lond B Biol Sci 360:781795. CrossRef Medline

Petrides M, Pandya DN (1994) Comparative architectonic analysis of the human and the macaque frontal cortex. In: Boller F, Grafman J (eds) Handbook of Neuropsychology. Elsevier, Amsterdam, 17-58.

Petrides M, Pandya DN (1999) Dorsolateral prefrontal cortex: comparative cytoarchitectonic analysis in the human and the macaque brain and corticocortical connection patterns. Eur J Neurosci 11: 1011-1036. Medline

Petrides M, Pandya DN (2002) Comparative cytoarchitectonic analysis of the human and the macaque ventrolateral prefrontal cortex and corticocortical connection patterns in the monkey. Eur J Neurosci 16:291-310. Medline

Petrides M, Pandya DN (2006) Efferent association pathways originating in the caudal prefrontal cortex in the macaque monkey. $J$ Comp Neur 498:227-251. CrossRef Medline

Petrides M, Pandya DN (2007) Efferent association pathways from the rostral prefrontal cortex in the macaque monkey. J Neurosci 27:11573-11586. CrossRef Medline

Petrides M, Alivisatos B, Frey S (2002) Differential activation of the human orbital, mid-ventrolateral, and mid-dorsolateral prefrontal cortex during the processing of visual stimuli. Proc Natl Acad Sci U S A 99:5649-5654. CrossRef Medline

Picard N, Strick PL (1996) Motor areas of the medial wall: a review of their location and functional activation. Cereb Cortex 6:342-353. Medline

Picard N, Strick PL (1997) Activation on the medial wall during remembered sequences of reaching movements in monkeys. $J$ Neurophysiol 77:2197-2201. Medline

Picard N, Strick PL (2003) Activation of the supplementary motor area (SMA) during performance of visually guided movements. Cereb Cortex 13:977-986. Medline

Pitzalis S, Fattori P, Galletti C (2015) The human cortical areas V6 and V6A. Vis Neurosci 32:E007. CrossRef Medline

Platt ML, Glimcher PW (1999) Neural correlates of decision variables in parietal cortex. Nature 400:233-238. CrossRef Medline

Pons TP, Kaas JH (1986) Corticocortical connections of area 2 of somatosensory cortex in macaque monkeys: a correlative anatomical and electrophysiological study. J Comp Neur 248:313335. CrossRef Medline

Premereur E, Janssen P, Vanduffel W (2015) Effector specificity in macaque frontal and parietal cortex. J Neurosci 35:3446-3459. CrossRef Medline

Preuss TM, Goldman-Rakic PS (1991) Myelo- and cytoarchitecture of the granular frontal cortex and surrounding regions in the strepsirhine primate Galago and the anthropoid primate Macaca. J Comp Neur 310:429-474. CrossRef Medline

Procyk E, Tanaka YL, Joseph JP (2000) Anterior cingulate activity during routine and non-routine sequential behaviors in macaques. Nat Neurosci 3:502-508. CrossRef Medline

Prud'homme MJ, Kalaska JF (1994) Proprioceptive activity in primate primary somatosensory cortex during active arm reaching movements. J Neurophysiol 72:2280-2301. Medline

Qi XL, Elworthy AC, Lambert BC, Constantinidis C (2015) Representation of remembered stimuli and task information in the monkey dorsolateral prefrontal and posterior parietal cortex. J Neurophysiol 113:44-57. CrossRef Medline
Raffi M, Siegel RM (2005) Functional architecture of spatial attention in the parietal cortex of the behaving monkey. J Neurosci 25:51715186. CrossRef Medline

Raffi M, Squatrito S, Maioli MG (2002) Neuronal responses to optic flow in the monkey parietal area PEc. Cereb Cortex 12:639-646. Medline

Raos V, Umiltà MA, Murata A, Fogassi L, Gallese V (2006) Functional properties of grasping-related neurons in the ventral premotor area F5 of the macaque monkey. J Neurophysiol 95:709-729. CrossRef Medline

Requin J, Lecas JC, Vitton N (1990) A comparison of preparationrelated neuronal activity changes in the prefrontal, premotor, primary motor and posterior parietal areas of the monkey cortex: preliminary results. Neurosci Lett 111:151-156. Medline

Reyes-Puerta V, Philipp R, Lindner W, Hoffmann KP (2011) Neuronal activity in the superior colliculus related to saccade initiation during coordinated gaze-reach movements. Eur J Neurosci 34:19661982. CrossRef Medline

Ridderinkhof KR, Wijnen JG (2011) More than meets the eye: age differences in the capture and suppression of oculomotor action. Front Psychol 2:267. CrossRef Medline

Rizzolatti G, Craighero L (2004) The mirror-neuron system. Annu Rev Neurosci 27:169-192. CrossRef Medline

Rizzolatti G, Camarda R, Fogassi L, Gentilucci M, Luppino G, Matell M (1988) Functional organization of inferior area 6 in the macaque monkey. II. Area F5 and the control of distal movements. Exp Brain Res 71:491-507. Medline

Rizzolatti G, Cattaneo L, Fabbri-Destro M, Rozzi S (2014) Cortical mechanisms underlying the organization of goal-directed actions and mirror neuron-based action understanding. Physiol Rev 94: 655-706. CrossRef Medline

Rizzolatti G, Fadiga L, Gallese V, Fogassi L (1996) Premotor cortex and the recognition of motor actions. Brain Res Cogn Brain Res 3:131-141. Medline

Rizzolatti G, Gentilucci M, Camarda RM, Gallese V, Luppino G, Matelli M, Fogassi L (1990) Neurons related to reaching-grasping arm movements in the rostral part of area 6 (area $6 a$ beta). Exp Brain Res 82:337-350. Medline

Rizzolatti G, Matelli M, Pavesi G (1983) Deficits in attention and movement following the removal of postarcuate (area 6) and prearcuate (area 8) cortex in macaque monkeys. Brain 106:655673. CrossRef

Robinson CJ, Burton H (1980) Somatotopographic organization in the second somatosensory area of M. fascicularis. J Comp Neur 192:43-67. CrossRef Medline

Roesch MR, Olson CR (2003) Impact of expected reward on neuronal activity in prefrontal cortex, frontal and supplementary eye fields and premotor cortex. J Neurophysiol 90:1766-1789. CrossRef Medline

Roesch MR, Olson CR (2004) Neuronal activity related to reward value and motivation in primate frontal cortex. Science 304:307310. CrossRef Medline

Roesch MR, Olson CR (2005) Neuronal activity in primate orbitofrontal cortex reflects the value of time. J Neurophysiol 94:2457-2471. CrossRef Medline

Roitman JD, Shadlen MN (2002) Response of neurons in the lateral intraparietal area during a combined visual discrimination reaction time task. J Neurosci 22:9475-9489. Medline

Roitman JD, Brannon EM, Platt ML (2007) Monotonic coding of numerosity in macaque lateral intraparietal area. PLoS Biol 5:e208. CrossRef Medline

Romanski LM, Averbeck BB (2009) The primate cortical auditory system and neural representation of conspecific vocalizations. Annu Rev Neurosci 32:315-346. CrossRef Medline

Romo R, Hernández A, Zainos A, Lemus L, Brody CD (2002) Neuronal correlates of decision-making in secondary somatosensory cortex. Nat Neurosci 5:1217-1225. CrossRef Medline

Rozzi S, Calzavara R, Belmalih A, Borra E, Gregoriou GG, Matelli M, Luppino $G$ (2006) Cortical connections of the inferior parietal cor- 
tical convexity of the macaque monkey. Cereb Cortex 16:13891417. CrossRef Medline

Rozzi S, Ferrari PF, Bonini L, Rizzolatti G, Fogassi L (2008) Functional organization of inferior parietal lobule convexity in the macaque monkey: electrophysiological characterization of motor, sensory and mirror responses and their correlation with cytoarchitectonic areas. Eur J Neurosci 28:1569-1588. CrossRef Medline

Rudebeck PH, Murray EA (2011a) Dissociable effects of subtotal lesions within the macaque orbital prefrontal cortex on rewardguided behavior. J Neurosci 31:10569-10578. CrossRef Medline

Rudebeck PH, Murray EA (2011b) Balkanizing the primate orbitofrontal cortex: distinct subregions for comparing and contrasting values. Ann N Y Acad Sci 1239:1-13. CrossRef Medline

Rudebeck PH, Buckley MJ, Walton ME, Rushworth MF (2006) A role for the macaque anterior cingulate gyrus in social valuation. Science 313:1310-1312. CrossRef Medline

Rushworth MF, Noonan MP, Boorman ED, Walton ME, Behrens TE (2011) Frontal cortex and reward-guided learning and decisionmaking. Neuron 70:1054-1069. CrossRef Medline

Russo GS, Backus DA, Ye S, Crutcher MD (2002) Neural activity in monkey dorsal and ventral cingulate motor areas: comparison with the supplementary motor area. J Neurophysiol 88:2612-2629. CrossRef Medline

Saga Y, Iba M, Tanji J, Hoshi E (2011) Development of multidimensional representations of task phases in the lateral prefrontal cortex. J Neurosci 31:10648-10665. CrossRef Medline

Saito N, Mushiake H, Sakamoto K, Itoyama Y, Tanji J (2005) Representation of immediate and final behavioral goals in the monkey prefrontal cortex during an instructed delay period. Cereb Cortex 15:1535-1546. CrossRef Medline

Sakata H, Taira M, Murata A, Mine S (1995) Neural mechanisms of visual guidance of hand action in the parietal cortex of the monkey. Cereb Cortex 5:429-438. Medline

Saleem KS, Kondo H, Price JL (2008) Complementary circuits connecting the orbital and medial prefrontal networks with the temporal, insular, and opercular cortex in the macaque monkey. $J$ Comp Neur 506:659-693. CrossRef Medline

Saleem KS, Miller B, Price JL (2014) Subdivisions and connectional networks of the lateral prefrontal cortex in the macaque monkey. $\mathrm{J}$ Comp Neur 522:1641-1690. CrossRef Medline

Sallet J, Mars RB, Noonan MP, Neubert FX, Jbabdi S, O'Reilly JX, Filippini N, Thomas AG, Rushworth MF (2013) The organization of dorsal frontal cortex in humans and macaques. J Neurosci 33: 12255-12274. CrossRef Medline

Sato N, Sakata H, Tanaka YL, Taira M (2006) Navigation-associated medial parietal neurons in monkeys. Proc Natl Acad Sci U S A 103:17001-17006. CrossRef Medline

Schaffelhofer S, Agudelo-Toro A, Scherberger H (2015) Decoding a wide range of hand configurations from macaque motor, premotor, and parietal cortices. J Neurosci 35:1068-1081. CrossRef Medline

Schall JD, Thompson KG (1999) Neural selection and control of visually guided eye movements. Annu Rev Neurosci 22:241-259. CrossRef Medline

Schall JD, Hanes DP, Thompson KG, King DJ (1995a) Saccade target selection in frontal eye field of macaque. I. Visual and premovement activation. J Neurosci 15:6905-6918. Medline

Schall JD, Morel A, Kaas JH (1993) Topography of supplementary eye field afferents to frontal eye field in macaque: implications for mapping between saccade coordinate systems. Vis Neurosci 10: 385-393. Medline

Schall JD, Morel A, King DJ, Bullier J (1995b) Topography of visual cortex connections with frontal eye field in macaque: convergence and segregation of processing streams. J Neurosci 15:4464-4487. Medline

Schieber MH (2000) Inactivation of the ventral premotor cortex biases the laterality of motoric choices. Exp Brain Res 130:497-507. Medline
Schlack A, Hoffmann KP, Bremmer F (2002) Interaction of linear vestibular and visual stimulation in the macaque ventral intraparietal area (VIP). Eur J Neurosci 16:1877-1886. Medline

Schlack A, Hoffmann KP, Bremmer F (2003) Selectivity of macaque ventral intraparietal area (area VIP) for smooth pursuit eye movements. J Physiol 551:551-561. CrossRef Medline

Schlack A, Sterbing-D'Angelo SJ, Hartung K, Hoffmann KP, Bremmer $F(2005)$ Multisensory space representations in the macaque ventral intraparietal area. J Neurosci 25:4616-4625. CrossRef Medline

Schlag J, Schlag-Rey M (1987) Does microstimulation evoke fixedvector saccades by generating their vector or by specifying their goal? Exp Brain Res 68:442-444. Medline

Schlag J, Schlag-Rey M, Pigarev I (1992) Supplementary eye field: influence of eye position on neural signals of fixation. Exp Brain Res 90:302-306. Medline

Schlag-Rey M, Amador N, Sanchez H, Schlag J (1997) Antisaccade performance predicted by neuronal activity in the supplementary eye field. Nature 390:398-401. CrossRef Medline

Schultz W (2015) Neuronal reward and decision signals: from theories to data. Physiol Rev 95:853-951. CrossRef Medline

Schultz W (2016) Dopamine reward prediction-error signalling: a two-component response. Nat Rev Neurosci 17:183-195. CrossRef Medline

Schwartz AB (1994) Direct cortical representation of drawing. Science 265:540-542. Medline

Seltzer B, Pandya DN (1978) Afferent cortical connections and architectonics of the superior temporal sulcus and surrounding cortex in the rhesus monkey. Brain Res 149:1-24. Medline

Sereno ME, Trinath T, Augath M, Logothetis NK (2002) Threedimensional shape representation in monkey cortex. Neuron 33: 635-652. Medline

Sergio LE, Hamel-Pâquet C, Kalaska JF (2005) Motor cortex neural correlates of output kinematics and kinetics during isometric-force and arm-reaching tasks. J Neurophysiol 94:2353-2378. CrossRef Medline

Shadlen MN, Newsome WT (2001) Neural basis of a perceptual decision in the parietal cortex (area LIP) of the rhesus monkey. $J$ Neurophysiol 86:1916-1936. Medline

Shepherd SV, Klein JT, Deaner RO, Platt ML (2009) Mirroring of attention by neurons in macaque parietal cortex. Proc Natl Acad Sci U S A 106:9489-9494. CrossRef Medline

Shikata E, Tanaka Y, Nakamura H, Taira M, Sakata H (1996) Selectivity of the parietal visual neurones in $3 \mathrm{D}$ orientation of surface of stereoscopic stimuli. Neuroreport 7:2389-2394. Medline

Shima K, Tanji J (2000) Neuronal activity in the supplementary and presupplementary motor areas for temporal organization of multiple movements. J Neurophysiol 84:2148-2160. Medline

Shima K, Aya K, Mushiake H, Inase M, Aizawa H, Tanji J (1991) Two movement-related foci in the primate cingulate cortex observed in signal-triggered and self-paced forelimb movements. J Neurophysiol 65:188-202. Medline

Shipp S, Blanton M, Zeki S (1998) A visuo-somatomotor pathway through superior parietal cortex in the macaque monkey: cortical connections of areas V6 and V6A. Eur J Neurosci 10:3171-3193. Medline

Sigala N, Kusunoki M, Nimmo-Smith I, Gaffan D, Duncan J (2008) Hierarchical coding for sequential task events in the monkey prefrontal cortex. Proc Natl Acad Sci U S A 105:11969-11974. CrossRef Medline

Silasi G, Murphy TH (2014) Stroke and the connectome: how connectivity guides therapeutic intervention. Neuron 83:1354-1368. CrossRef Medline

Simone L, Rozzi S, Bimbi M, Fogassi L (2015) Movement-related activity during goal-directed hand actions in the monkey ventrolateral prefrontal cortex. Eur J Neurosci 42:2882-2894. CrossRef Medline

Snyder LH, Batista AP, Andersen RA (1997) Coding of intention in the posterior parietal cortex. Nature 386:167-170. CrossRef Medline 
Snyder LH, Grieve KL, Brotchie P, Andersen RA (1998) Separate body- and world-referenced representations of visual space in parietal cortex. Nature 394:887-891. CrossRef Medline

Sporns O (2013) The human connectome: origins and challenges. Neuroimage 80:53-61. CrossRef Medline

Sporns O, Tononi G, Kötter R (2005) The human connectome: a structural description of the human brain. PLoS Comput Biol 1:e42CrossRef Medline

Stanton GB, Bruce CJ, Goldberg ME (1993) Topography of projections to the frontal lobe from the macaque frontal eye fields. J Comp Neur 330:286-301. CrossRef Medline

Stanton GB, Bruce CJ, Goldberg ME (1995) Topography of projections to posterior cortical areas from the macaque frontal eye fields. J Comp Neur 353:291-305. CrossRef Medline

Stanton GB, Deng SY, Goldberg ME, McMullen NT (1989) Cytoarchitectural characteristic of the frontal eye fields in macaque monkeys. J Comp Neur 282:415-427. CrossRef Medline

Steinmetz MA, Constantinidis C (1995) Neurophysiological evidence for a role of posterior parietal cortex in redirecting visual attention. Cereb Cortex 5:448-456. Medline

Strait CE, Blanchard TC, Hayden BY (2014) Reward value comparison via mutual inhibition in ventromedial prefrontal cortex. Neuron 82:1357-1366. CrossRef Medline

Stuphorn V, Taylor TL, Schall JD (2000) Performance monitoring by the supplementary eye field. Nature 408:857-860. CrossRef Medline

Suzuki M, Gottlieb J (2013) Distinct neural mechanisms of distractor suppression in the frontal and parietal lobe. Nat Neurosci 16:98104. CrossRef Medline

Taira M, Mine S, Georgopoulos AP, Murata A, Sakata H (1990) Parietal cortex neurons of the monkey related to the visual guidance of hand movement. Exp Brain Res 83:29-36. Medline

Takada M, Nambu A, Hatanaka N, Tachibana Y, Miyachi S, Taira M, Inase M (2004) Organization of prefrontal outflow toward frontal motor-related areas in macaque monkeys. Eur $\mathrm{J}$ Neurosci 19: 3328-3342. CrossRef

Takeda K, Funahashi S (2002) Prefrontal task-related activity representing visual cue location or saccade direction in spatial working memory tasks. J Neurophysiol 87:567-588. Medline

Takahara D, Inoue K, Hirata Y, Miyachi S, Nambu A, Takada M, Hoshi E (2012) Multisynaptic projections from the ventrolateral prefrontal cortex to the dorsal premotor cortex in macaques - anatomical substrate for conditional visuomotor behavior. Eur J Neurosci 36:3365-3375.

Tanji J, Shima K (1994) Role for supplementary motor area cells in planning several movements ahead. Nature 371:413-416. CrossRef Medline

Tanji J, Shima K (1996) Supplementary motor cortex in organization of movement. Eur Neurol 36: Suppl 1:13-19. Medline

Tanne-Gariépy J, Rouiller EM, Boussaoud D (2002) Parietal inputs to dorsal versus ventral premotor areas in the macaque monkey: evidence for largely segregated visuomotor pathways. Exp Brain Res 145:91-103. CrossRef Medline

Taoka M, Tanaka M, Hihara S, Ojima H, Iriki A (2013) Neural response to movement of the hand and mouth in the secondary somatosensory cortex of Japanese monkeys during a simple feeding task. Somat Mot Res 30:140-152. CrossRef

Thompson KG, Bichot NP (2005) A visual salience map in the primate frontal eye field. Prog Brain Res 147:251-262. CrossRef Medline

Thompson KG, Biscoe KL, Sato TR (2005) Neuronal basis of covert spatial attention in the frontal eye field. J Neurosci 25:9479-9487. CrossRef Medline

Tkach D, Reimer J, Hatsopoulos NG (2007) Congruent activity during action and action observation in motor cortex. J Neurosci 27: 13241-13250. CrossRef Medline

Tremblay L, Schultz W (1999) Relative reward preference in primate orbitofrontal cortex. Nature 398:704-708. CrossRef Medline

Treue S, Maunsell JH (1996) Attentional modulation of visual motion processing in cortical areas MT and MST. Nature 382:539-541. CrossRef Medline
Tsao DY, Schweers N, Moeller S, Freiwald WA (2008) Patches of face-selective cortex in the macaque frontal lobe. Nat Neurosci 11:877-879. CrossRef Medline

Tsujimoto S, Genovesio A, Wise SP (2010) Evaluating self-generated decisions in frontal pole cortex of monkeys. Nat Neurosci 13:120126. CrossRef Medline

Tsujimoto S, Genovesio A, Wise SP (2011) Comparison of strategy signals in the dorsolateral and orbital prefrontal cortex. J Neurosci 31:4583-4592. CrossRef Medline

Umilta MA, Brochier T, Spinks RL, Lemon RN (2007) Simultaneous recording of macaque premotor and primary motor cortex neuronal populations reveals different functional contributions to visuomotor grasp. J Neurophysiol 98:488-501. CrossRef Medline

Vaadia E, Benson DA, Hienz RD, Goldstein MH Jr. (1986) Unit study of monkey frontal cortex: active localization of auditory and of visual stimuli. J Neurophysiol 56:934-952. Medline

Vallar G, Bolognini N (2014) Unilateral spatial neglect. In: Oxford Handbook of Attention (Nobre AC and Kastner S, eds.). pp. 972 1024. Oxford: Oxford University Press.

Vanduffel W, Fize D, Peuskens H, Denys K, Sunaert S, Todd JT, Orban GA (2002) Extracting 3D from motion: differences in human and monkey intraparietal cortex. Science 298:413-415. CrossRef Medline

Van Essen DC (2013) Cartography and connectomes. Neuron 80: 775-790.

Vargas-Irwin CE, Franquemont L, Black MJ, Donoghue JP (2015) Linking objects to actions: encoding of target object and grasping strategy in primate ventral premotor cortex. J Neurosci 35:1088810897. CrossRef Medline

Vigneswaran G, Philipp R, Lemon RN, Kraskov A (2013) M1 corticospinal mirror neurons and their role in movement suppression during action observation. Curr Biol 23:236-243. CrossRef Medline

Vogt BA, Pandya DN (1987) Cingulate cortex of the rhesus monkey: II. Cortical afferents. J Comp Neur 262:271-289. CrossRef Medline

Vogt BA, Finch DM, Olson CR (1992) Functional heterogeneity in cingulate cortex: the anterior executive and posterior evaluative regions. Cereb Cortex 2:435-443. Medline

Vogt BA, Hof PR, Zilles K, Vogt LJ, Herold C, Palomero-Gallagher N (2013) Cingulate area 32 homologies in mouse, rat, macaque and human: cytoarchitecture and receptor architecture. J Comp Neur 521:4189-4204. CrossRef Medline

Vogt BA, Pandya DN, Rosene DL (1987) Cingulate cortex of the rhesus monkey: I. Cytoarchitecture and thalamic afferents. $J$ Comp Neur 262:256-270. CrossRef Medline

Vogt BA, Vogt L, Farber NB, Bush G (2005) Architecture and neurocytology of monkey cingulate gyrus. J Comp Neurol 485:218-239.

Walker AE (1940) A cytoarchitectural study of the prefrontal area of the macaque monkey. J Comp Neur 73:59-86. CrossRef

Wallis JD, Anderson KC, Miller EK (2001) Single neurons in prefrontal cortex encode abstract rules. Nature 411:953-956. CrossRef Medline

Wang M, Zhang H, Li BM (2000) Deficit in conditional visuomotor learning by local infusion of bicuculline into the ventral prefrontal cortex in monkeys. Eur J Neurosci 12:3787-3796. Medline

Wang X, Zhang M, Cohen IS, Goldberg ME (2007) The proprioceptive representation of eye position in monkey primary somatosensory cortex. Nat Neurosci 10:640-646. CrossRef Medline

Wang Y, Isoda M, Matsuzaka Y, Shima K, Tanji J (2005) Prefrontal cortical cells projecting to the supplementary eye field and presupplementary motor area in the monkey. Neurosci Res 53:1-7. CrossRef Medline

Watanabe K, Igaki S, Funahashi S (2006) Contributions of prefrontal cue-, delay-, and response-period activity to the decision process of saccade direction in a free-choice ODR task. Neural Netw 19:1203-1222. CrossRef Medline

Watts DJ, Strogatz SH (1998) Collective dynamics of 'small-world' networks. Nature 393:440-442. CrossRef Medline 
Werner W (1993) Neurons in the primate superior colliculus are active before and during arm movements to visual targets. Eur J Neurosci 5:335-340. Medline

Werner W, Dannenberg S, Hoffmann KP (1997b) Arm-movementrelated neurons in the primate superior colliculus and underlying reticular formation: comparison of neuronal activity with EMGs of muscles of the shoulder, arm and trunk during reaching. Exp Brain Res 115:191-205.

Werner W, Hoffmann KP, Dannenberg S (1997a) Anatomical distribution of arm-movement-related neurons in the primate superior colliculus and underlying reticular formation in comparison with visual and saccadic cells. Exp Brain Res 115:206216.

White IM, Wise SP (1999) Rule-dependent neuronal activity in the prefrontal cortex. Exp Brain Res 126:315-335. Medline
Wilson FA, Scalaidhe SP, Goldman-Rakic PS (1993) Dissociation of object and spatial processing domains in primate prefrontal cortex. Science 260:1955-1958. Medline

Wise SP, Boussaoud D, Johnson PB, Caminiti R (1997) Premotor and parietal cortex: corticocortical connectivity and combinatorial computations. Annu Rev Neurosci 20:25-42. CrossRef Medline

Xie J, Padoa-Schioppa C (2016) Neuronal remapping and circuit persistence in economic decisions. Nat Neurosci 19:855-861. CrossRef Medline

Yoshida K, Saito N, Iriki A, Isoda M (2012) Social error monitoring in macaque frontal cortex. Nat Neurosci 15:1307-1312. CrossRef Medline

Yttri EA, Liu Y, Snyder LH (2013) Lesions of cortical area LIP affect reach onset only when the reach is accompanied by a saccade, revealing an active eye-hand coordination circuit. Proc Natl Acad Sci U S A 110:2371-2376. CrossRef Medline 